\title{
ॠUSGS
}

science for a changing world

Prepared in cooperation with the U.S. Army Corps of Engineers

\section{Characterization of Subsurface Stratigraphy along the Lower American River Floodplain Using Electrical Resistivity, Sacramento, California, 2011}

By Bethany L. Burton, Michael H. Powers, and Lyndsay B. Ball

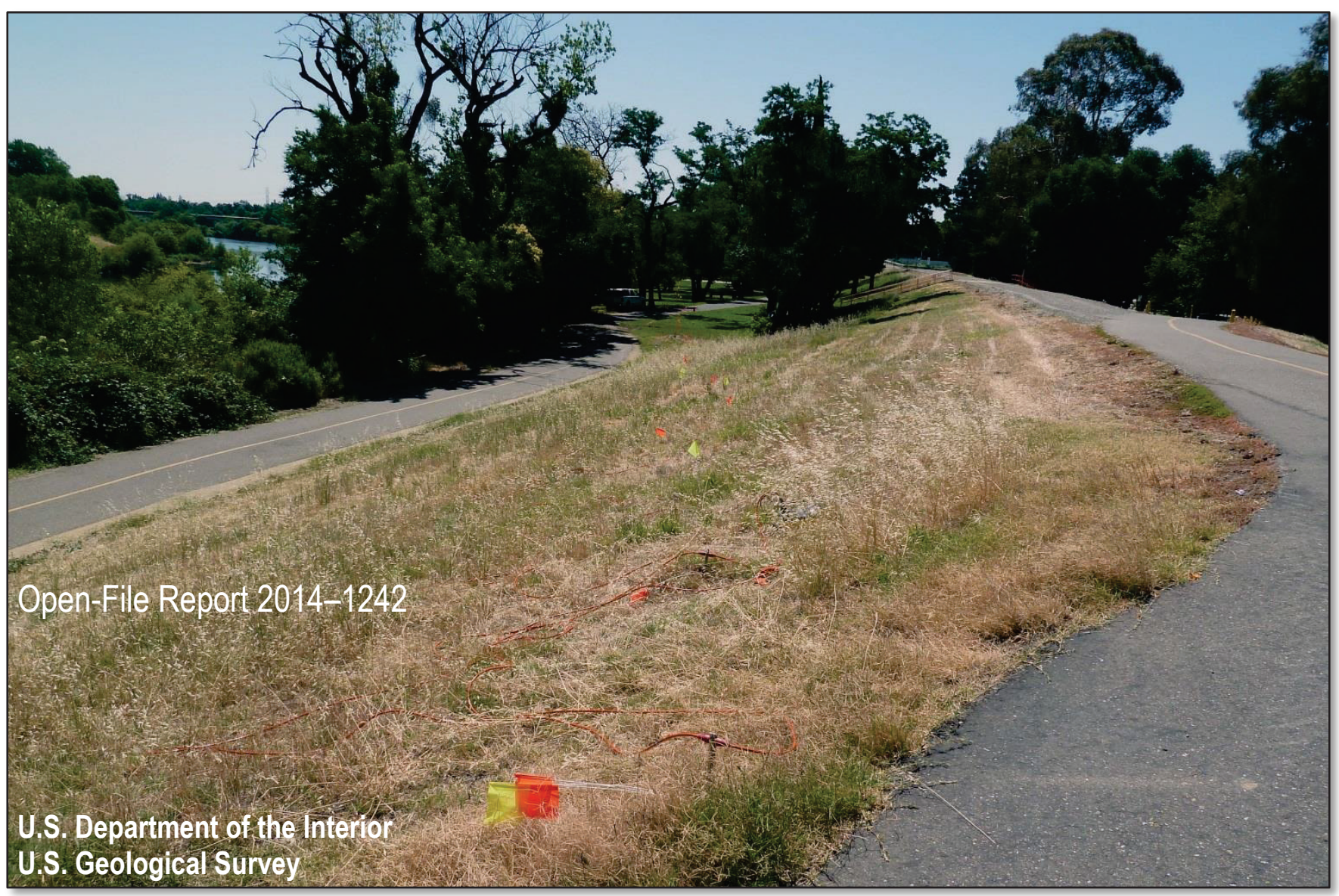




\section{U.S. Department of the Interior \\ SALLY JEWELL, Secretary}

\section{U.S. Geological Survey \\ Suzette M. Kimball, Acting Director}

U.S. Geological Survey, Reston, Virginia: 2014

For more information on the USGS—-the Federal source for science about the Earth, its natural and living resources, natural hazards, and the environment-visit http://www.usgs.gov or call 1-888-ASK-USGS

For an overview of USGS information products, including maps, imagery, and publications, visit $h$ ttp://www.usgs.gov/pubprod

To order this and other USGS information products, visit $h$ ttp://store.usgs.gov

Suggested citation:

Burton, B.L., Powers, M.H., and Ball, L.B., 2014, Characterization of subsurface stratigraphy along the lower American River floodplain using electrical resistivity, Sacramento, California, 2011: U.S. Geological Survey Open-File Report 2014-1242, 62 p., http://dx.doi.org/10.3133/ofr20141242.

ISSN 2331-1258 (online)

Any use of trade, product, or firm names is for descriptive purposes only and does not imply endorsement by the U.S. Government.

Although this report is in the public domain, permission must be secured from the individual copyright owners to reproduce any copyrighted material contained within this report. 


\section{Contents}

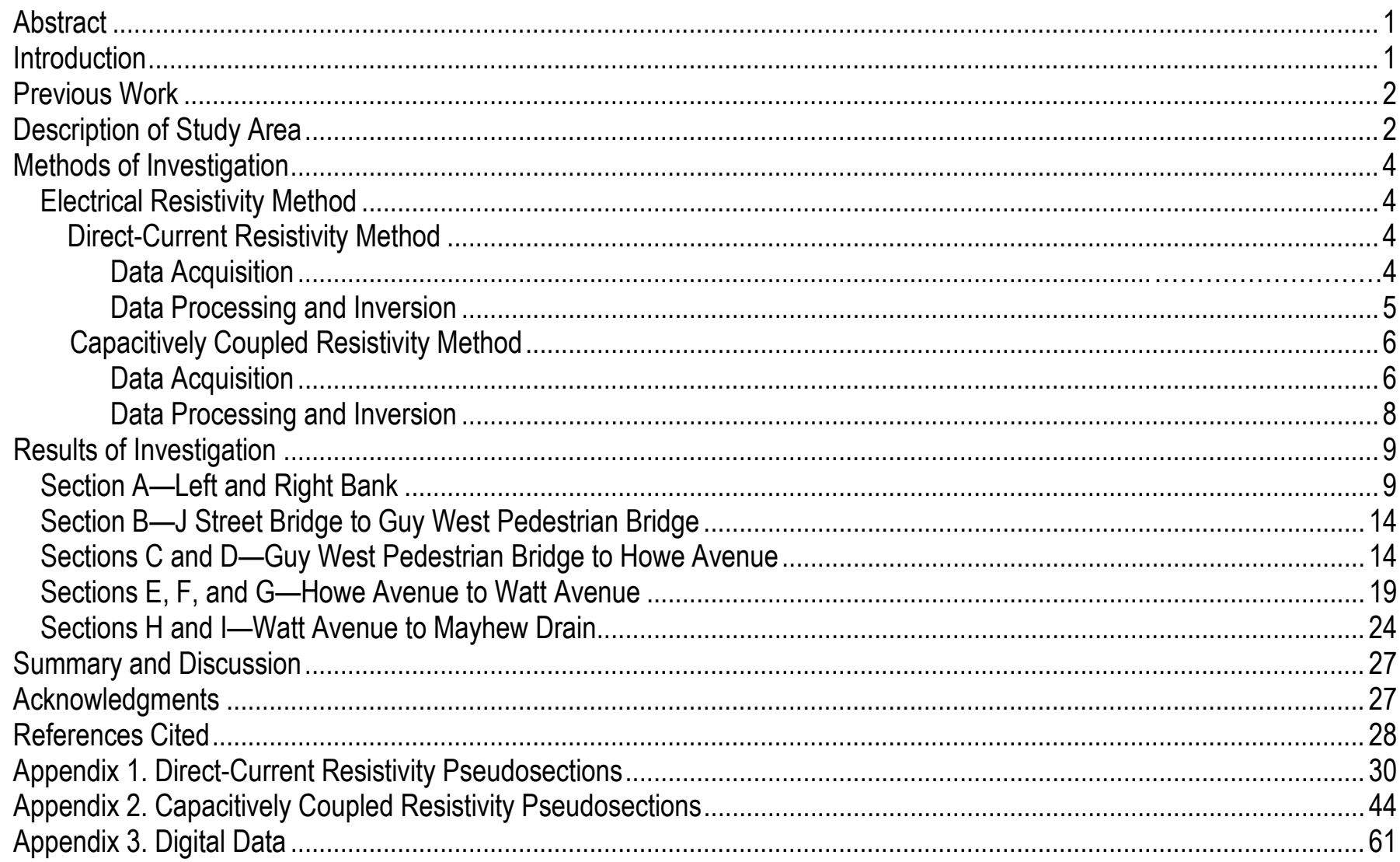

\section{Figures}

Figure 1. Maps showing the distribution of resistivity and boring data with respect to the lower American River near Sacramento, California

Figure 2. Schematic illustration of the capacitively coupled resistivity system ........................................................

Figure 3. Explanation of the lithologic logs, resistivity color scale, and symbology for figures 4 through $13 \ldots \ldots \ldots \ldots . . . .10$

Figure 4. Map of section A right bank and resistivity profiles with lithologic logs overlaid ........................................11

Figure 5. Map of section A left bank and resistivity profiles with lithologic logs overlaid ........................................13

Figure 6. Map of section B left bank and resistivity profiles with lithologic logs overlaid ........................................... 15

Figure 7. Map of section C left bank and resistivity profiles with lithologic logs overlaid ............................................16

Figure 8. Map of section D left bank and resistivity profiles with lithologic logs overlaid .......................................... 18

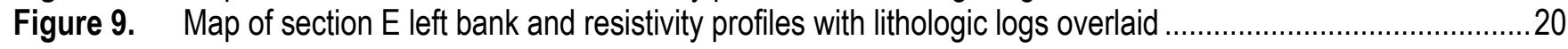

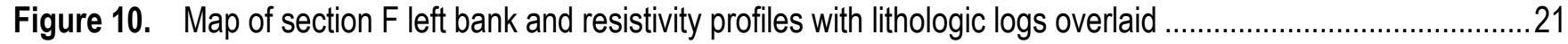

Figure 11. Map of section $\mathrm{G}$ left bank and resistivity profiles with lithologic logs overlaid............................................23

Figure 12. Map of section $\mathrm{H}$ left bank and resistivity profiles with lithologic logs overlaid ........................................25

Figure 13. Map of section I left bank and resistivity profiles with lithologic logs overlaid .............................................. 26

\section{Table}

Table 1. Summary of direct-current resistivity acquisition parameters ........................................................ 


\section{Conversion Factors}

\begin{tabular}{lcl}
\multicolumn{1}{c}{ Inch/Pound to SI } & \multicolumn{1}{c}{ Bultiply } & \multicolumn{1}{c}{ To obtain } \\
\hline inch (in.) & 2.54 & centimeter $(\mathrm{cm})$ \\
inch (in.) & 25.4 & millimeter $(\mathrm{mm})$ \\
foot (ft) & 0.3048 & meter $(\mathrm{m})$ \\
mile (mi) & 1.609 & kilometer $(\mathrm{km})$ \\
cubic foot per second (cfs) & 0.02832 & cubic meter per second $\left(\mathrm{m}^{3} / \mathrm{s}\right)$ \\
mile per hour (mi/h) & 1.609 & kilometer per hour $(\mathrm{km} / \mathrm{h})$ \\
\hline
\end{tabular}

Temperature in degrees Fahrenheit $\left({ }^{\circ} \mathrm{F}\right)$ may be converted to degrees Celsius $\left({ }^{\circ} \mathrm{C}\right)$ as follows:

${ }^{\circ} \mathrm{C}=\left({ }^{\circ} \mathrm{F}-32\right) / 1.8$

Vertical coordinate information is referenced to the North American Vertical Datum of 1988 (NAVD 88).

Horizontal coordinate information is referenced to North American Datum of 1983 California State Plane zone 2 (CS83 zone 2).

Elevation, as used in this report, refers to distance above the vertical datum. 


\title{
Characterization of Subsurface Stratigraphy along the Lower American River Floodplain Using Electrical Resistivity, Sacramento, California, 2011
}

\author{
By Bethany L. Burton, Michael H. Powers, and Lyndsay B. Ball
}

\begin{abstract}
In July 2011, the U.S. Geological Survey, in cooperation with the U.S. Army Corps of Engineers, completed a geophysical survey using electrical resistivity along an approximately 6-mile reach of the lower American River in Sacramento, California, to map near-surface lithological variations. This survey is a part of a manifold and comprehensive study of river-flow dynamics and geologic boundary-property knowledge necessary to estimate scour potential and levee erosion risk. Data were acquired on the left (south or west) bank between river mile 5 and 10.7 as well as a short section on the right bank from river mile 5.4 to 6 . Thirteen direct-current resistivity profiles and approximately 8.3 miles of capacitively coupled resisistivity data were acquired along accessible areas of the floodplain between the levee and river bank. Capacitively coupled resistivity was used as a reconnaissance tool, because it allowed for greater spatial coverage of data but with lower resolution and depth of investigation than the DC resistivity method. The study area contains Pleistocene-age alluvial deposits, dominated by gravels, sands, silts, and clays, that vary in both lateral extent and depth. Several generations of lithologic logs were used to help interpret resistivity variations observed in the resistivity models.

\section{Introduction}

The lower American River in Sacramento, California, has been extensively studied to determine the best mitigation procedures for erosion control along its banks. This river has levees along both banks, and the reach between river mile (RM) 5 and 11 is a particularly narrow section that may be prone to erosion during high-water events. A critical aspect of erosion mitigation is knowledge of the subsurface lithology. Sand deposits, in particular, have been observed to preferentially scour along this stretch, while finer grained deposits tend to be more resistant to erosion.

Using geophysical methods to map images of subsurface property variations is one part of the manifold and comprehensive study of river-flow dynamics and geologic boundary-property knowledge necessary to estimate scour potential and levee erosion risk. In this report, we use lithologic logs from boreholes in the area provided by the U.S. Army Corps of Engineers (USACE) (Lew Hunter, USACE, written commun., February 2012; Michael Kynett, USACE, written commun., October 2012) to help correlate our geophysical property variations with lithology. This correlation varies spatially across the site, as geophysical property values are not unique with regard to lithology. Furthermore, even if a good correlation exists and a locally identified lithology is confidently interpreted with the geophysical images, estimation of the scour potential and erosion risk still requires broader knowledge of position with regard to river-flow dynamics and other factors beyond the scope of this report.
\end{abstract}


The U.S. Geological Survey (USGS), in cooperation with the USACE, has completed several geophysical surveys since 2007 along this river reach including ground-based and water-borne electrical and electromagnetic surveys (Asch and others, 2008; Ball and Teeple, 2013). The goal of the survey in this report, conducted in July 2011, was to acquire data on the left (south or west) bank between RM 5 and 10.7 and a short section on the right bank from RM 5.4 to 6 which had not previously been surveyed with ground-based methods (fig. 1). For this study, direct-current (DC) resistivity and capacitively coupled (CC) resistivity were the primary methods of investigation. Thirteen DC resistivity profiles and approximately 8.3 miles (mi) of CC resisistivity data were acquired along accessible areas of the floodplain between the levee and river bank. Capacitively coupled resistivity was used as a reconnaissance tool that has a higher acquisition rate but lower resolution and lower depth of investigation than the DC resistivity method. For this study, the maximum depth of investigation of the $\mathrm{CC}$ resistivity data is approximately $35 \mathrm{feet}(\mathrm{ft})$ and ranges from 110 to $170 \mathrm{ft}$ for the DC resistivity data, depending on the length of the line (number of electrodes).

Extensive borehole drilling has been completed along this river stretch, which provides highresolution lithologic and stiffness information about the deposits. Because of the one-dimensional nature of boreholes, however, it can be difficult to extend lithologic interpretations beyond the extent of any individual borehole, especially in an area such as this with highly spatially variable deposits. The twodimensional (2D) resistivity models can help provide for more spatially continuous interpretations of lithologic boundaries when used in conjunction with the borehole data.

\section{Previous Work}

There have been many studies completed along the lower American River to aid in mitigating potential erosion along the banks of the river in this narrow, approximately 6-mile reach. The USGS acquired electrical resistivity and electromagnetic induction data along a similar reach on the right bank of the American River in 2007 (Asch and others, 2008) between RM 6 and 10.8. The purpose of the survey was to identify sand deposits that may exist between the active river channel and the levee embankment. The sand deposits, related to historical hydraulic mining that took place farther upstream, can preferentially scour in a high-water event and potentially undermine the levees if the deposits extend below the embankment. In 2008, water-borne resistivity data were acquired along the same river reach (RM 6 to 11) to identify the extent and thickness of possible scour-resistant layers that are common in the American River bed in this region (Ball and Teeple, 2013). Ball and others (2014) is a compilation of these prior studies and the 2011 survey that provides all of the resistivity and geotechnical data in a digital three-dimensional framework project that can be viewed using freely available software.

\section{Description of Study Area}

The study area encompasses the floodplain between the levee embankment and the river along RM 5 to 10.7 in Sacramento County, California (fig. 1). This is an urban area with existing infrastructure immediately beyond the levees. The floodplain area preserved between the levees and the river bank is locally part of the American River Parkway that is generally undeveloped. A series of paved and gravel paths and roads run parallel to the levees within the parkway and are surrounded by wild and irrigated grass and wooded areas. Within the confines of the levees, the dominant lithologies are Pleistocene-age channel and floodplain deposits, consisting of fine gravel, sand, silt, and clay with high spatial variability and extent (Pearce and Kelson, 2008). Sand deposits related to historical 

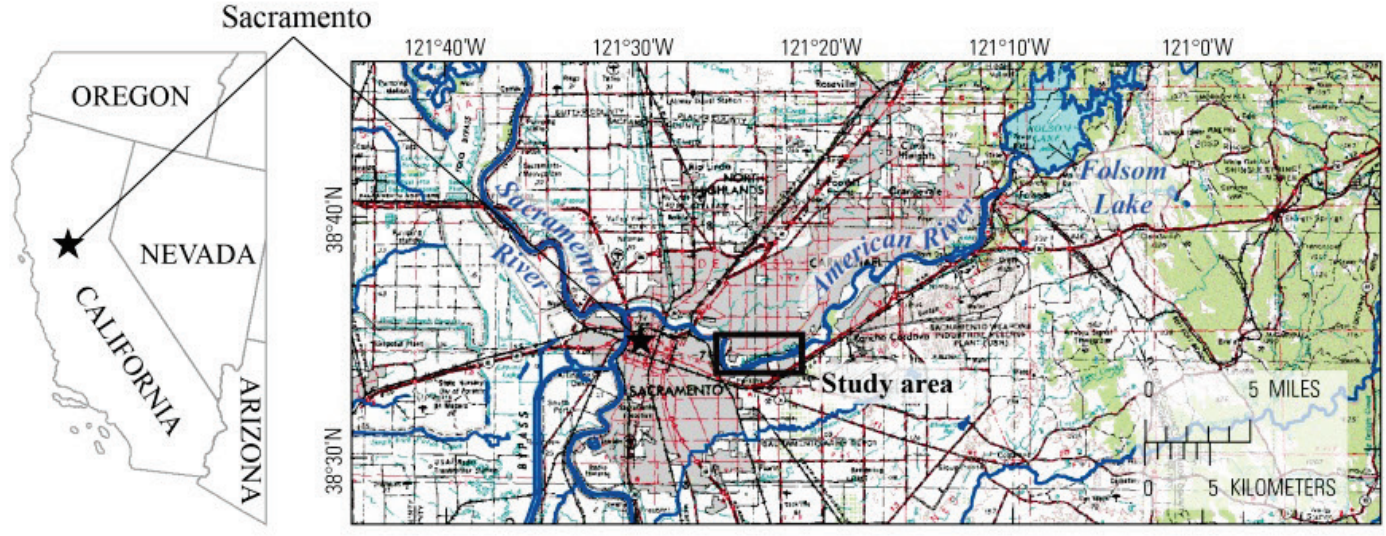

Figure 1. Maps showing the location of the 2011 lower American River study reach and associated electrical resistivity and boring data.
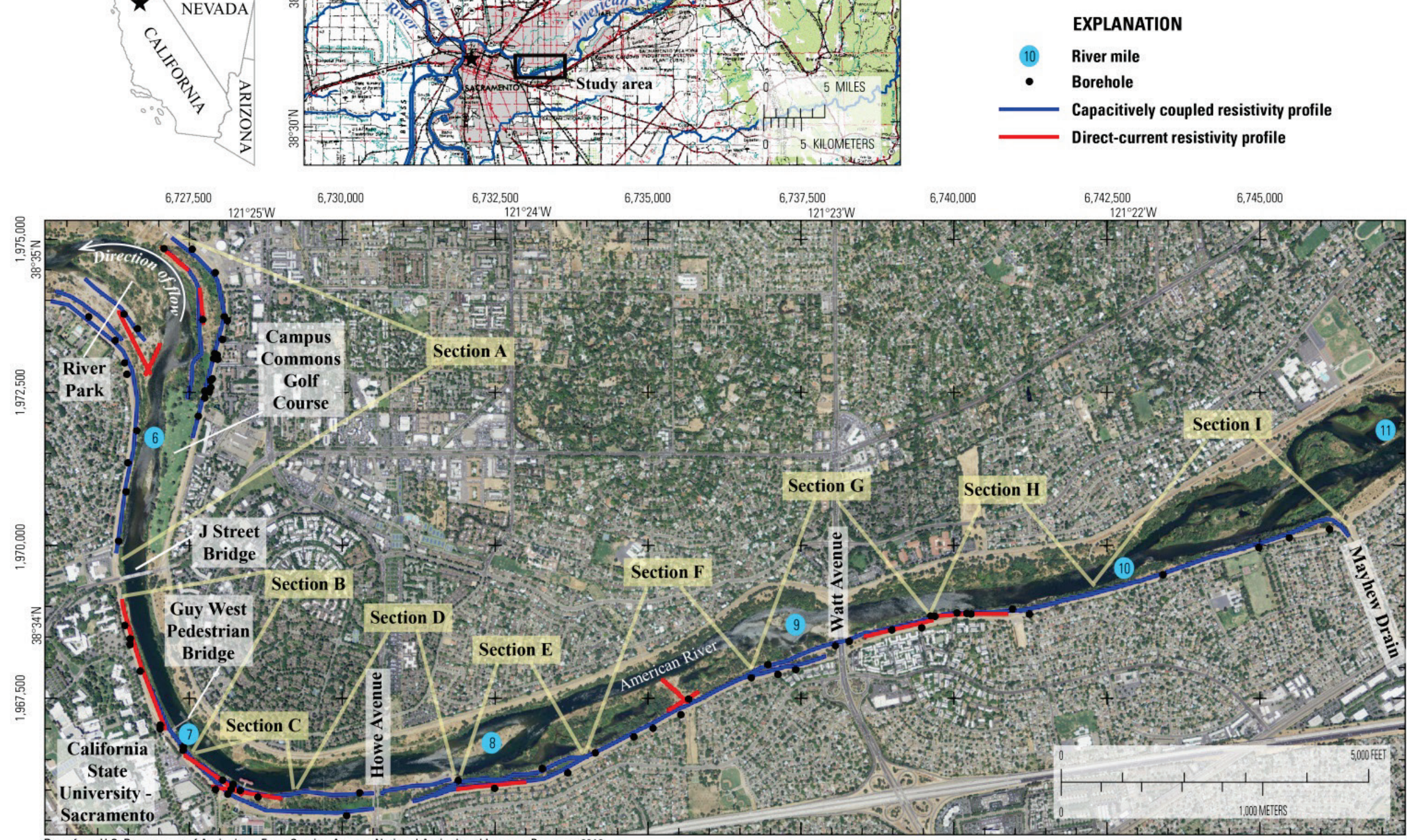
Base from U.S. Department of Agriculture Farm Service Agency National Agricultural Imagery Program, 2012 California State Plane projection, zone 2, in U.S. survey feet North American Datum of 1983 
hydraulic mining (post-1860) that occurred upstream are in the study area and are considered to be more prone to scour during high-water events (Asch and others, 2008).

\section{Methods of Investigation}

\section{Electrical Resistivity Method}

Resistivity is the intrinsic material property that resists the flow of electric current. Resistivity measurements are made by injecting a known current into the subsurface using two current electrodes and measuring the resulting voltage difference between two potential electrodes. Based on Ohm's law, the resistance is calculated by taking the ratio of the measured voltage and the transmitted current. The apparent resistivity of the material, expressed in ohm-meters (ohm-m), can then be determined by multiplying each resistance value by the corresponding geometric factor, which is based on the electrode geometry and spacing.

The main factors that affect the resistivity of a material are the amount of interconnected pore water, the water quality (level of total dissolved solids, TDS), and the amount of mineralogical clay. In the unsaturated zone, if no mineralogical clay is present, a fine-grained material (for example, silt or clay) will generally retain more interconnected water from capillary forces than a coarse-grained material (for example, sand or gravel). The fine-grained material will therefore have a lower resistivity compared with coarser grained materials. Water quality is an important factor because the concentration of ions in the water affects its ability to conduct electricity. Materials containing water with high TDS will have lower resistivity than materials containing water with low TDS. Even a small amount of clay minerals can sharply decrease the overall bulk resistivity of a material, because current is conducted through ion mobilization in the pore fluid (electrolytically) as well as through cation exchange in the clay (electronically). Because of the relation among grain size, water content, and resistivity, the resistivity method has already proven to be a useful tool in differentiating the lithologies at this site (Asch and others, 2008; Ball and Teeple, 2013). Reynolds (1997), Sharma (1997), and Butler (2005) provide more detailed descriptions of the resistivity method and resistivity values for common geologic materials.

\section{Direct-Current Resistivity Method}

\section{Data Acquisition}

Direct-current resistivity data were acquired using an Advanced Geosciences, Inc. (AGI) SuperSting R8 resistivity/induced polarization meter (Advanced Geosciences, Inc., Austin, Tex., U.S.A.) with a maximum of 112 electrodes. Each stainless steel electrode is approximately 18 inches (in.) long with a 0.5 -in. diameter. For each profile, a linear array of electrodes spaced at regular intervals is placed in the ground, and many different combinations of current and potential electrode pairs are used to take resistance measurements. Information about lateral resistivity variability in the subsurface is gained as the measuring electrodes are translated across the array, whereas information about greater depths is obtained by increasing the separation between the electrode pairs. The 8-channel resistivity meter uses a command file to acquire measurements from predetermined current electrode and potential electrode configurations. Measurements were made for a period of 0.8 seconds, equivalent to $1.25 \mathrm{Hertz}$ $(\mathrm{Hz})$, during which the polarity of the current electrodes is reversed in order to minimize electrode polarization effects to further improve contact resistance. The resistivity meter is powered by two 12volt batteries and is capable of injecting up to 2,000 milliamperes (mA) of current into the ground. At this site, most of the transmitted current levels were generally between 400 and 1,000 mA but were less than $100 \mathrm{~mA}$ in more resistive areas, like River Park. 
All electrodes were hammered into the ground as far as possible to minimize electrical contact resistance between the electrode and ground. A dilute saltwater solution was poured on each of the electrodes to further reduce the contact resistances. High-contact resistance can cause lower quality data because of greater difficulties in injecting current into the ground and measuring accurate voltages.

Overall, the observed contact resistances were low to moderate at this site, typically ranging from 0.5 to 4 kilohm (kohm), although the two profiles acquired in River Park on the left bank were typically higher (5-10 kohm) due to the presence of drier sand and gravel.

An inverse Schlumberger array geometry was used for all 13 profiles, which provides a good balance among lateral and vertical sensitivity to resistivity changes as well as a large depth of investigation (Loke, 2014). With this geometry, the four electrodes used for each measurement are symmetric about a central location, with the current electrode pair nearest to the central location. Line lengths were varied on the basis of available accessible space, and a constant electrode spacing of $10 \mathrm{ft}$ was chosen based on the project objectives while maintaining high levels of lateral and vertical sensitivity. A summary of the acquisition parameters for the 13 profiles is provided in table 1 .

Table 1. Summary of direct-current resistivity acquisition parameters.

\begin{tabular}{lcccclc}
\hline Line & $\begin{array}{c}\text { Total line } \\
\text { length }\end{array}$ & $\begin{array}{c}\text { Total number } \\
\text { of electrodes }\end{array}$ & $\begin{array}{c}\text { Electrode } \\
\text { spacing }\end{array}$ & Heading & Location & $\begin{array}{c}\text { Date } \\
\text { acquired }\end{array}$ \\
\hline 201 & $1,110 \mathrm{ft}$ & 112 & $10 \mathrm{ft}$ & W-E & Left bank & 11-Jul-11 \\
202 & $1,110 \mathrm{ft}$ & 112 & $10 \mathrm{ft}$ & NW-SE & Left bank & 12-Jul-11 \\
203 & $550 \mathrm{ft}$ & 56 & $10 \mathrm{ft}$ & NW-SE & Right bank & 13-Jul-11 \\
204 & $550 \mathrm{ft}$ & 56 & $10 \mathrm{ft}$ & S-N & Right bank & 13-Jul-11 \\
205 & $550 \mathrm{ft}$ & 56 & $10 \mathrm{ft}$ & NW-SE & Left bank & 14-Jul-11 \\
206 & $550 \mathrm{ft}$ & 56 & $10 \mathrm{ft}$ & SW-NE & Left bank & 14-Jul-11 \\
207 & $1,110 \mathrm{ft}$ & 112 & $10 \mathrm{ft}$ & S-N & Left bank & 15-Jul-11 \\
208 & $1,110 \mathrm{ft}$ & 112 & $10 \mathrm{ft}$ & S-N & Left bank & 16-Jul-11 \\
209 & $1,110 \mathrm{ft}$ & 112 & $10 \mathrm{ft}$ & S-N & Left bank & 16-Jul-11 \\
210 & $1,110 \mathrm{ft}$ & 112 & $10 \mathrm{ft}$ & W-E & Left bank & 17-Jul-11 \\
211 & $1,110 \mathrm{ft}$ & 112 & $10 \mathrm{ft}$ & W-E & Left bank & 17-Jul-11 \\
212 & $1,110 \mathrm{ft}$ & 112 & $10 \mathrm{ft}$ & W-E & Left bank & 18-Jul-11 \\
213 & $550 \mathrm{ft}$ & 56 & $10 \mathrm{ft}$ & SSW-NNE & Left bank & 19-Jul-11 \\
\hline
\end{tabular}

All electrode locations were determined using a Leica GPS1200 differential global positioning system (GPS). The GPS base station was set up over a single unknown location throughout the survey, and the raw observational data were converted to receiver independent exchange (RINEX) format and submitted to the National Geodetic Survey's Online Positioning User Service (OPUS) to determine a more accurate location and elevation. The rover GPS data were corrected by first postprocessing the base and rover raw observational data using Leica Geo Office ver. 7.0 (Leica Geosystems AG, Heerbrugg, Switzerland) and then applying horizontal and vertical translations based on the OPUS base station location.

\section{Data Processing and Inversion}

The raw DC resistivity data consist of measured voltage and injected current values and the down-line locations of the electrodes used for each measurement. For each of these measurements, an 
apparent resistivity is calculated using the raw data, Ohm's law, and the assumption of a homogeneous and isotropic half-space. The subsurface is typically heterogeneous and sometimes anisotropic, and apparent resistivity data require inverse modeling to determine a best-fit, layered-earth resistivity model.

The DC resistivity profile data were inverted using the robust, finite-element inversion method in AGI's EarthImager 2D software version 2.4.0 build 617 (Advanced Geosciences, Inc., 2008). The robust method is based on the assumption of an exponential distribution of data errors and minimizes an L1-norm parameter that is a combination of the model data misfit and stabilizing function. The method typically performs well on datasets containing low-quality data and resolves resistivity boundaries well (Advanced Geosciences, Inc., 2008). Topographic information was incorporated into the inversion to accurately account for electrode geometry and the influence of the irregular earth surface on the distribution of subsurface electric currents, which is an important step toward determining a more accurate subsurface resistivity model. The inversions were allowed to run a maximum of 10 iterations with a stop criterion of 3 percent or less root-mean-square error between the measured and calculated forward model values or an L2-norm value of 1.0 or less. If stop criteria were not met, the lowestquality data were removed using a percentage data misfit threshold. This threshold was chosen on the basis of a good balance between the noise levels of the data and on the overall percentage of data that would be removed at that data misfit level. The inversion was then run another time with the culled data. The raw data plots (pseudosections) for all 13 profiles are in appendix 1, and the raw ASCII data are included in this report and described in appendix 3. The inverted data will be available in another report that includes final resistivity data for all three USGS surveys from 2007 through 2011 (Ball and others, 2014).

\section{Capacitively Coupled Resistivity Method}

The CC resistivity method differs from the DC resistivity method in that it does not require the insertion of electrodes in the ground and can be acquired kinematically as a towed array. The depth of investigation is more limited, typically between $26 \mathrm{ft}$ and $40 \mathrm{ft}$ ( $8 \mathrm{~m}$ to $12 \mathrm{~m})$, and the vertical resolution is often lower because $\mathrm{CC}$ resistivity systems generally have fewer electrode pairs and dipole separations. The $\mathrm{CC}$ resistivity system can be a useful reconnaissance horizontal profiling tool to locate anomalous zones for further investigation with other tools such as boreholes or higher resolution DC resistivity profiles.

\section{Data Acquisition}

Approximately $8.3 \mathrm{mi}$ of $\mathrm{CC}$ resistivity data were acquired with the Geometrics OhmMapper TR5 (Geometrics, Inc., San Jose, Calif., U.S.A.) towed behind an all-terrain vehicle (ATV). The profiles were generally acquired on the bike and foot paths between the levee toe and active river channel. Where this area was relatively wide, as between the Guy West Pedestrian Bridge and Watt Avenue, multiple sub-parallel profiles were acquired (fig. 1).

The $\mathrm{CC}$ resistivity systems uses a dipole-dipole array with five receiver dipoles, equivalent to five potential electrode pairs, and one transmitter dipole, equivalent to a current electrode pair (fig. 2). The dipole-dipole array is most sensitive to lateral resistivity variations but has a relatively low sensitivity to vertical resistivity variations. With this geometry, the current and potential electrode pairs have the same electrode spacing but the distance between the pairs can be increased to obtain deeper measurements. Each receiver dipole samples the subsurface over a particular depth range based on its length and distance from the transmitter dipole. Based on the survey objective, the survey is designed for the optimal compromise between vertical and horizontal resolution and maximum depth of investigation by varying the geometry (dipole and rope lengths) of the array. The transmitter, located at the rear of the array, is attached to the receivers by a nonconductive rope, and transmits an alternating 


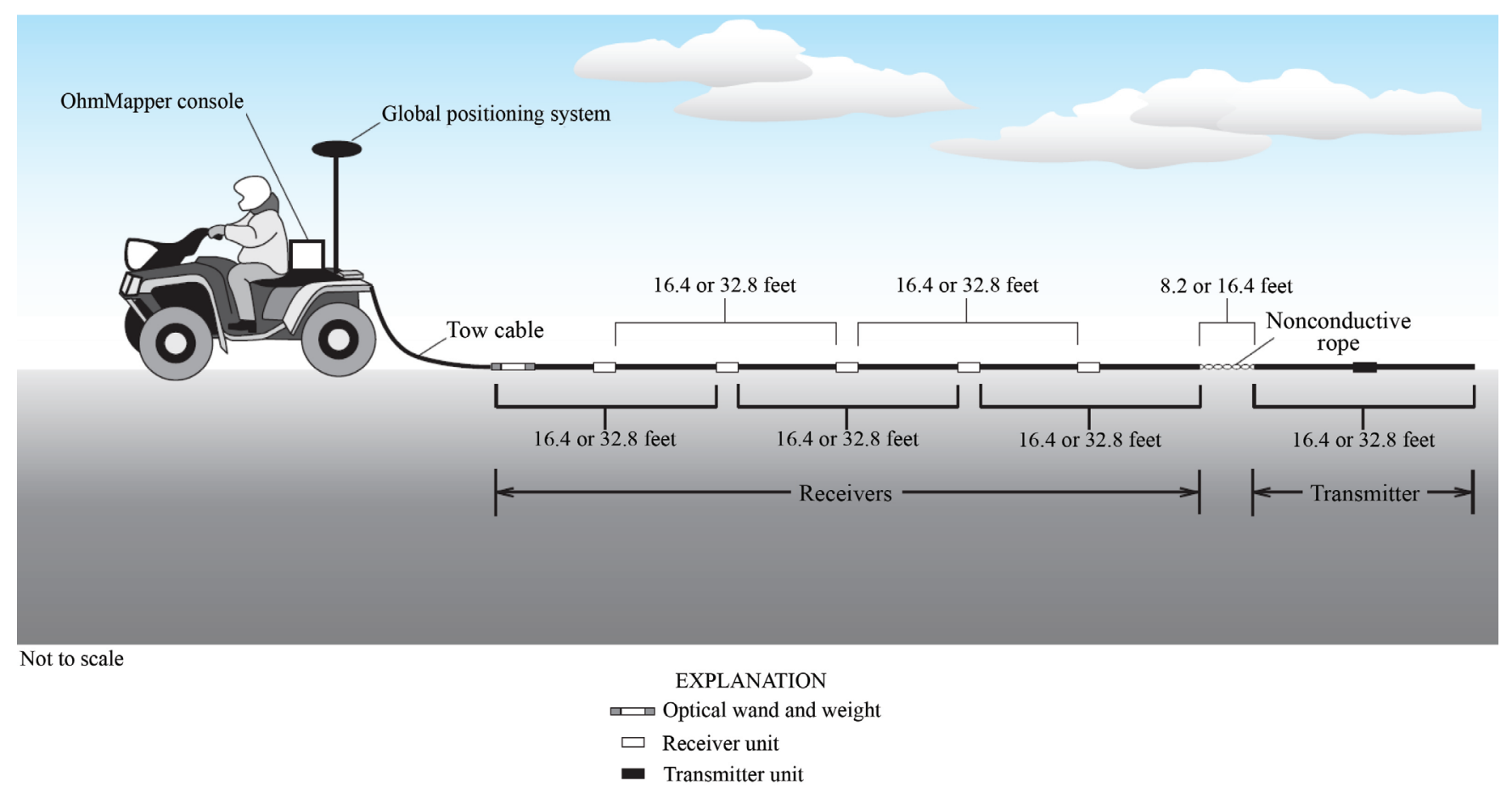

Figure 2. Schematic illustration showing the capacitively coupled resistivity acquisition system setup and geometry (modified from Ball and others, 2006). 
current at a frequency of 16.5 kilohertz $(\mathrm{kHz})$. Current is transmitted into the ground through the use of capacitance; this negates the need for the electrodes to be in direct contact with the ground and thus allows for more efficient and faster data acquisition than land-based DC resistivity techniques. The wire in each dipole cable and the ground act as the opposing conductor "plates" of a capacitor, and the insulating sheath of the wire and air between the dipole cable and the ground act as the insulator between the plates (Geometrics, 2001).

For this survey, two array geometries were used to increase the total depth of investigation and vertical resolution, for a total of 10 depth measurements. Each profile was therefore acquired twice, once with each array geometry. For acquiring shallower data, a 16.4-ft (5-m) transmitter and receiver dipole length with an 8.2-ft $(2.5-\mathrm{m})$ rope was chosen, resulting in a towed array length of $74 \mathrm{ft}(22.5 \mathrm{~m})$. Each 16.4-ft dipole consists of an 8.2-ft cable attached to each end of an electronics unit (fig. 2). For acquiring deeper data, a 32.8-ft (10-m) dipole and rope lengths were selected, for a towed array length of $164 \mathrm{ft}(50 \mathrm{~m})$. The $\mathrm{CC}$ resistivity data were acquired at a rate of $1 \mathrm{Hertz}(\mathrm{Hz})$ while traveling between 2-3 miles per hour $(\mathrm{mi} / \mathrm{h})$. Raw positional data were acquired at a $1 \mathrm{~Hz}$ sample rate simultaneously using the same GPS system and post-processing techniques described for the DC resistivity method. For further details on the capacitively coupled resistivity method and acquisition system, refer to Timofeev and others (1994), Geometrics (2001), Ball and others (2006), and Lucius and others (2008).

\section{Data Processing and Inversion}

The raw binary data files were downloaded from the OhmMapper instrument using Geometrics MagMap2000 version 4.90 software (Geometrics, 2009). The binary files were imported into a pair of not released USGS GPS and OhmMapper data-processing software programs named GPSpathtool and OhmBin, respectively. In GPSpathtool, the geographic positions in the imported raw binary file are automatically projected to the appropriate NAD83 Universal Transverse Mercator (UTM) zone in meters. The position and elevation of the center of each transmitter-receiver dipole pair for every measurement is interpolated and extrapolated from the National Marine Electronics Association (NMEA) GGA message string (includes time-, position-, and fix-related data). The data are mapped to a fitted path and imported into the OhmBin program where the resistivity data can be viewed and processed.

Within the OhmBin program, the data can be viewed as either line plots for each receiver or as contoured pseudosections of the apparent resistivity, measured voltage, calculated resistance $(\mathrm{mV} / \mathrm{mA})$, and transmitted current levels. The data were processed by (1) automatically removing data spikes using a single data-point-spike width and factor of 1.5, (2) manually removing obvious data spikes in the voltage and resistance data, and (3) binning (or averaging) the data to a 5-m bin size.

The binned data are exported in a RES2DINV (Loke, 2014) data format, including elevation data, which can also be imported into the EarthImager 2D inversion program. All CC resistivity data were inverted using the robust, finite-element inversion method in EarthImager 2D version 2.4.0 build 617. The inverted data were reprojected to NAD83 California State Plane zone 2, in U.S. survey feet, and imported into Encom Profile Analyst (Pitney Bowes Software, North Sydney, Australia), along with the DC resistivity profiles and digitized soil borings, for analysis and interpretation. The raw data plots (pseudosections) for all CC resistivity profiles are in appendix 2, and the binned, processed, uninverted ASCII data are included in this report and described in appendix 3. The inverted data are available in Ball and others (2014). 


\section{Results of Investigation}

To aid in the interpretation of the observed variations in the resistivity structure, lithologic log data from available boreholes were used (Lew Hunter, USACE, written commun., February 2012; Michael Kynett, USACE, written commun., October 2012). These data are from several acquisition periods between 1996 and 2011 and include a total of 238 lithologic logs in the survey area. The logs are generally shallow, with average depths of 30-50 ft. Lithologic logs proximal to the resistivity profiles (generally within $50 \mathrm{ft}$ ) are displayed in the figures with the inverted resistivity sections for comparison (figs. 4 through 13). Figure 3 shows the lithologic log description used in figures 4 through 13 .

The main geologic units are alluvial deposits that include clay, silt, sand, and gravel and a hardpan layer at depth that forms the river bed in some erosion-resistant locations. Generally, the coarser grained deposits, such as sand and gravel, will have a higher resistivity than finer grained sediments. Because of the variability and complexity of the alluvial deposits in the study area, it is difficult to interpret continuous units between the available lithologic logs. The logs are used, instead, to infer the most likely lithologies responsible for the observed resistivity structure near those logs. The vertical resolution of the lithologic logs is higher than both the DC and CC resistivity models. Lithologic log layers that are less than about $5 \mathrm{ft}$ will generally not be resolved in these resistivity model sections as individual layers.

Other cultural and hydrologic factors may impact the subsurface resistivity beyond the previously described lithologic composition. Cultural features, such as utilities or buried infrastructure, may result in resistivity anomalies. To aid in the interpretation of possible artifacts in the resistivity models from cultural features, the location and extent of levee penetrations (for example, pipes, conduits, utility lines) are discussed where they coincide with the resistivity section data. Additionally, historical erosion events associated with the 1986 and 1997 flood events and proximal embankment revetment, or slope stabilization, activities (URS, 2010) are shown on the section maps (figs. 4 to 13) and discussed in the context of the resistivity models for each of the sections. The 1986 and 1997 flood events resulted in discharge rates of up to 134,000 and 117,000 cubic feet per second (cfs), respectively, with average annual discharge rates ranging between 2,000 and 4,000 cfs (U.S. Geological Survey, 2014; American R A Fair Oaks, Calif., gaging station 11446500). Furthermore, variations in porosity and degree of saturation will affect resistivity, where higher saturation levels generally correspond to lower resistivity values. Groundwater quality may also impact the resistivity structure, where changes in TDS concentrations and the presence of industrial contaminants can result in variable fluid resistivity. No soil moisture or water quality data are available to confirm or rule out these hydrologic variables in the interpretation of the resistivity models, but we acknowledge their potential influence on the interpretation.

The data are presented in sections along the river with coincident and sub-parallel DC and CC resistivity profiles shown together for better comparison. The sections are presented from west to east or in the upstream direction. The color scale is consistent for all profiles as well as the plotting scale with no vertical exaggeration. All profiles are plotted from south to north or west to east. Long profiles are split into multiple segments in order to accommodate them on a single figure.

\section{Section A-Left and Right Bank}

The right bank of the section A survey area extends from the south end of the Campus Commons Golf Course to just north of Northrop Avenue (RM 5.4 to 6). Two CC resistivity profiles (lines 251 and 252) and two short DC resistivity profiles (lines 203 and 204; table 1; figure 4) were acquired on the right bank. Capacitively coupled resistivity line 252 was acquired along the paved levee toe road, and 


\section{Universal Soil Classification System}

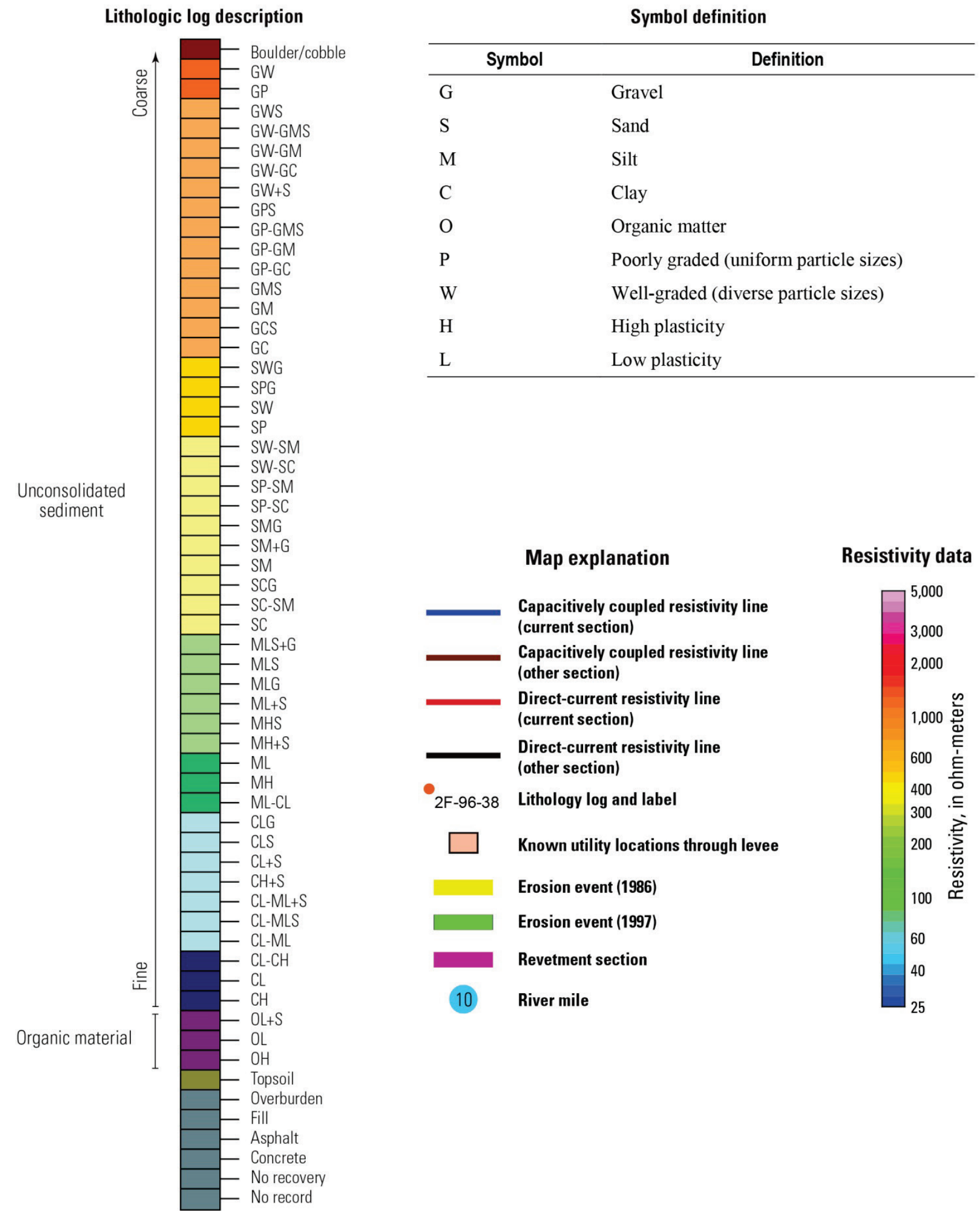

Figure 3. Explanation of symbols for the map, resistivity profiles, and lithologic logs for figures 4 through 13. 


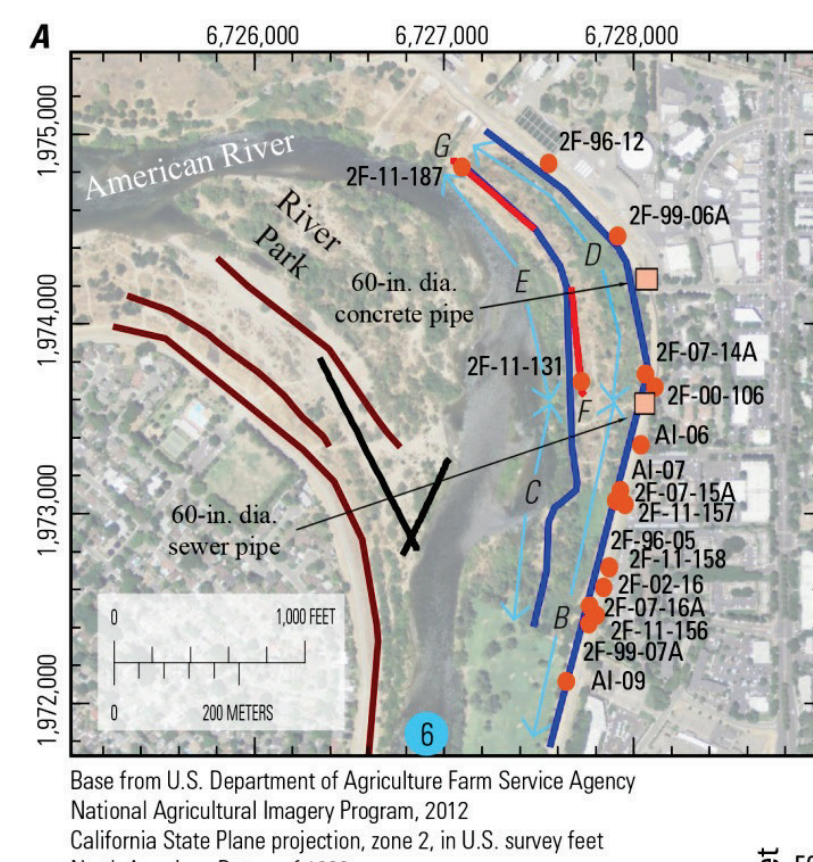

Figure 4. Right bank of Section $A(A)$ map showing the location of the resistivity profiles and relevant lithologic logs and $(B, C, D, E)$ inverted capacitively coupled resistivity and ( $F$ and $G$ ) direct-curren resistivity profiles with the lithologic logs overlaid. The extents of each of the capacitively coupled resistivity sections are indicated by the light blue arrows on $A$. The lithology log explanation is in figure

3. Utility locations are from URS (2010).

\section{EXPLANATION}

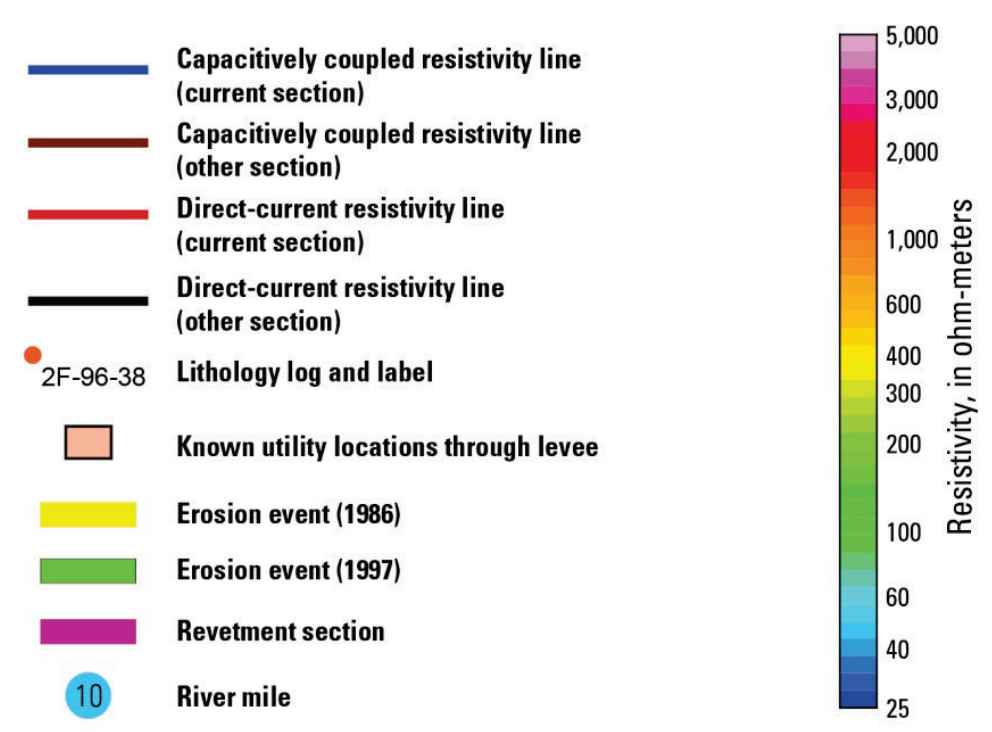

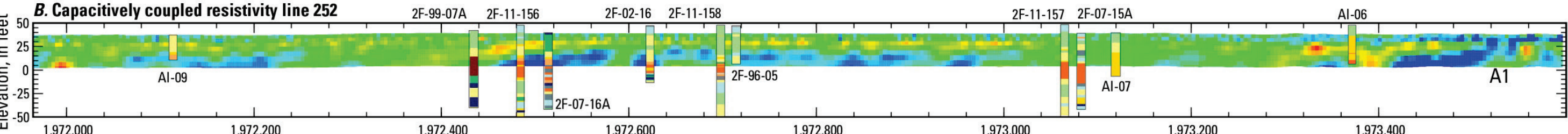

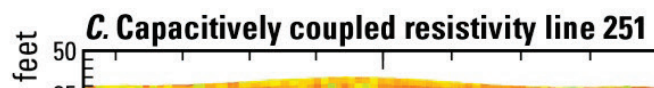

$1,972,800$

$1,973,200$

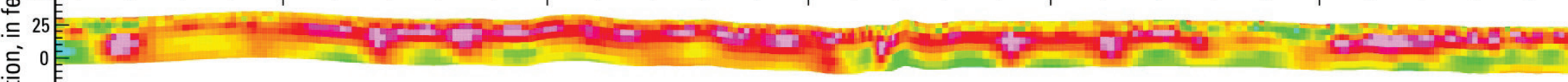
$-25$
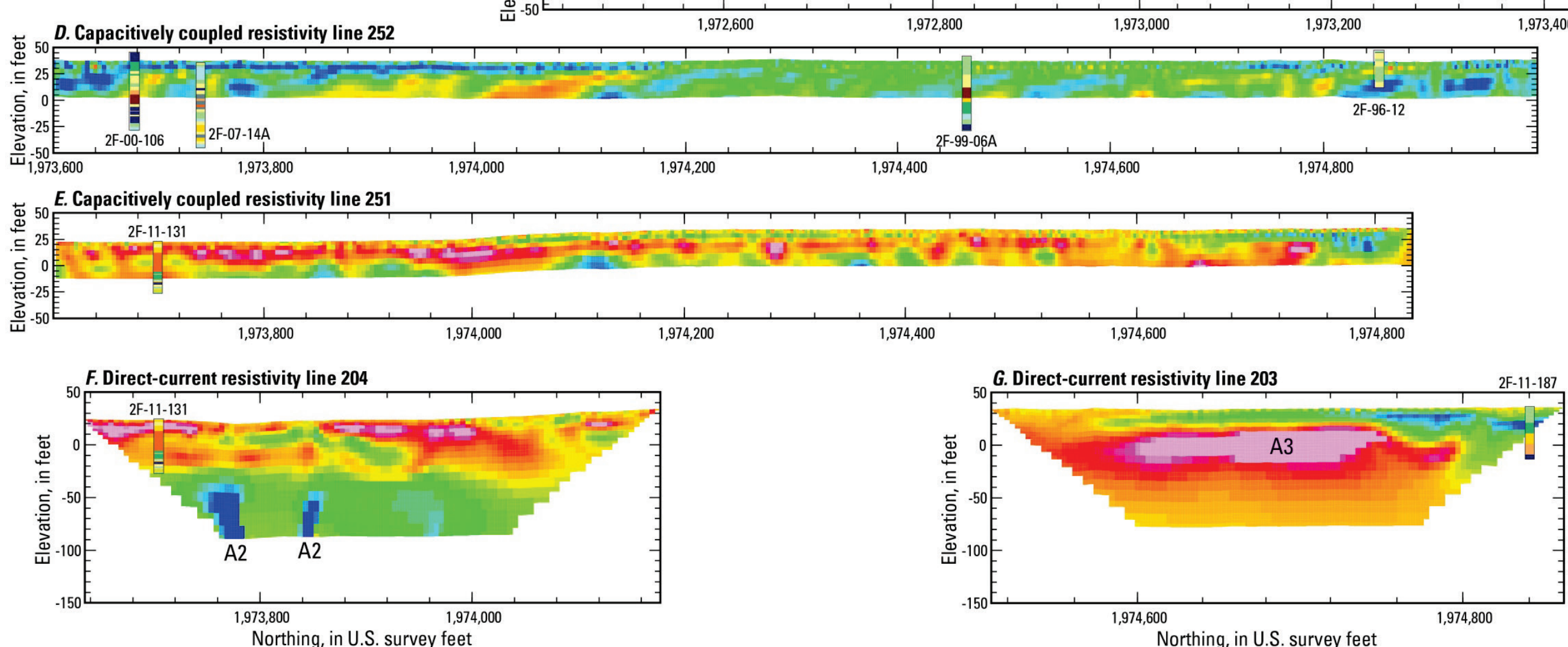

Northing, in U.S. survey feet 
line 251 was acquired along a more sinuous, paved bike path closer to the river. Line 252 has a lower overall resistivity structure than line 251 . Because most of the lithologic logs in this section are along the levee, closer to line 252, it is difficult to definitively interpret the causes of these variations along the entire lengths of the profiles. Because this section is on a bluff, elevated above the river, the CC resistivity profiles are most likely not penetrating deep enough to be imaging variations in saturation levels. The resistivity variations are therefore assumed to be from changes in lithology. Log 2F-11-131 along line 251 has an approximately 20-ft-thick gravel section and generally exhibits coarser grained lithologies overall than the logs along line 252, which are more dominated by clay, silt, and sand.

Two, 60-in. diameter pipes intersect the levee in this section (URS, 2010). The southern sewer pipe may be related to the surface conductor between northing 1,973,520 and 1,973,560 $\mathrm{ft}$ on CC resistivity line 252 (labeled as $A 1$ in fig. $4 B$ ). There is no obvious anomaly associated with this pipe on $\mathrm{CC}$ resistivity line 251 . The northern pipe is described as a concrete pipe but does not appear to correlate with any obvious surface anomalies on the profiles in this area.

The shallow sections of the DC resistivity profiles correlate well with CC resistivity line 251 . Direct-current resistivity line 204 (fig. 4F) exhibits a laterally varying, more highly resistive surface layer $\sim 20 \mathrm{ft}$ thick overlying a less resistive layer. The lower resistivity may be due to higher saturation levels. The two discrete conductors (blue) centered at northing 1,973,800 ft at depth $(A 2)$ have the appearance of anomalies because of cultural features but do not appear to be in line with the locations of the noted 60-in. diameter pipes noted along the levee.

The upper 10-15 ft of the DC resistivity line 203 (fig. 4G) is more conductive than line 204 and becomes increasingly more conductive to the north. Based on $\log 2 \mathrm{~F}-11-187$ on the north end of the profile, the moderately resistive (green) layer correlates with a sandy silt and the more conductive, discrete (blue) layers correlate with a more clay-rich silt. The high resitivity (pink) underlying layer that extends from northing $1,974,600$ to $1,974,760 \mathrm{ft}(A 3)$ is most likely a coarser grained material like sand or gravel.

The left bank of Section A (fig. 5) extends north from the J Street Bridge to River Park (RM 5.1 to 6.4). This section includes three CC resistivity profiles (lines 201, 202, and 203) and two DC resistivity profiles (lines 207 and 213; table 1). The line locations were chosen based on accessibility through the vegetated patches in River Park. Capacitively coupled resistivity line 203 was acquired along the gravel levee toe road. At the time of the survey, the river level was higher than what is shown in the aerial photo in the figures.

Capacitively coupled resistivity line 203 exhibits increasing resistivity to the north (fig. $5 G$ ), with an abrupt change at northing 1,971,560 ft ( $A 4$ in fig. 5F). Logs $2 \mathrm{~F}-11-146$ and 2F-11-145 indicate that the lower resistivity layers (50-300 ohm-m) correspond to sand deposits, and that the middle layer with a higher resitivity (350-2,000 ohm-m) corresponds to gravel deposits that vary in thickness laterally. From northing 1,971,560 ft northward, a shallow, thicker, and laterally extensive high resistivity layer is observed that corresponds with the thick (10-25 ft) sand and gravel without interlayered thin finer grained deposits in logs 2F-11-144, 2F-97-02, ARFCD-DH-26, 2F-11-195, and $2 \mathrm{~F}-11-190$. The conductive anomaly between northing 1,970,000 and 1,970, $040 \mathrm{ft}$ at approximately 40 -ft elevation ( $A 5$ in fig. $5 F$ ) may be related to three 36 -in. diameter drain pipes (URS, 2010) that cross the levee in this area. The periodic blue, low-resistivity features at the surface between the southern end and northing 1,971,600 ft are artifacts that may be either due to noise introduced during acquisition (for example, cable noise) or during inversion but is not fully understood. In this case, the 5 - to 10 -ft-thick surface layer is interpreted to be a laterally varying sand layer, but the discrete 

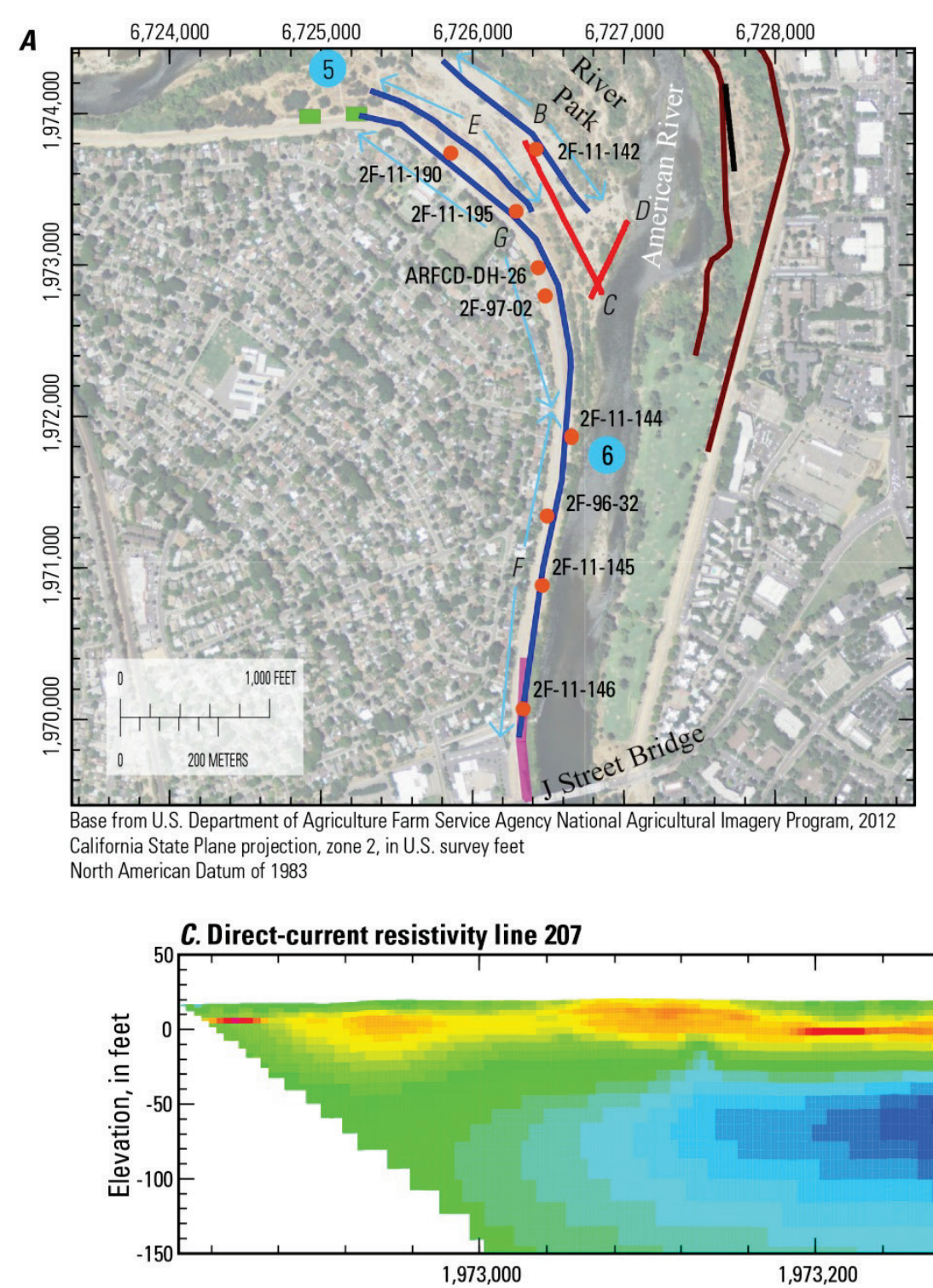

$\frac{1}{1,973,200}$
Figure 5. Left bank of section $A(A)$ map showing the location of the resistivity profiles and relevant lithologic logs and $(B, E, F, G)$ inverted resistivity and $(C$ and $D$ ) direct-current resistivity profiles with the lithologic logs overlaid. The extents of each of the resistivity sections are indicated by the light blue arrows on $A$. The lithology log explanation is in figure 3. Erosion event and revetment locations are from URS (2010).
EXPLANATION

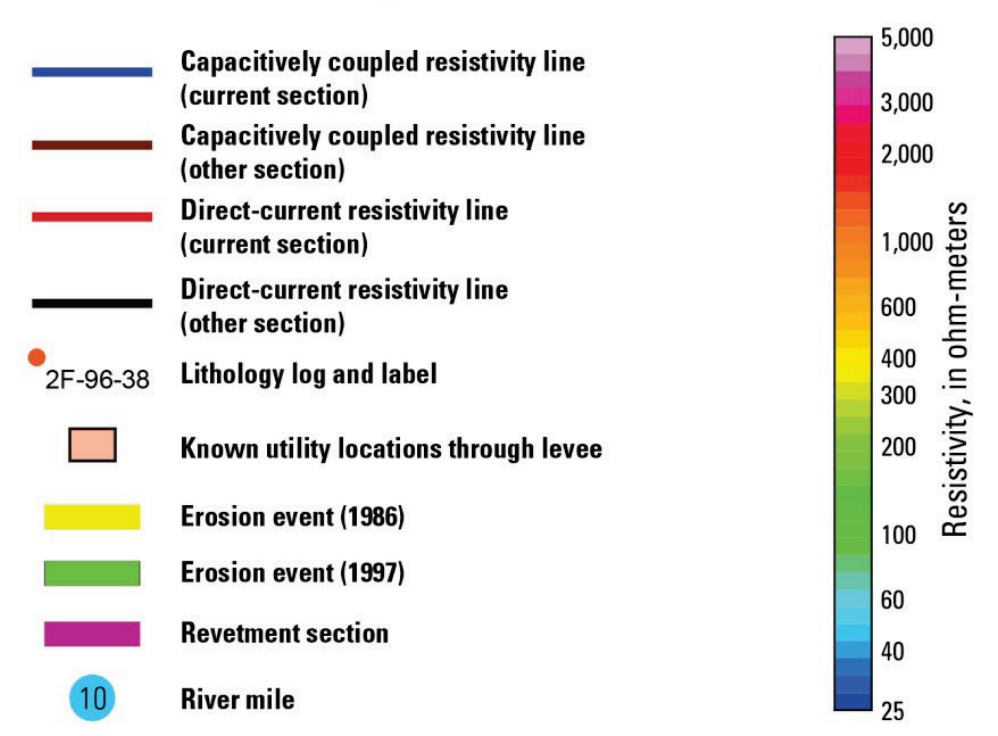

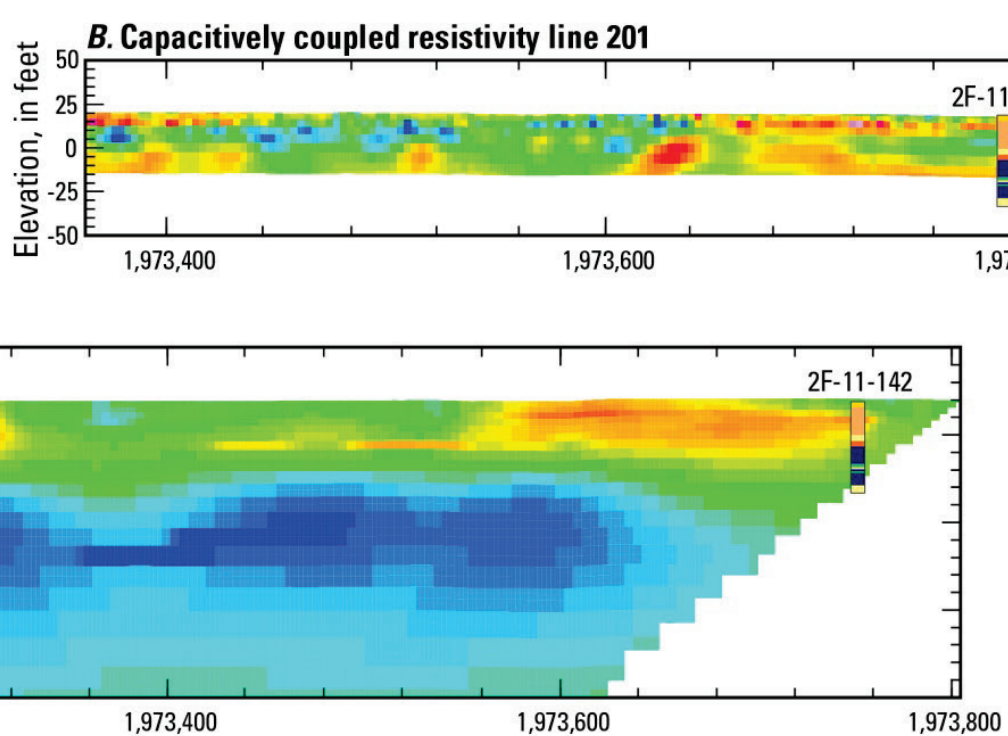

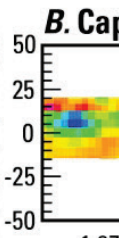

$1,973,80$

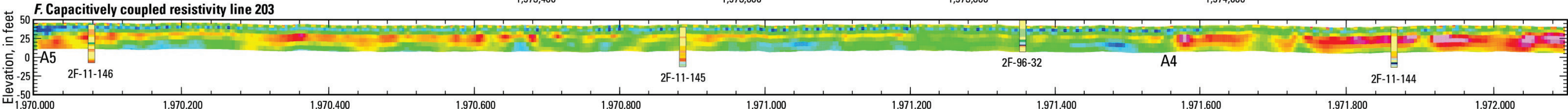

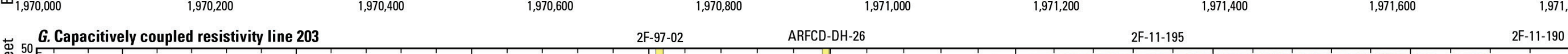

${ }_{50}$ E. Capacitively coupled resistivity line 202

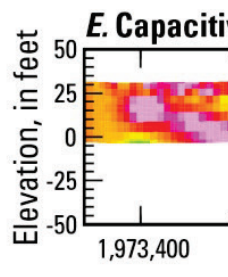

2F-11-142 -

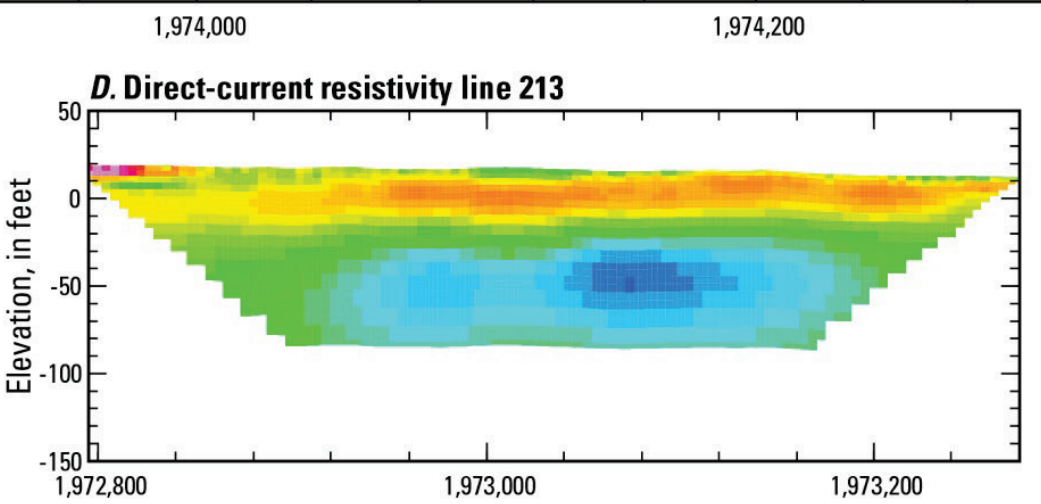

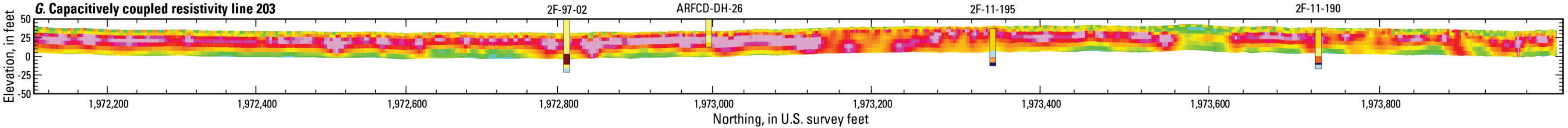


blue features should not be interpreted. The sand and gravel in the south transitions to finer grained silts and sands in the vicinity of $\log 2 \mathrm{~F}-96-32$.

In the vicinity of the point bar at River Park, both DC resistivity profiles and the $\mathrm{CC}$ resistivity profile closest to the river, line 201 (fig. $5 B$ ), have a moderate resistivity structure that is lower overall than CC resistivity lines 202 and 203, interpreted to indicate higher levels of water saturation in the lines closest to the river. Log 2F-11-142 along CC resistivity line 201 indicates an 8-10-ft-thick gravel layer overlying silts and clays. The moderately resistive (300-2,000 ohm-m) surface layers and underlying more conductive layer (25-300 ohm-m) in resistivity lines 201, 207, and 203 are most likely gravel and finer grained deposits such as silt and clay, respectively. The low resistivity layer (25-50 ohm-m) in the

DC resistivity lines at approximately -25 -ft elevation may be due to the presences of a more clay-rich or very fine-grained deposit or to increased saturation but is difficult to determine without additional log information. Capacitively coupled resistivity lines 202 and 203 exhibit an overall higher resistivity structure most likely due to lower saturation levels, since these profiles are located farther from, and elevated above, the river. The CC resistivity profiles indicate a laterally varying, two-layered system with a high resistivity (greater than 5,000 ohm-m) surface layer overlying a more conductive (60-300 ohm-m) layer. The 25- to 50-ft-thick sand and gravel overlying clay in logs 2F-97-02, 2F-11-195, and 2F-11-190 correlate well with the observed resistivity structure.

\section{Section B-J Street Bridge to Guy West Pedestrian Bridge}

Section B (fig. 6) extends southward from the J Street Bridge to just south of the Guy West Pedestrian Bridge (RM 6.5 to 7.0). Included in this section are the northern section of CC resistivity line 204 and DC resistivity lines 208 and 209 (table 1). These profiles were acquired along a grassy bench on the slope of the levee, just above the thicker vegetation that extends down to the river.

Direct-current resistivity lines 208 and 209 exhibit a similar resistivity structure to CC resistivity line 204 with moderate resistivity (70-400 ohm-m) extending to approximately $-50-\mathrm{ft}$ elevation. Based on the lithologic logs, the moderate resistivity correlates with sand and gravel layers. Silt layers in logs correlate well with a thin conductive layer (less than $50 \mathrm{ohm}-\mathrm{m}$ ) between 15- and 28-ft elevation on DC resistivity line 208. The conductive layer at depth (below -50-ft elevation) is most likely due to increased saturation levels.

The discrete conductive anomalies on CC resistivity line 204 between northing 1,966,900 and $1,966,980 \mathrm{ft}$ ( $B 1$ in fig. $6 B$ ) correlate with the locations of six 14-24-in. diameter pipes as well as two 5-in. diameter concrete-encased electrical conduits (URS, 2010) located near the base of the pedestrian bridge. An 800-ft long section of the levee toe was eroded in the 1986 flood, and the river bank was subsequently revetted (URS, 2010). The 5-ft-thick surface layer that is observed in all three profiles north of the pedestrian bridge that transitions from a low (less than $60 \mathrm{ohm}-\mathrm{m}$ ) to a higher resistivity (300-800 ohm-m) at around northing 1,967,700 ft (B2) may be related to the revetment activities in 1986.

\section{Sections C and D-Guy West Pedestrian Bridge to Howe Avenue}

Section C (fig. 7) extends south of Guy West Pedestrian Bridge past the water intake tower, west of Howe Avenue (RM 7.0 to 7.4). This section contains portions of two CC resistivity profiles (lines 204 and 205) and two DC resistivity profiles (lines 201 and 202; table 1). Direct-current resistivity line 202 was acquired across the irrigated lawn of Alumni Grove and an open, dry grass area, ending at the bridge extending from the water intake tower in the river to the intake station. Direct-current resistivity line 201 was acquired across an open, dry grassy area, extending below the water intake bridge to the start of the forested area. Capacitively coupled resistivity line 205 was acquired along a gravel foot path 


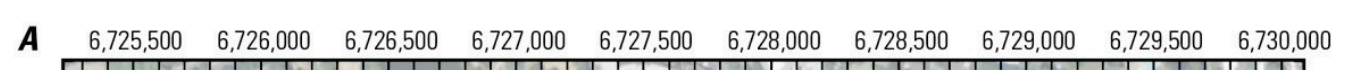

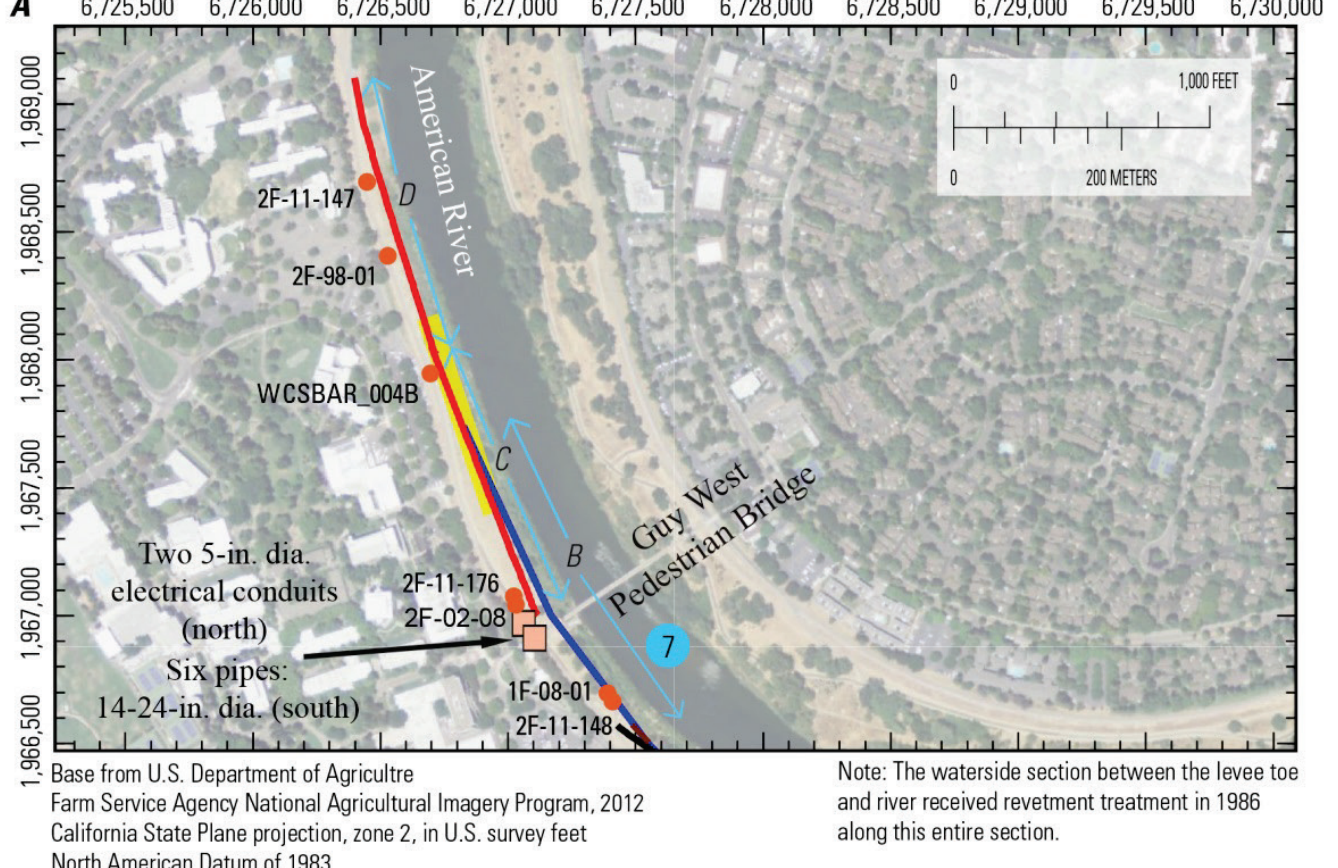

B. Capacitively coupled resistivity line 204

2F-02-08 $2 F-11-176$

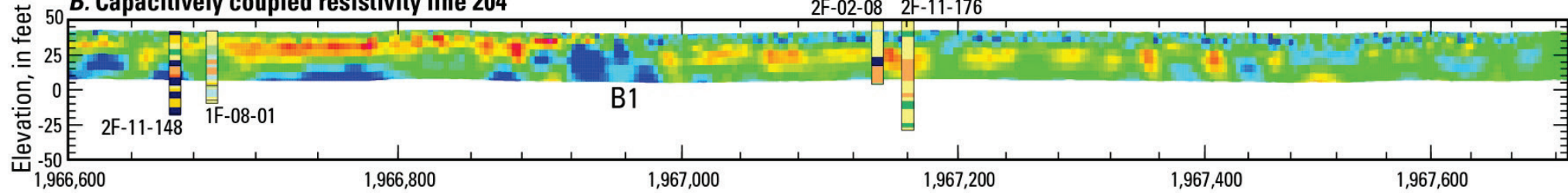

1,00800

\section{EXPLANATION}

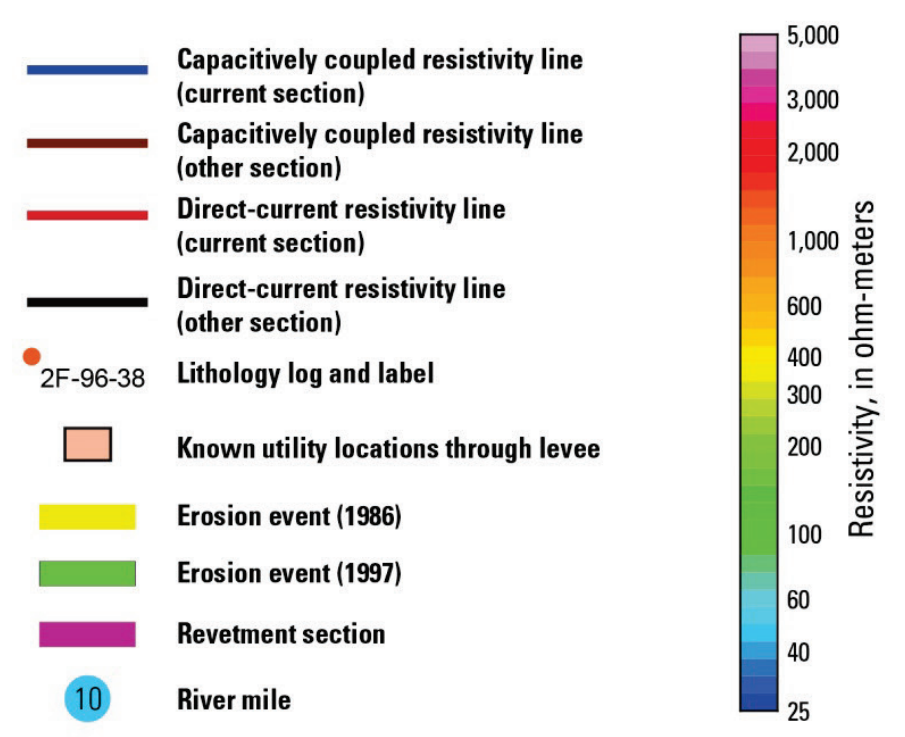

Figure 6. Section $B(A)$ map showing the location of the resistivity profiles and relevant lithologic logs and $(B)$ inverted capacitively coupled resistivity and $(C$ and $D)$ direct-current resistivity profiles with the lithologic logs overlaid. The extents of each of the resistivity sections are indicated by the light blue arrows on $A$. The lithology log explanation is in figure 3 . Utility, erosion event, and revetment locations are from URS (2010).
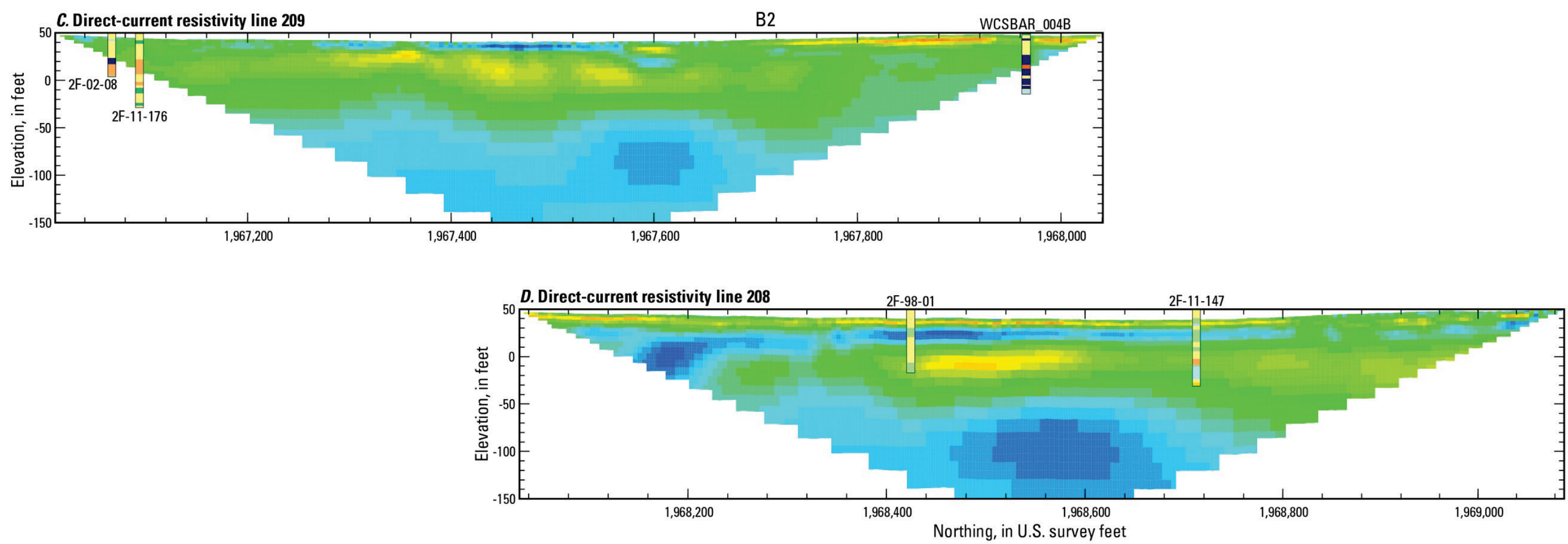


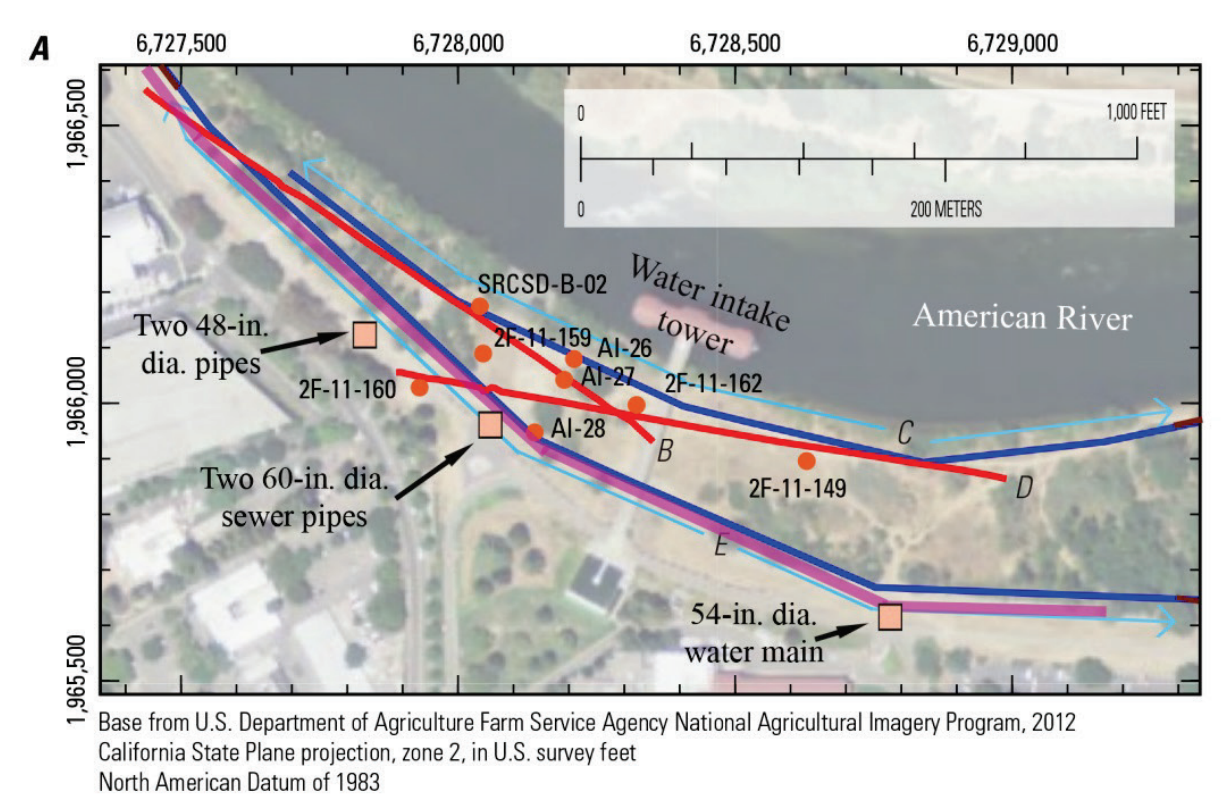

\section{EXPLANATION}

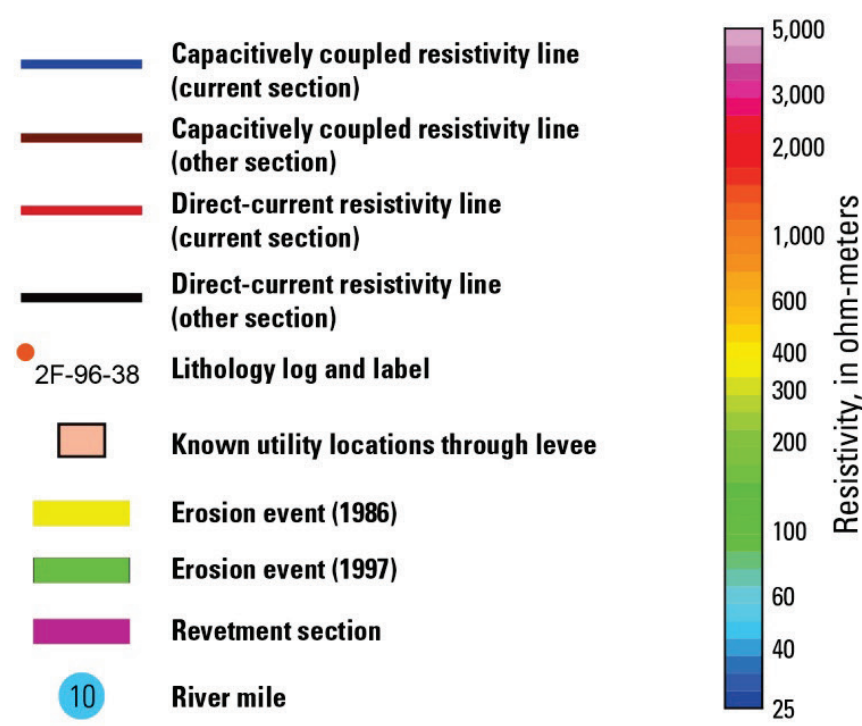

Figure 7. Section $C(A)$ map showing the location of the resistivity profiles and relevant lithologic logs and $(B$ and $D$ ) inverted direct-current resistivity and ( $C$ and $E$ ) capacitively coupled resistivity profiles with the lithologic logs overlaid. The extents of each of the resistivity sections are indicated by the light blue arrows on $A$. The lithology log explanation is in figure 3. Utility and revetment locations are from URS (2010).
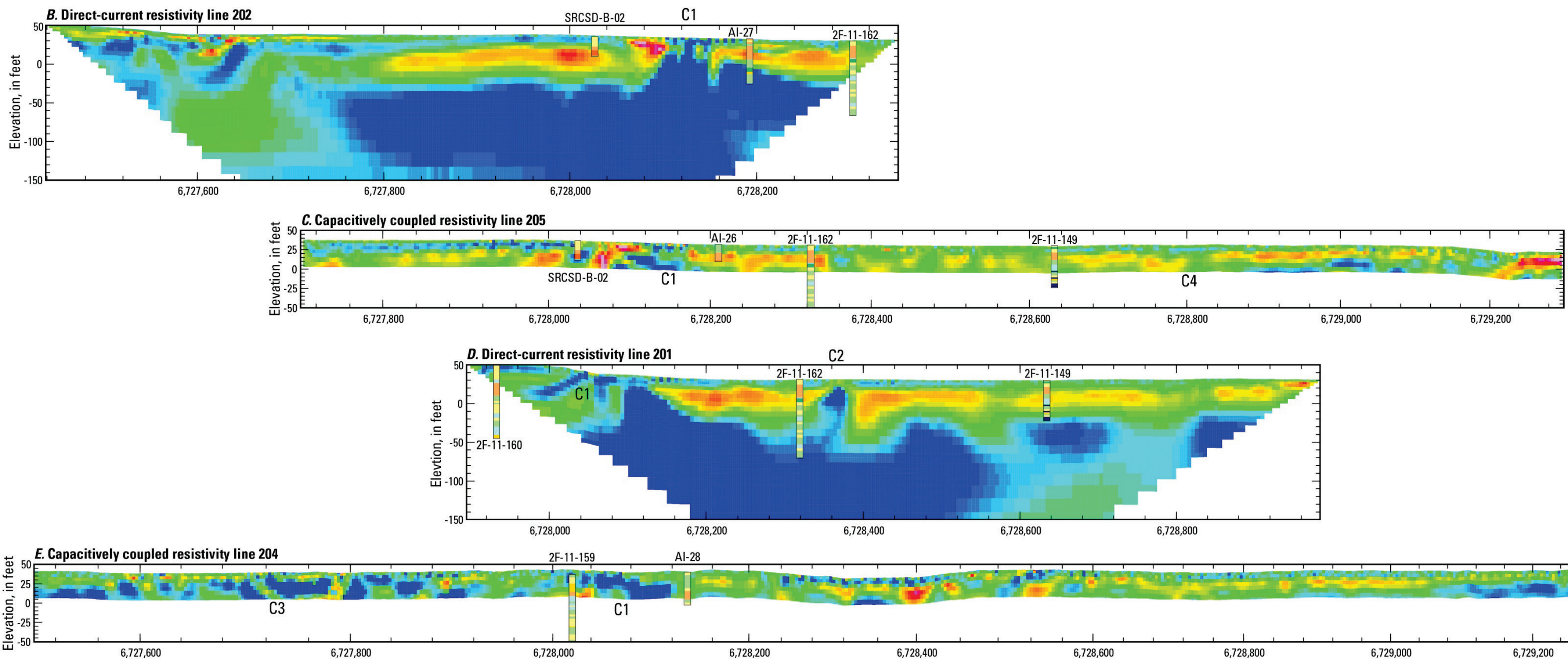

2F-11-159 Al-28$$
\frac{1}{6,728,800}
$$ 
near the edge of the wide, flat bench between the levee and river in this area. Capacitively coupled resistivity line 204 was acquired along the paved bike path along the levee toe. All four profiles subparallel one another and exhibit a similar, moderate shallow resistivity structure (80-300 ohm-m) with an intermittent conductive surface layer (less than $40 \mathrm{ohm}-\mathrm{m}$ ) and an intermittent 5- to 15-ft-thick highresistivity layer (300-2,000 ohm-m) approximately $10 \mathrm{ft}$ below the surface. Logs SRCSD-B-02, AI-27, and 2F-11-162 all indicate sand and gravel in the upper $20 \mathrm{ft}$ with alternating silt and clay layers at depth. The presence of silt and clay layers correlate with the very conductive layer (less than $30 \mathrm{ohm}-\mathrm{m}$ ) that generally starts at $-20-\mathrm{ft}$ elevation that is observed in both DC resistivity profiles. This conductive layer may be a result of the presence of finer grained deposits and higher saturation levels.

Several subsurface cultural features are in these profiles, creating artifacts that are not related to geology. The shallow conductive feature on DC resistivity line 202 between approximately easting $6,728,100$ to $6,728,150 \mathrm{ft}(C 1)$ and on $\mathrm{CC}$ resistivity line 205 from easting 6,728,115 to 6,728,170 ft (C1) corresponds to an area through which two 60-in. diameter sewer pipes and two 48-in. diameter pipes pass (URS, 2010). There is also an above-ground concrete block with several utility manhole covers, assumed to be related to the same utility pipes, that DC resistivity line 202 passed by directly. Capacitively coupled resistivity line 204 and DC resistivity line 201 also contain conductive features that are most likely related to the same utilities from easting 6,728,030 to 7,728,120 $\mathrm{ft}$ and from $6,728,040$ to $6,728,130 \mathrm{ft}$, respectively $(C 1)$. There is a conductive anomaly centered at easting $6,728,370 \mathrm{ft}$ and 5-ft elevation on DC resistivity line $201(C 2)$ that corresponds with the location of the bridge and may also be a cultural artifact possibly related to the proximity to one of the bridge supports (the resistivity profiles is within $20 \mathrm{ft}$ of the footer) since there is no indication in the URS (2010) levee structure summary of any utilities or other structures in this area. The multiple conductive anomalies on CC resistivity line 204 between easting 6,727,580 and 6,727,910 ft (C3) correspond with the irrigated lawn within Alumni Grove and don't have a typical geologic appearance, but with no lithologic logs in this area, it is difficult to make a definitive interpretation. According to URS (2010), there is a 54-in. diameter water main that passes through the levee at approximately easting $6,728,780 \mathrm{ft}$ but there is no obvious anomaly in either CC resistivity line 204 or 205 in this area. There is, however, a break in the shallow resistive layer centered at easting 6,728,800 ft in CC resistivity line 205 (C4) that may be related to the pipeline.

Section D (fig. 8) extends east of the water intake tower to the east side of Howe Avenue (RM 7.4 to 7.9). This section contains five CC resistivity lines. Capacitively coupled resistivity lines 204, western section of 207, and 209 were acquired along the paved levee toe road. Lines 205 and 206 were acquired closer to the river along a gravel foot path, with the eastern section of line 206 acquired across a paved parking lot. The eastern section of line 207 diverges from the toe road and follows another paved path through the trees. Lines 206 and this section of 207 were only acquired with the shorter of the two geometries, resulting in a reduced depth of investigation of $15 \mathrm{ft}$. This section contains only two lithologic logs, located west of Howe Avenue: 2F-11-150 and 2F-97-27.

Capacitively coupled resistivity line 205 exhibits a two- to three-layer structure with a high resistivity top layer (400-3,000 ohm-m) overlying a more conductive layer (less than $200 \mathrm{ohm}-\mathrm{m}$ ) from easting $6,729,300$ to $6,729,600 \mathrm{ft}$. The resistive top layer transitions to a more moderately resistive layer (80-300 ohm-m) to easting 6,730,150 ft (Dl), where a 20- to 25-ft-thick resistive layer appears again. Based on $\log 2 \mathrm{~F}-11-150$, the thicker resistive layer correlates with a sand layer that transitions to a silt and clay layer at depth, corresponding to the more moderate resistivity below approximately 0 - $\mathrm{ft}$ elevation. The moderate resistivity values between easting 6,729,600 and 6,730,150 ft may indicate finer grained deposits. The periodic shallow resistive features across this range are most likely acquisition or inversion artifacts. Although there may be a more resistive layer at depth, the resistivity 


\section{EXPLANATION}

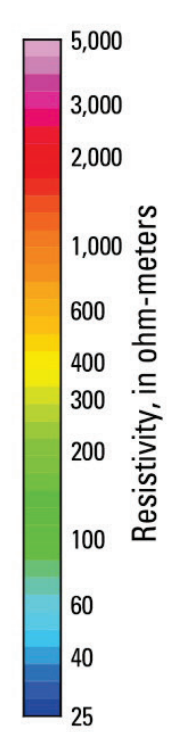

Figure 8. Section $D(A)$ map showing the location of

the resistivity profiles and relevant lithologic logs and

the $C, D, E, F)$ inverted capacitively coupled resistivity

profiles with the lithologic logs overlaid. The extents

of each of the resistivity sections are indicated by the

light blue arrows on $A$. The lithology log explanation

is in figure 3. Utility locations are from URS (2010).
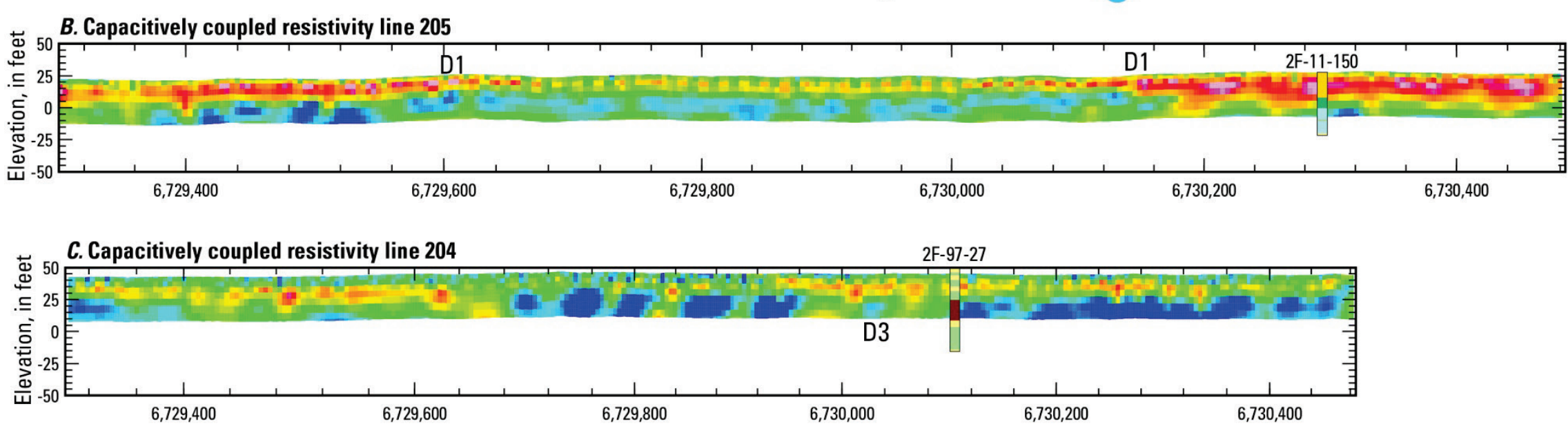

$\square$ D. Capacitively coupled resistivity line 206

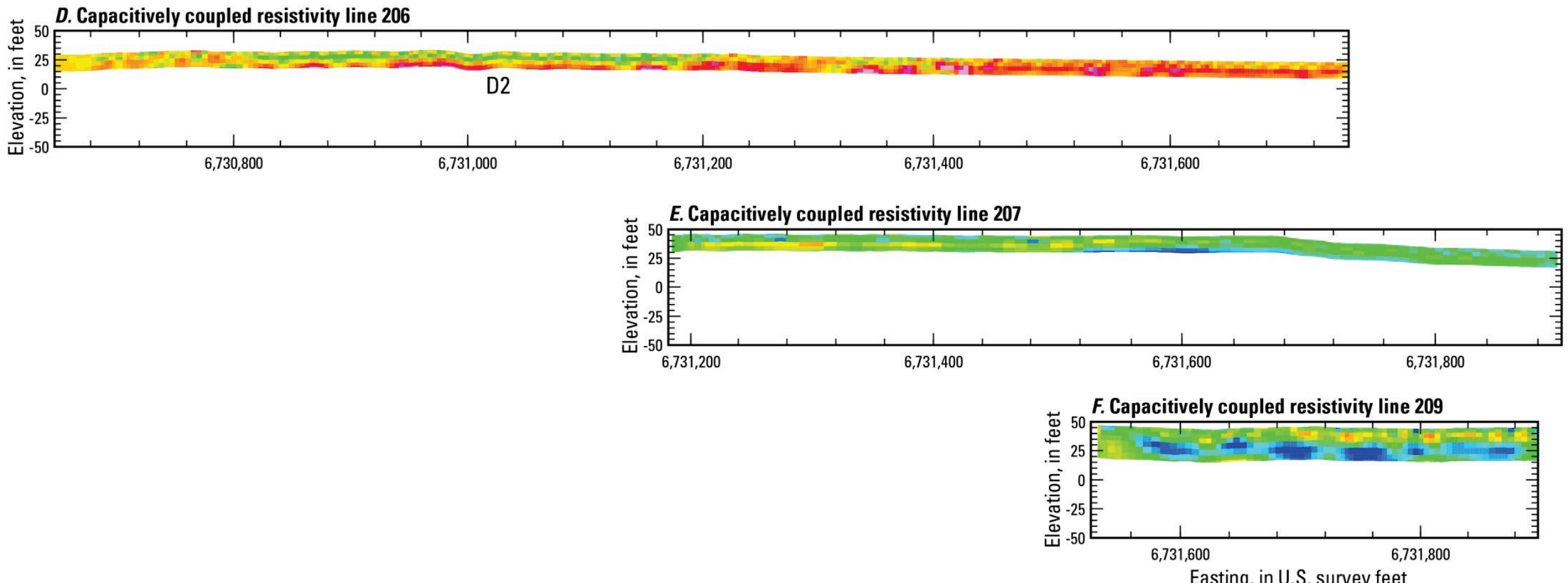

$6,731,600$
Easting, in U.S. survey feet

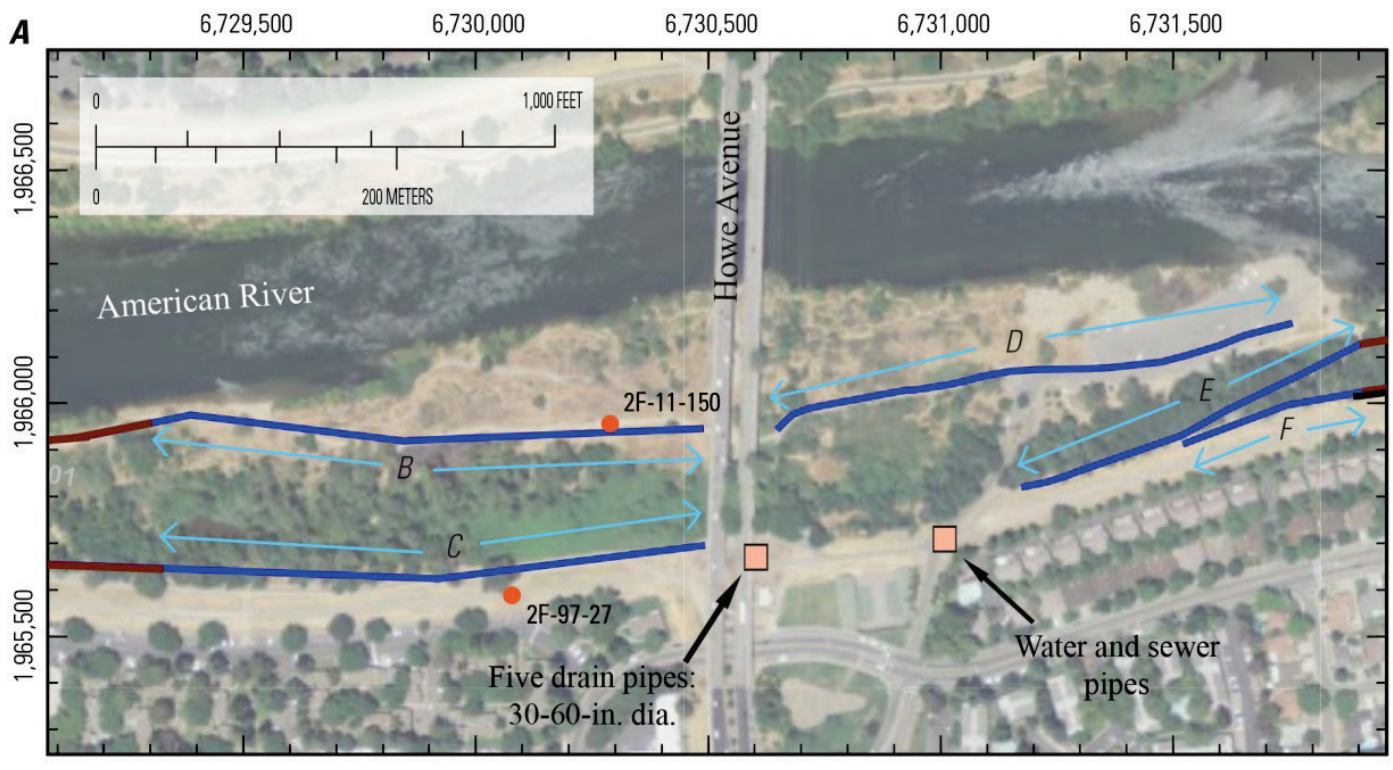

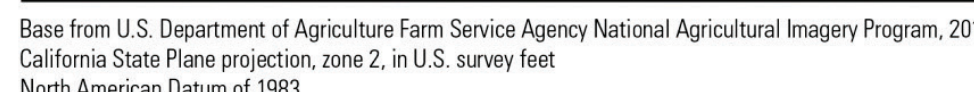


structure is most likely not as periodic as shown in the inversion. Line 206, which is a continuation of line 205 on the east side of Howe Avenue, exhibits similar moderate to high resistivity transitions but does not have any lithologic log control. This line also exhibits similar shallow periodic artifacts between easting 6,730,800 and 6,731,200 $\mathrm{ft}(D 2)$.

The three lines closer to the levee toe, the eastern section of line 204 and the western sections of lines 207 and 209, exhibit an overall lower resistivity with a moderately resistive layer (100-1,200 ohm$\mathrm{m}$ ) overlying an intermittently more conductive layer (less than $70 \mathrm{ohm}-\mathrm{m}$ ). Based on $\log 2 \mathrm{~F}-97-27$ along line 204, the deposits in its vicinity are a 20-ft-thick package of thin, alternating sand and silt layers with an underlying cobble layer that corresponds with moderate resistivity values between easting $6,729,960$ and 6,730,120 ft (D3). The intermittent conductive anomalies (less than $50 \mathrm{ohm}-\mathrm{m}$ ) below 25-ft elevation along lines 205 and 209 may be finer grained deposits (silts and clays). Five 30-60 in. diameter drain pipes and water and sewer pipes intersect the levee immediately east of Howe Avenue (URS, 2010), between CC resistivity lines 204 and 207. Capacitively coupled resistivity line 206, north of the levee, however, contains no indications of those pipes.

\section{Sections E, F, and G-Howe Avenue to Watt Avenue}

Section E (fig. 9) is about a 2,000-ft long section that extends eastward from the Howe Avenue bridge (RM 7.9 to 8.3). Two sub-parallel CC resistivity lines contain three profiles and a single DC resistivity profile (line 212; table 1). Capacitively coupled resistivity lines 207 (shallow acquisition geometry only) and 208 were acquired along a paved path through a forested section, and CC resistivity line 209 and DC resistivity line 212 were acquired along the gravel levee toe road. The resistivity structure becomes increasingly more resistive to the east. The three lines in the western half of section $\mathrm{E}$ (DC resistivity line 212 and CC resistivity lines 207 and middle section of 209) exhibit a moderately resistive (100-1,200 ohm-m), 10- to 75-ft-thick surface layer overlying a more conductive layer (less than $90 \mathrm{ohm}-\mathrm{m})$. Log 2F-97-28 indicates $40 \mathrm{ft}$ of alternating clay-rich and sand layers overlying clay and silt layers that appear to be well correlated with this conductive layer. An increase in saturation levels may also be the cause of the decrease in resistivity at depth on DC resistivity line 212 beyond the total depth of the lithologic log.

The two CC resistivity profiles in the eastern half of the section (line 208 and eastern section of line 209) exhibit a higher overall resistivity, which correlates with gravel layers in $\log 2 \mathrm{~F}-11-152$. Because of the thin, alternating layers in $\log 2 \mathrm{~F}-11-152$, the deposits in this area are most likely discrete and vary laterally and in thickness, which correlates with the variations in the high resistivity zones (greater than $400 \mathrm{ohm}-\mathrm{m}$ ) exhibited on CC resistivity line 208.

Section F (fig. 10) is located midway between Howe and Watt Avenues (RM 8.3 to 8.8) and includes a single CC resistivity line (contains two profiles; lines 210 and 211) acquired along the paved levee toe road and two orthogonal DC resistivity profiles (lines 205 and 206; table 1) acquired in an open area through which overhead high voltage power lines cross the river. The CC resistivity profiles generally exhibit a moderately resistive (70-300 ohm-m) surface layer overlying a more resistive layer (300-2,000 ohm-m) that has considerable lateral variation. Along line 210, logs 2F-98-02 and ARFCD-DH-29 indicate silt near the surface whereas logs 2F-11-153 and 2F-98-02 indicate sands, gravels, and even a boulder/cobble layer at depth, which correlates with higher resistivity values observed at depth. Line $211(F 1)$ has more conductive deposits from easting 6,736,040 ft eastward at about 20 -ft elevation. Also on line 211 , the conductive anomaly grouping from approximately easting $6,735,320$ to $6,735,440 \mathrm{ft}(F 2)$ appears to be more indicative of a cultural artifact and corresponds to the location of four 30-54 in. diameter drain pipes (URS, 2010). There is also a 60-in. diameter pipe intersecting the levee at approximately easting 6,734,440 ft (URS, 2010), but there is no obvious anomaly in CC resistivity line 210 associated with this feature. 


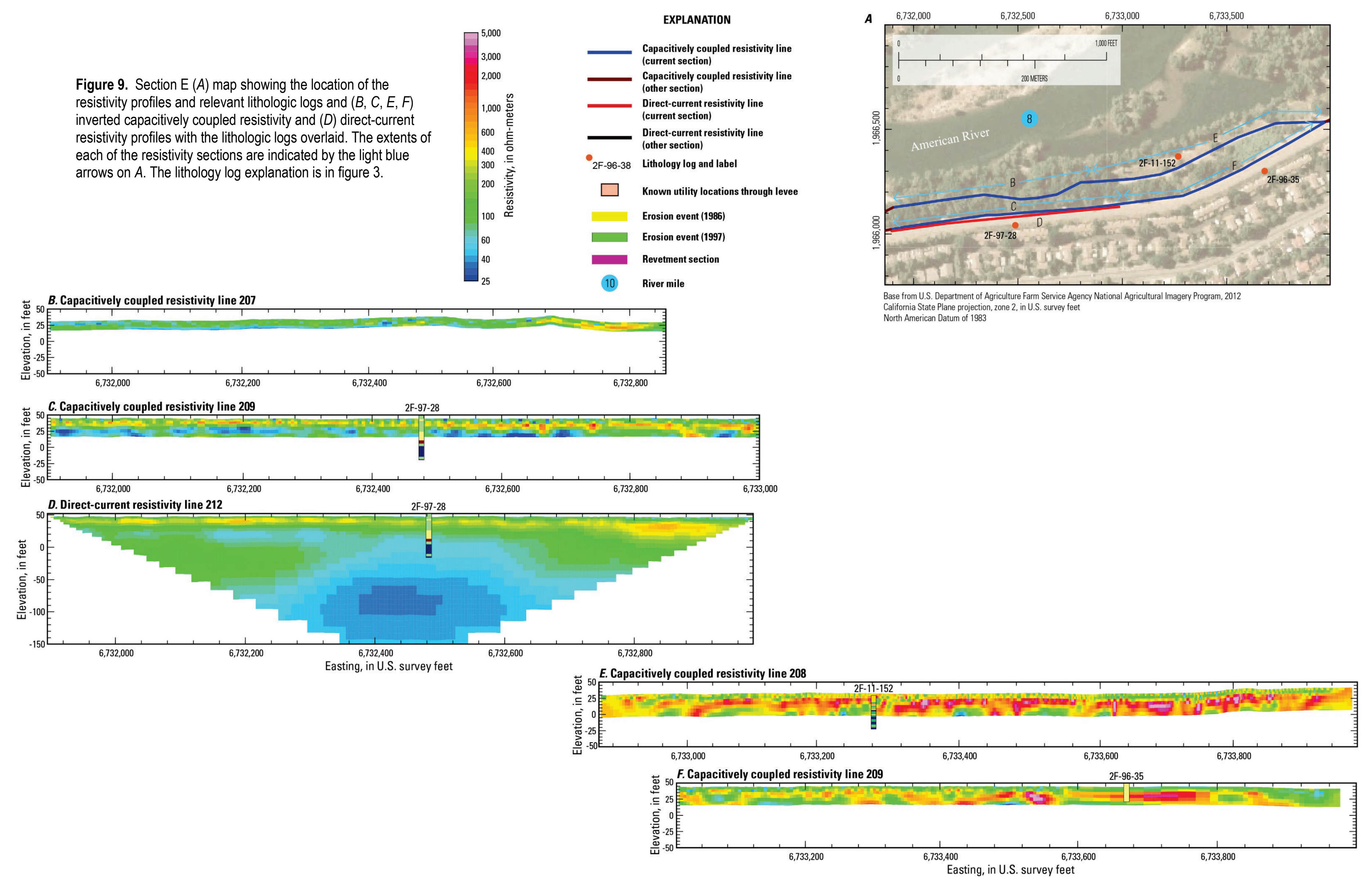




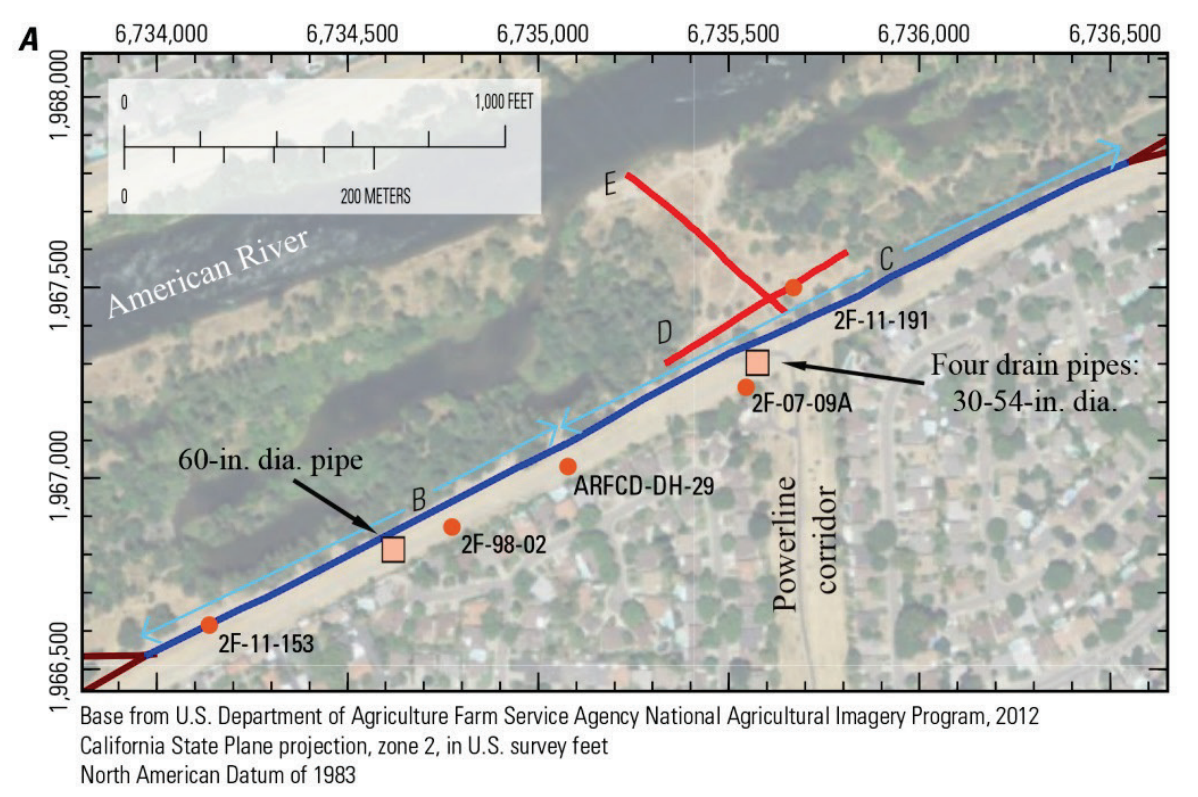

\section{EXPLANATION}

Capacitively coupled resistivity line

(current section)

Capacitively coupled resistivity line

lother section

Direct-current resistivity line

$\bullet_{2 F-96-38}$ Lithology log and label

$\square \quad$ Known utility locations through levee

Erosion event (1986)

Erosion event (1997)

Revetment section

(10) River mile
Figure 10. Section $F(A)$ map showing the location of the resistivity profiles and relevant lithologic logs and $(B$ and $C$ ) inverted capacitively coupled resistivity and ( $D$ and $E$ ) direct-current resistivity profiles with the lithologic logs overlaid. The extents of each of the resistivity section are indicated by the light blue arrows on $A$. The lithology log explanation is in figure 3. Utility locations are from URS (2010).

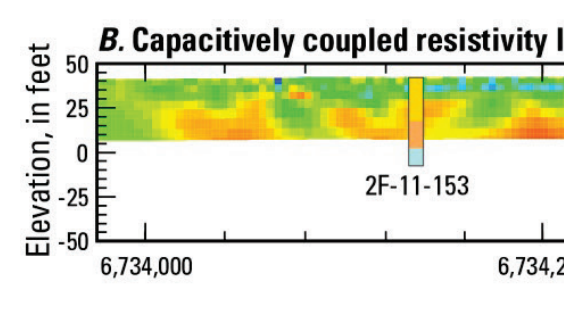

2F-98-02

ARFCD-DH-2

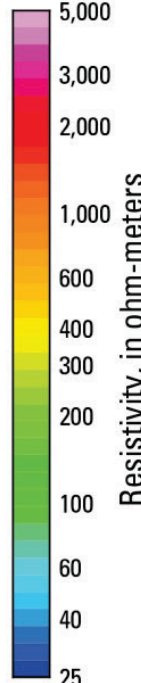

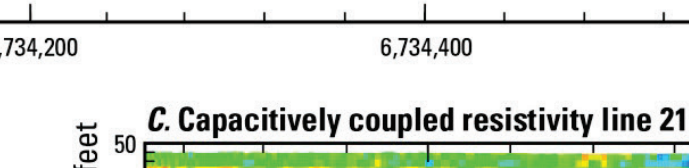

1 1 -

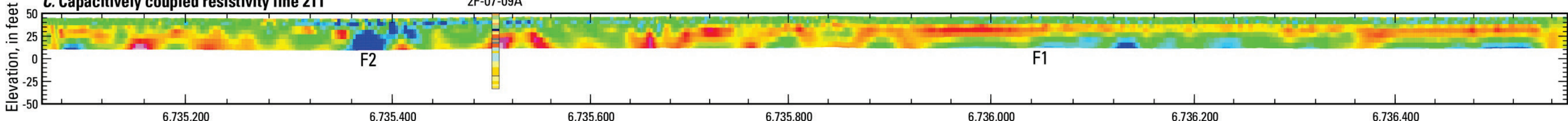
D. Direct-current resistivity line 206

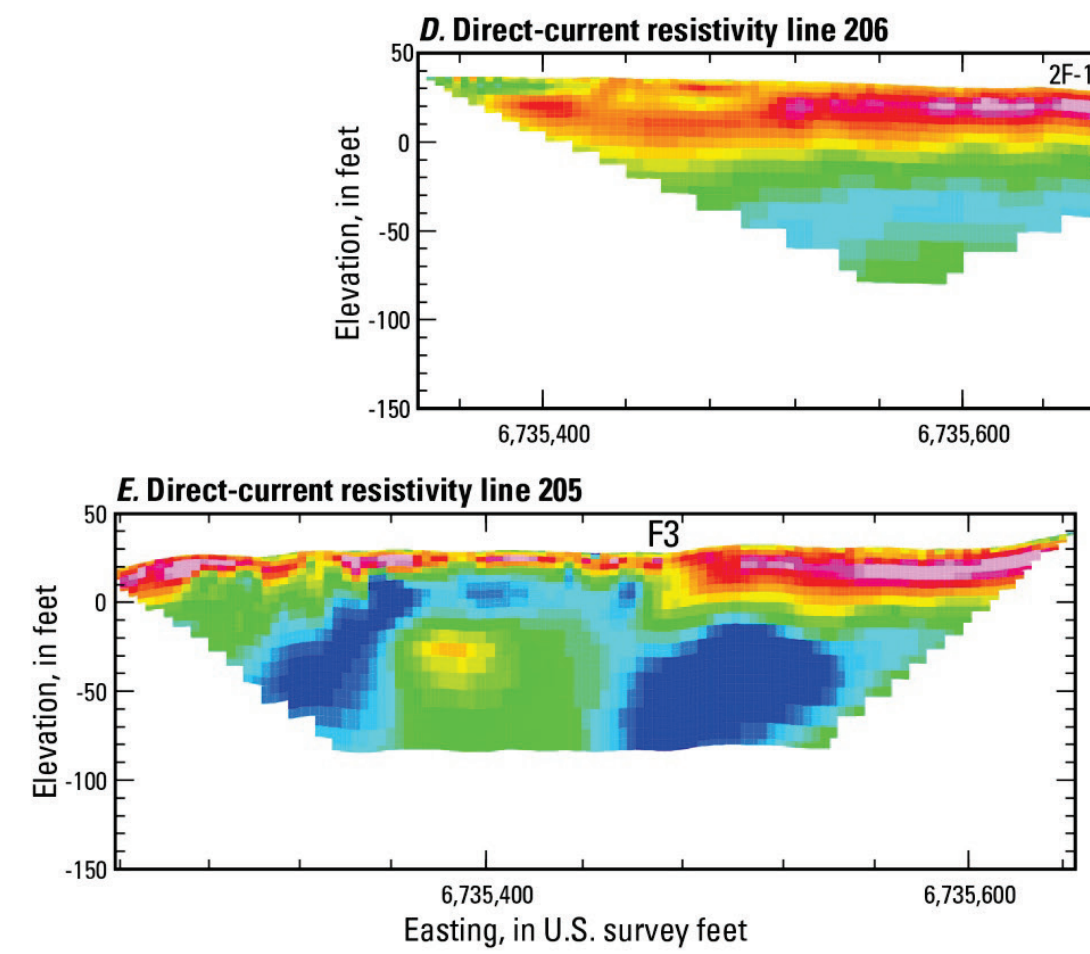


Direct-current resistivity line 206 parallels the levee and CC resistivity line 211 and obliquely crosses DC resistivity line 205. There is good correlation between these two lines at their intersection, both showing a 20 -ft-thick surface, highly resistive layer (greater than 1,200 ohm-m) overlying a more moderately resistive layer. Log $2 \mathrm{~F}-11-191$ indicates a 20 -ft-thick sand underlain by a thick clay, which correlates well with the observed resistivity structure. The resistive surface layer thins toward the river, as observed on line 205 , with an overall relatively abrupt change in resistivity character at easting $6,735,480 \mathrm{ft}(F 3)$. In general, the resistivity structure of line 205 correlates with sand overlying a thick clay, as shown in $\log 2 \mathrm{~F}-11-191$. Without additional boreholes closer to the river, however, it is difficult to interpret the structure at depth west of easting 6,735,480 ft. Possible interpretations include cultural interference, disturbance from the presence of the power line corridor, or that the line is obliquely crossing the four drain pipes if they continue toward the river from the levee. This area is dry but surrounded by ponds on either side between the main river channel and the levee (fig. 10A), and it is unknown whether this is a natural feature or a result of mitigation for the powerline corridor or drain pipe installation.

Section G (fig. 11) straddles Watt Avenue (RM 8.8 to 9.5 ) and has two resistivity profiles (lines 212 and 213) and one DC resistivity profile (line 210; table 1). Capacitively coupled resistivity line 212 was acquired along a gravel path on the levee toe road and ends at the intersection of the paved bike path west of Watt Avenue. Capacitively coupled resistivity line 213 was acquired along the paved bike path as it diverges from the levee toward the river, across the paved parking lot that extends underneath on either side of the Watt Avenue bridge, and along the paved road as it once again approaches the levee toe. Direct-current resistivity line 210 was acquired along the levee toe in the gravel and grassy area to the south of the paved road on the east side of Watt Avenue.

Capacitively coupled resistivity line 212 exhibits a more moderate resistivity structure overall $(50-1,000 \mathrm{ohm}-\mathrm{m})$ than line 213 , which is closer to the river, with a general trend of becoming less resistive to the east. $\log 2 \mathrm{~F}-97-37 \mathrm{~A}$ indicates the upper $20 \mathrm{ft}$ are interlayered sand and silt deposits, and $\operatorname{logs} 2 \mathrm{~F}-96-36$ and $2 \mathrm{~F}-97-29$ show a similar structure but with interlayered sands and clays. Logs 2F-97-37A and 2F-97-29 both indicate a 5-ft-thick boulder/cobble layer at depth but $\log 2 \mathrm{~F}-97-37 \mathrm{~A}$ shows an additional $15 \mathrm{ft}$ of silt and clay layers beneath, which would make the relatively thin boulder/cobble layer difficult to resolve with the $\mathrm{CC}$ resistivity method.

Capacitively coupled resistivity line 213 generally exhibits a three-layer resistivity structure with some indications at depth of an intermittent, conductive fourth layer. There is an intermittent 10- to 15$\mathrm{ft}$-thick resistive layer (greater than $600 \mathrm{ohm}-\mathrm{m}$ ) between two more moderately resistive layers (70-500 ohm-m). The discrete anomalies from easting 6,737,320 to 6,737,720 ft (Gl) correspond to the western section of the paved parking lot on the west side of Watt Avenue. This area has no boreholes, but the discrete, non-layered nature of these anomalies may indicate cultural causes, possibly underground utilities or another subsurface disturbance. Logs 2F-11-154, WRDA_2F-11-02, and WRDA_2F-1101 show mostly interlayered sand gravel deposits with occasional thin (less than $5 \mathrm{ft}$ thick) clay and silt layers. On the east side of Watt Avenue, $\log 2 \mathrm{~F}-97-30 \mathrm{~A}$ shows a 20 -ft-thick boulder/cobble layer bounded on either side by interlayered sand and silt deposits that correlate with the high resistivity layer below the surface. The gravel layer observed in $\log 2 \mathrm{~F}-11-15$ also correlates with the higher resistivity layer that is closer to the surface in this area.

Direct-current resistivity line 210 exhibits a similar resistivity structure as CC resistivity line 213 but with generally lower resistivity values. The different resistivity values may be due to differences in the values between the two locations or due to differences in the inversion parameters used to produce the best-fit model between the two different types of profiles. In the vicinity of $\log 2 \mathrm{~F}-97-30 \mathrm{~A}$, the higher resistivity layer (350-1,000 ohm-m) correlates with a 15 -ft-thick boulder/cobble layer bounded 


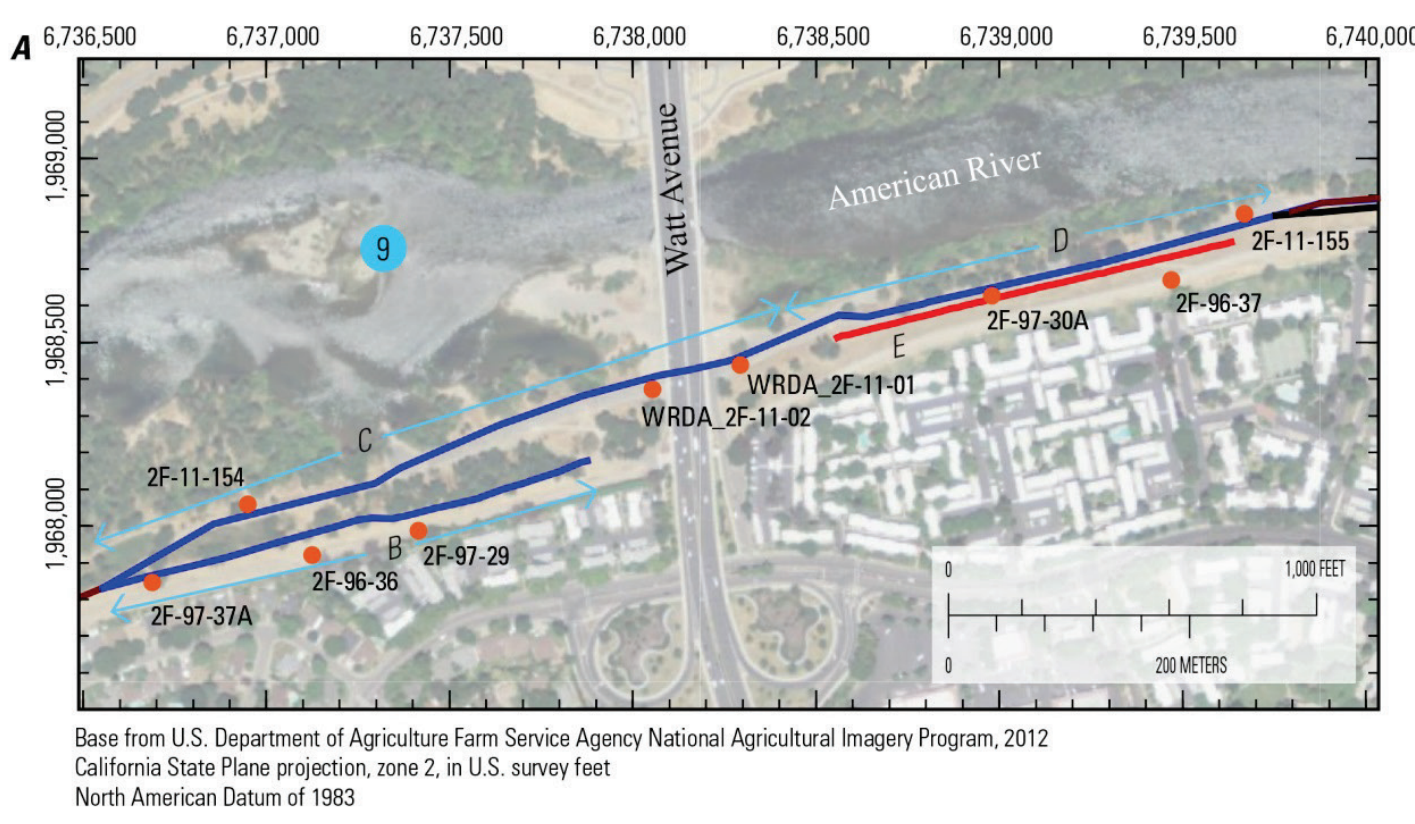

\section{EXPLANATION}

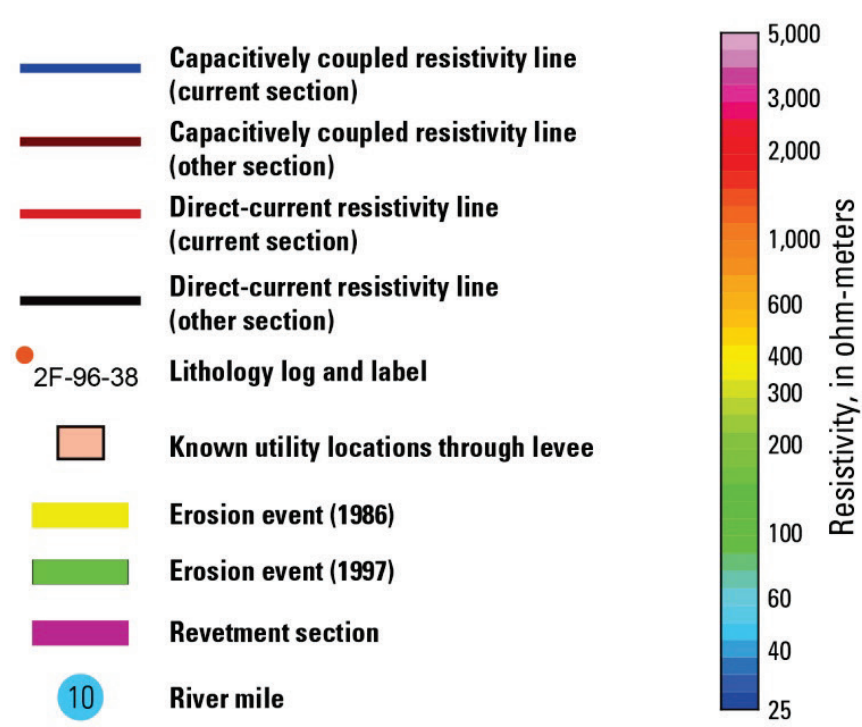

Figure 11. Section $G(A)$ map showing the location of the resistivity profiles and relevant lithologic logs and $(B, C, D)$ inverted capacitively coupled resistivity and $(E)$ direct-current resistivity profiles with the lithologic logs overlaid. The extents of each of the resistivity sections are indicated by the light blue arrows on $A$. The lithology log explanation is in figure 3 .

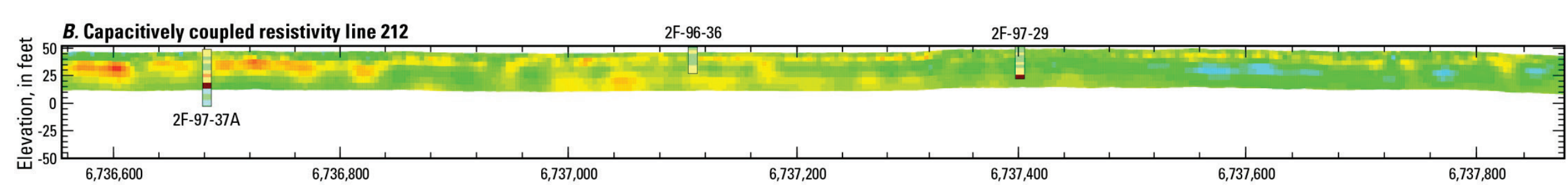

$\underset{\mathrm{\Phi}}{50}$ C. Capacitively coupled resistivity line 213 $\begin{array}{llll}6,737,200 & 6,737,400 & 6,737,600 & 6,737,800\end{array}$

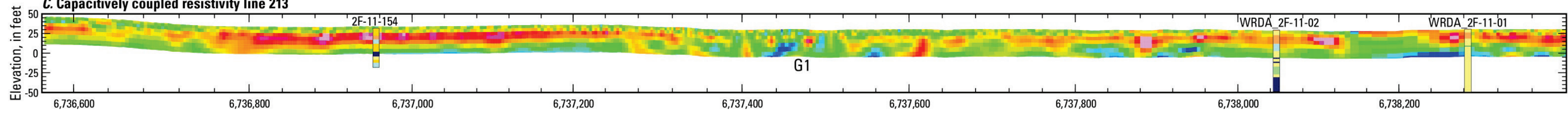
$6,736,600$ $6,736,800$

D. Capacitively coupled resistivity line 213

2F-97-30A

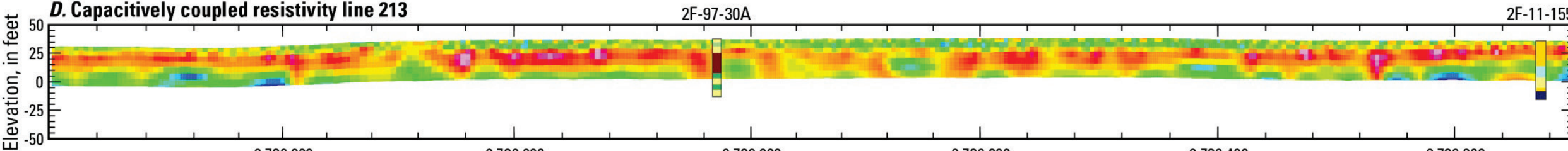

$6,738,800$

$6,739,000$

$6,739,200$

$6,739,400$

$6,739,600$

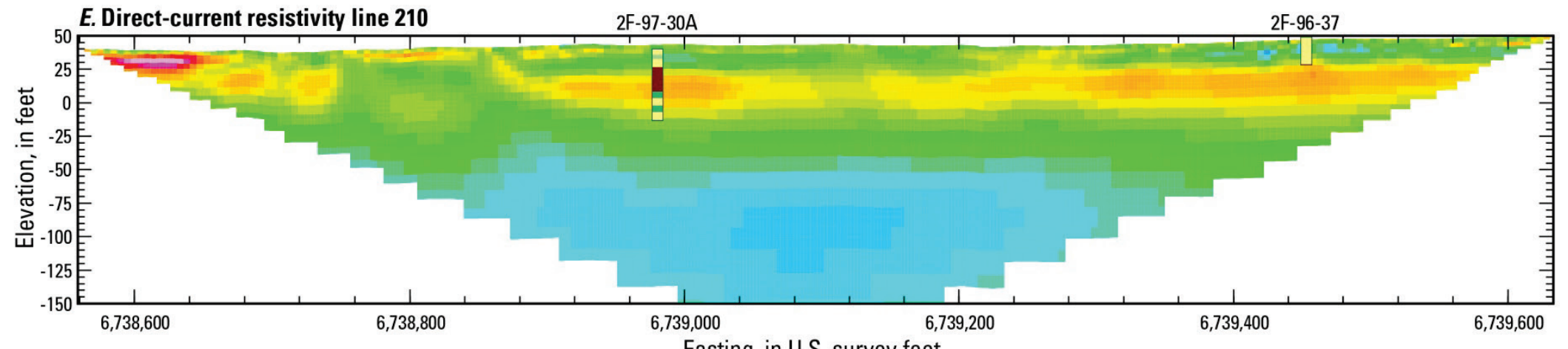


by sand and silt layers. The lower resistivity layer that begins at about -40 - $\mathrm{ft}$ elevation may be either due to higher saturation levels and (or) a transition to finer grained deposits.

\section{Sections $\mathrm{H}$ and $\mathrm{I}-$ Watt Avenue to Mayhew Drain}

Section H (fig. 12) is located between Watt Avenue and the Mayhew Drain that is the eastern boundary of this survey (RM 9.5 to 10.0) and contains one DC resistivity profile (line 211; table 1) and one $\mathrm{CC}$ resistivity profile (lines 213 and 214). The eastern and western sections of CC resistivity lines 213 and 214, respectively, are coincident and provide a comparison and representation of the repeatability of the $\mathrm{CC}$ resistivity measurements. Direct-current resistivity line 211 was acquired along the grassy area to the south of the gravel levee toe road, and the CC resistivity profile was acquired along the gravel path located approximately one-half to one-third of the way between the levee and river.

Direct-current resistivity line 211 has an overall similar resistivity structure to DC resistivity line 210 with a 5-15-ft thick, moderately resistive (80-300 ohm-m) surface layer overlying a 20- to 30-ftthick, laterally varying more resistive (greater than $500 \mathrm{ohm}-\mathrm{m}$ ) layer. The moderate-to-low resistivity layer at depth (below about -10-ft elevation) varies laterally and may be more indicative of lithology variations in finer grained deposits as shown in $\log 2 \mathrm{~F}-11-180$, which has silt at depth, and in $\operatorname{logs} 1 \mathrm{~F}-$ 08-02 and 1F-08-03, which both have clay at depth.

There is a concave upward, highly resistive feature (greater than 5,000 ohm-m) centered at 15-ft elevation between easting 6,740,170 and 6,740,260 ft ( $H 1$ in fig. 12B) with an overlying thin, conductive layer (less than $50 \mathrm{ohm}-\mathrm{m}$ ) whose shape is typically indicative of an inversion artifact created by a near surface feature. In 1997, the waterside toe road was scoured, centered at easting 6,740,280 ft and repaired by rock fill and compacted soil in January 1997 (URS, 2010). This anomaly may be a result of the post-erosion mitigation activity. Because a similar anomaly is not observed on CC resistivity line 213 , located just north of the DC resistivity profile and farther away from the levee embankment, the resistive anomaly seems less likely to be an undisturbed geologic feature. The discontinuity in the resistive layer at easting 6,740,440 ft (H2) observed in both DC resistivity line 211 and CC resistivity line 213 corresponds to the location of an 8-in. diameter abandoned pipe (URS, 2010). The vertical, conductive features between easting 6,740,920 and 6,740,980 ft (H3, line 213) correlate with the location of four drain pipes that range in diameter from 42 to 54 inches (URS, 2010) and are considered inversion artifacts from the presence of these pipes.

The CC resistivity profile along the levee toe in this section exhibits a distinct decrease in overall resistivity to the east of $\log 2 \mathrm{~F}-11-192$. Log 2F-97-03 has a 30-ft-thick silt layer overlying a deeper boulder/cobble layer but with little sand and gravel in the upper 20-25 ft as is the case for the three logs to the west of the open utility corridor. The lateral variation in resistivity to the east of $\log 2 \mathrm{~F}-11-192$, in particular the conductive zone (less than $50 \mathrm{ohm}-\mathrm{m}$ ) between easting 6,741,600 and 6,741,960 ft (H4), is most likely due to the presence of finer grained deposits, such as silts and clays.

Section I (fig. 13) is the easternmost section (RM 10.0 to 10.7) and includes a single CC resistivity line (line 214) acquired along the gravel path along the levee toe. At approximately easting $6,745,450 \mathrm{ft}$, the path diverges from the levee toe toward the river but approaches the toe again as the levee turns south to parallel the Mayhew Drain.

Capacitively coupled resistivity line 214 in section I continues with a more moderate resistivity structure as was shown in the eastern half of section $\mathrm{H}$ but a laterally varying resistive layer (greater than $350 \mathrm{ohm}-\mathrm{m}$ ) appears again around easting 6,742,720 ft and extends to easting 6,744,100 ft (II). Based on $\log 2 \mathrm{~F}-97-36 \mathrm{~A}$, the resistive layer correlates well with a boulder/cobble layer that is bounded by silt deposits. The resistivity structure becomes more moderate with less obvious layering throughout 


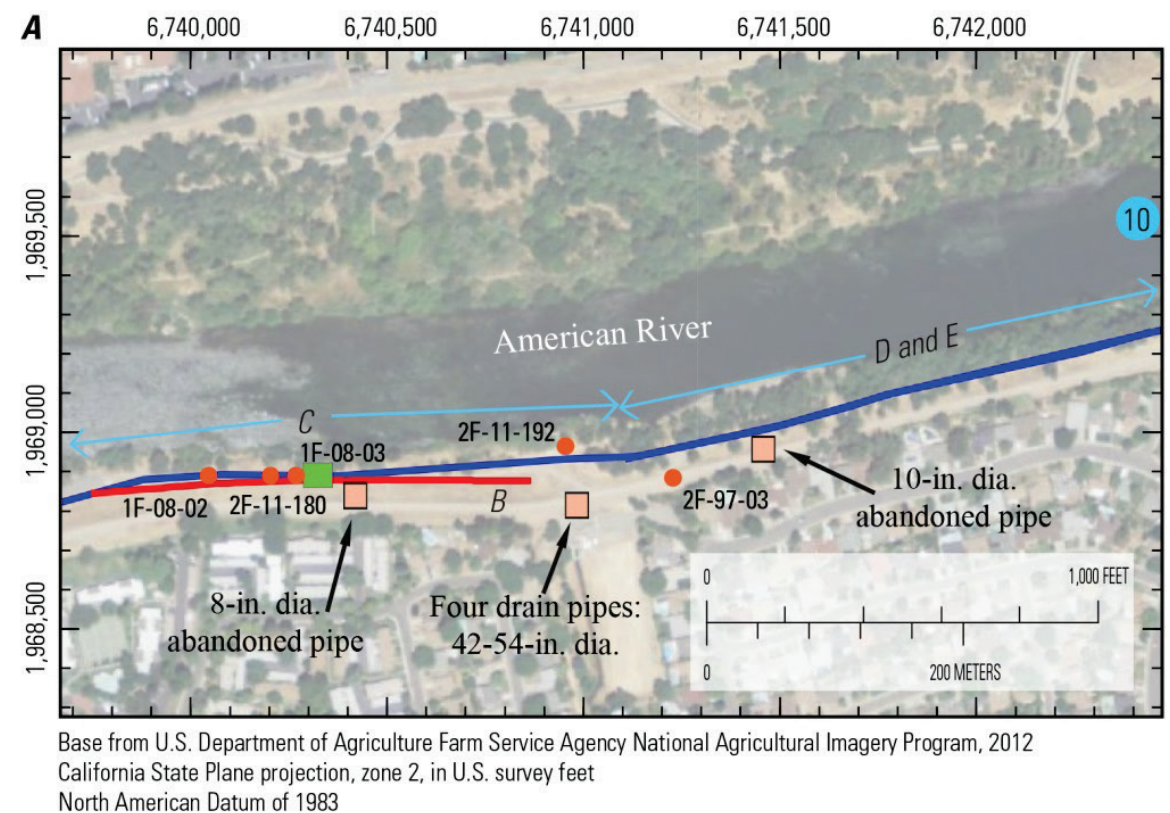

EXPLANATION

\begin{tabular}{|c|c|}
\hline & $\begin{array}{l}\text { Capacitively coupled resistivity line } \\
\text { (current section) } \\
\text { Capacitively coupled resistivity line }\end{array}$ \\
\hline & $\begin{array}{l}\text { Direct-current resistivity line } \\
\text { (current section) }\end{array}$ \\
\hline & $\begin{array}{l}\text { Direct-current resistivity line } \\
\text { (other section) }\end{array}$ \\
\hline $2 F-96-38$ & Lithology log and label \\
\hline$\square$ & Known utility locations through levee \\
\hline$\square$ & Erosion event (1986) \\
\hline$\square$ & Erosion event (1997) \\
\hline ש & Revetment section \\
\hline 10 & River mile \\
\hline
\end{tabular}

Figure 12. Section $\mathrm{H}(A)$ map showing the location of the resistivity profiles and relevant lithologic logs and $(B)$ inverted direct-current resistivity and $(C, D, E)$ capacitively coupled resistivity profiles with the lithologic logs overlaid. The extents of each of the resistivity sections are indicated by the light blue arrows on $A$. The lithology log explanation is in figure 3. Utility and erosion event locations are from URS (2010).

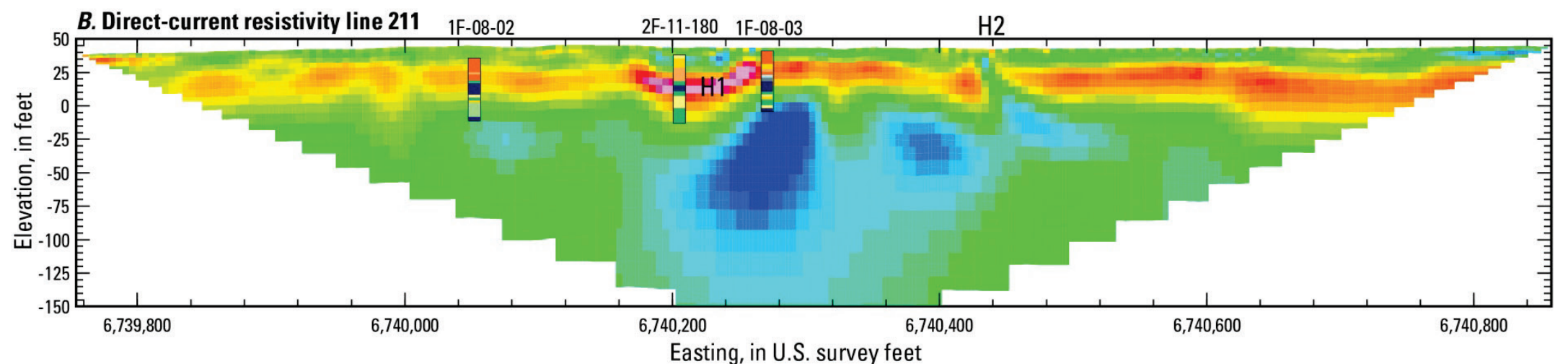

C. Capacitively coupled resistivity line 213 1F-08-02

2F-11-180

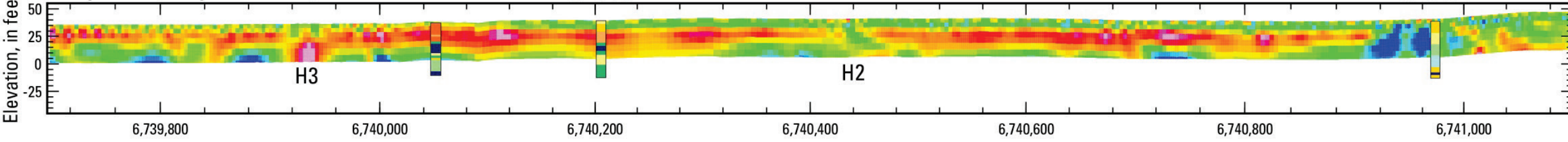

$6,739,800$ $6,740,000$ $6,740,200$

D. Capacitively coupled resistivity line 213
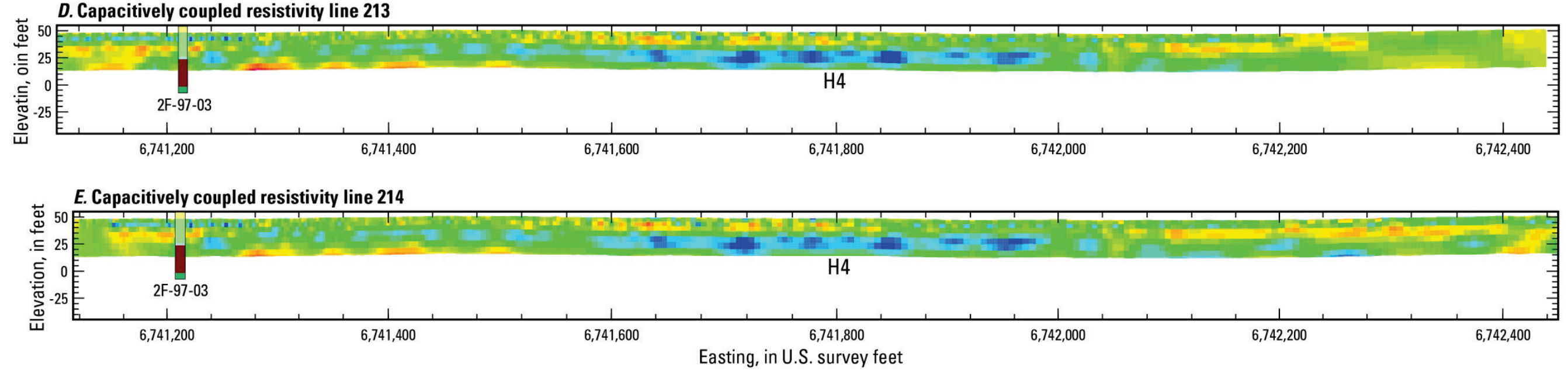


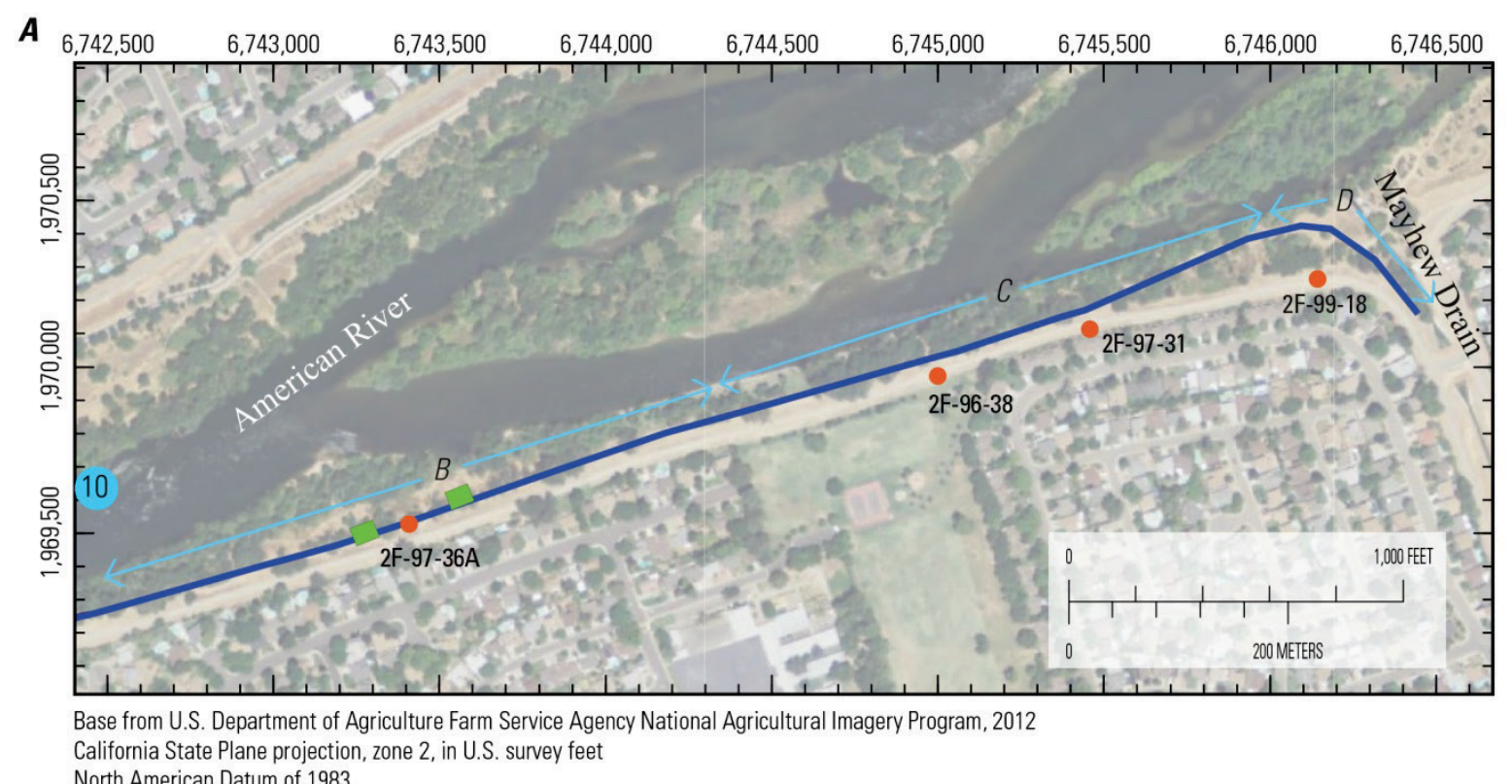

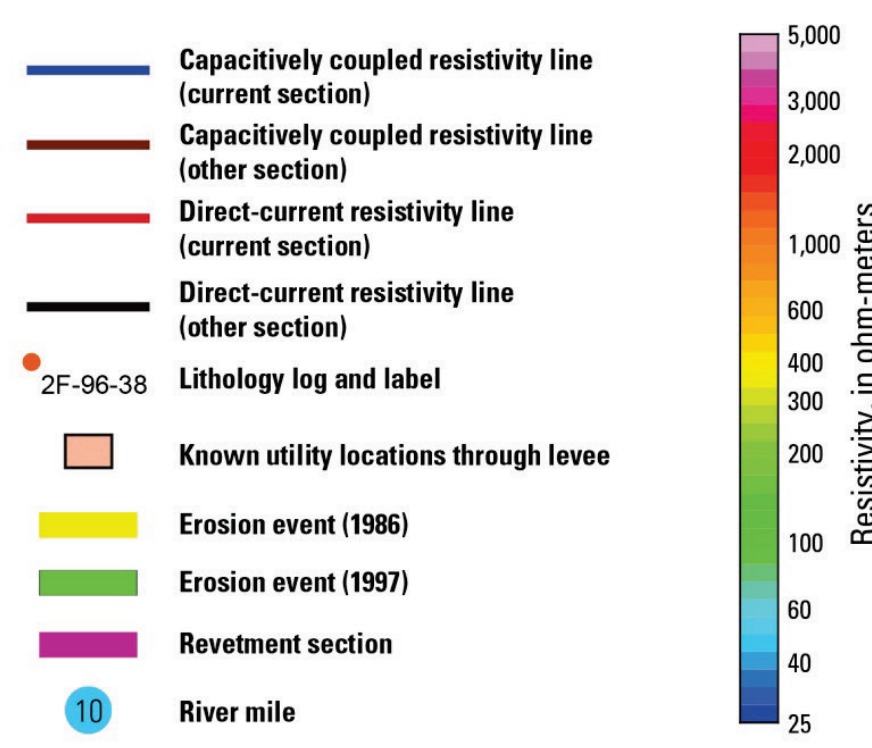

Figure 13. Section I $(A)$ map showing the location of the resistivity profiles and relevant lithologic logs and $(B, C, D)$

inverted capacitively coupled resistivity profiles with the lithologic

logs overlaid. The extents of each of the resistivity sections are

indicated by the light blue arrows on $A$. The lithology log

explanation is in figure 3. Erosion event locations are from URS

(2010). Califorina State Plane projoection, zone 2, in U.S. survey feet
Noth

(10) River milo

2F-97-36A
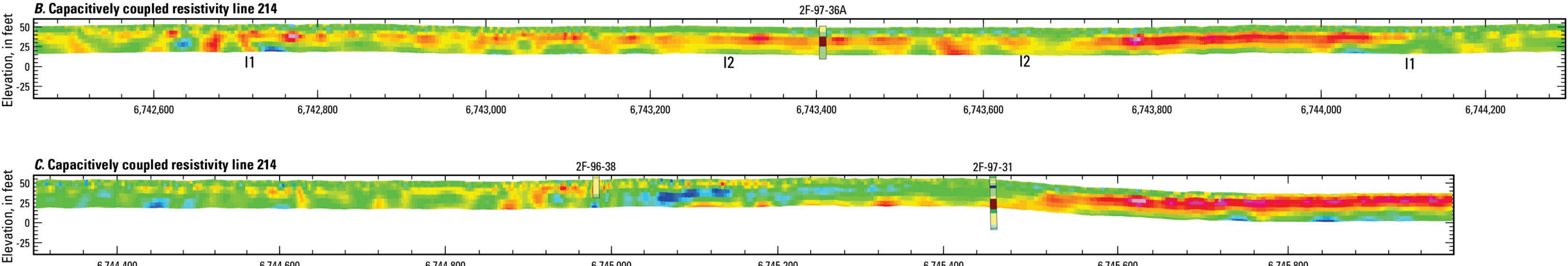

D. Capacitively coupled resistivity line 214

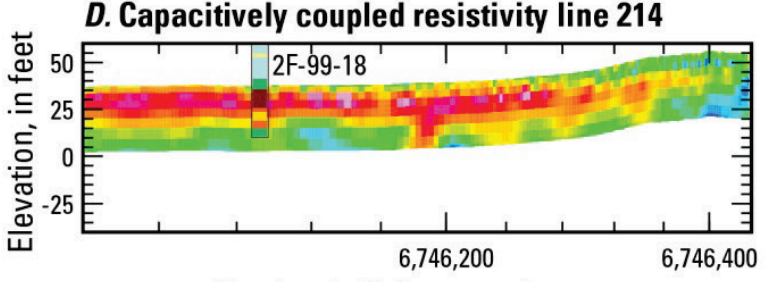

Easting, in U.S. survey feet 
the section until about $\log 2 \mathrm{~F}-99-18$, where a 15-ft-thick, high-resistivity layer approaches the surface toward the end of the profile. Log 2F-96-38 shows a 20-ft-thick sand layer underlain by silt deposits, which could indicate the dominant lithologies in the moderately resistive section, possibly with additional discrete, thin clay layers as shown in $\log 2 \mathrm{~F}-97-31$. The boulder/cobble layers in $\operatorname{logs} 2 \mathrm{~F}-$ 97-31 and 2F-99-18 (additional sand and gravel layers also in this log) correlate well in depth to the location of the high resistivity layer, although it should be noted that $\log 2 \mathrm{~F}-99-8$ is approximately 150 $\mathrm{ft}$ away from the $\mathrm{CC}$ resistivity profile. Two small zones are centered at easting 6,743,290 and 6,743,650 $\mathrm{ft}$ (I2) where the waterside lower road was scoured in 1997 and repaired in January1997 by rock fill and compacted soil (URS, 2010), but there are no obvious anomalies in the CC resistivity data that correlate with these locations.

\section{Summary and Discussion}

The study area encompasses a narrow reach of the lower American River in east Sacramento that is underlain by alluvial and flood deposits from clay to gravel that vary considerably in extent and depth. Sand deposits related to historical hydraulic mining activities, in particular, have been observed to preferentially scour during high-water events (Asch and others, 2008). The U.S. Geological Survey (USGS), in cooperation with the U.S. Army Corps of Engineers (USACE), completed ground-based electrical resistivity surveys along the left (south and west) and right (north and east) banks of the river between RM 5 and 10.7 to cover areas that had not been surveyed during previous USGS studies. Capacitively coupled resistivity was used as a reconnaissance tool to efficiently survey accessible areas on the water side of the levees, and DC resistivity lines were placed in accessible areas to acquire higher resolution and deeper data. Many borings provided by the USACE aided in interpreting the resistivity structure in all profiles.

Overall, there is a strong correlation between lithology and resistivity with coarser grained deposits exhibiting higher resistivity values than finer grained deposits. The discrete nature of these alluvial and flood deposits, however, makes it difficult to extend interpretations far beyond the locations of the borings. The deposits are generally laterally and vertically discontinuous with very thin layers (less than $5 \mathrm{ft}$ ) observed in the lithologic logs that can not be resolved with either of the surface resistivity methods. There is not a simple correlation between a particular resitivity value range and the identification of scour-prone deposits, but the resistivity data can be useful in helping to locate additional borings in areas exhibiting higher resistivity values. The combination of the high-resolution lithologic logs with the greater coverage that the surface resistivity methods provide is a useful tool in mapping lithologic contacts and gaining a more regional geologic picure of the study area.

\section{Acknowledgments}

This work was completed in cooperation with the U.S. Army Corps of Engineers (USACE) Sacramento District for intergovernmental order W62N6M11815397. We thank Lewis Hunter, USACE, for providing background reports and literature for the study site, field support during data acquisition, and review of this report. We also thank Chad Ailes and Michael Wussow, U.S. Geological Survey (USGS), for providing field support during data acquisition and Jeff Lucius, USGS, for his help as reviewer of this report. 


\section{References Cited}

Advanced Geosciences, Inc., 2008, Instruction manual for EarthImager 2D version 2.3.0—Resistivity and IP inversion software: Austin, Tex., Advanced Geosciences, Inc., 139 p.

Asch, T.H., Deszcz-Pan, M., Burton, B.L., and Ball, L.B., 2008, Geophysical characterization of American River levees, Sacramento, California, using electromagnetics, capacitively coupled resistivity, and DC resistivity: U.S. Geological Survey Open-File Report 2008-1109, 12 p. [Available online at http://pubs.usgs.gov/of/2008/1109/.]

Ball, L.B., Kress, W.H., Steele, G.V., Cannia, J.C., and Andersen, M.J., 2006, Determination of canal leakage potential using continuous resistivity profiling techniques, Interstate and Tri-State Canals, western Nebraska and eastern Wyoming, 2004: U.S. Geological Survey Scientific Investigations Report 2006-5032, 53 p. [Available online at http://pubs.usgs.gov/sir/2006/5032/.]

Ball, L.B. and Teeple, A.P., 2013, Characterization of major lithologic units underlying the lower American River using water-borne continuous resistivity profiling, Sacramento, California, June 2008: U.S. Geological Survey Open-File Report 2013-1050, 17 p, 5 plates. [Available online at http://pubs.usgs.gov/of/2013/1050/.]

Ball, L.B., Burton, B.L., Powers, M.H., and Asch, T.H., 2014, Digital geospatial presentation of geoelectrical and geotechnical data for the lower American River and floodplain, east Sacramento, California: U.S. Geological Survey Data Series 902, 16 p.

Butler, D.K., ed., 2005, Near-surface geophysics-Investigations in geophysics 13: Tulsa, Okla., Society of Exploration Geophysicists, 732 p.

Geometrics, 2001, OhmMapper TR1 operation manual rev. F: San Jose, Calif., Geometrics, Inc., 147 p., accessed January 2014 at ftp://geom.geometrics.com/pub/GeoElectric/Manuals/OhmMapper-ManualTRN-2004.PDF.

Geometrics, 2009, Magmap 20004.0 user guide rev. H: San Jose, Calif., Geometrics, Inc., 235 p., accessed January 2014 at http://www.geometrics.com/geometrics-products/geometricsmagnetometers/download-magnetometer-software/.

Geotomo, 2014, RES2DINVx32 ver. 3.71-Rapid 2-D resistivity and IP inversion using the least-squares method, February 2014: Penang, Malaysia, Geotomo Software, 124 p., accessed March 2014 at http://www.geotomosoft.com/downloads.php.

Loke, M.H., 2014, Tutorial: 2-D and 3-D electrical imaging surveys: Penang, Malaysia, Geotomo Software, 173 p., accessed March 2014 at http://www.geotomosoft.com/downloads.php.

Lucius, J.E., Abraham, J.D., and Burton, B.L., 2008, Resistivity profiling for mapping gravel layers that may control contaminant migration at the Amargosa Desert Research Site, Nevada: U.S. Geological Survey Scientific Investigations Report 2008-5091, 30 p., available online at http://pubs.usgs.gov/sir/2008/5091/. 
Pearce, J. and Kelson, K., 2008, Surficial geologic map and geomorphic assessment, American River study area, Sacramento County, California, Technical Memorandum, Appendix O, in URS, Supplemental geotechnical data draft report, American River study area: Prepared for California Department of Water Resources, February 2010, Urban Levee Geotechnical Evaulations Program Contract 4600007418, p. 355-379.

Reynolds, J.M., 1997, An introduction to applied and environmental geophysics: Chichester, England, Wiley, $796 \mathrm{p}$.

Sharma, P.V., 1997, Environmental and engineering geophysics: Cambridge, United Kingdom, Cambridge University Press, 475 p.

Timofeev, V.M., Rogozinski, A.W., Hunter, J.A., and Douma, M., 1994, A new ground resistivity method for engineering and environmental geophysics, in Symposium on the Application of Geophysics to Engineering and Environmental Problems, Boston, Mass., 1994, Proceedings: Denver, Colo., Environmental Engineering Geophysical Society, p. 701-715.

URS, 2010, Supplemental geotechnical data draft report, American River study area: Prepared for California Department of Water Resources, February 2010, Urban Levee Geotechnical Evaulations Program Contract 4600007418, $409 \mathrm{p}$.

U.S. Geological Survey, 2014, National Water Information System: Web Interface: USGS 11446500 American R A Fair Oaks CA web page, accessed January 12, 2014, at http://waterdata.usgs.gov/usa/nwis/uv?site_no $=11446500$. 


\section{Appendix 1. Direct-Current Resistivity Pseudosections}

Direct-current resistivity measured data apparent resistivity pseudosection (top image), calculated forward model apparent resistivity pseudosection (middle image), and preliminary inverted resistivity section (bottom image) are presented for each line. For each figure, the vertical axis on the top two pseudosections is estimated depth, in feet, of the measured data points and on the inverted section is a more accurate NAVD88 elevation, in feet. The horizontal axis for all three images is the downline distance, in feet. The black dots on the top two pseudosections are individual data points, and gaps in the data coverage indicate areas where noisy data points were removed using the percentage data misfit threshold removal tool to improve the inverted model fit. All inverted sections are displayed with the same color scale: 1 to $2,000 \mathrm{ohm}-\mathrm{m}$. 

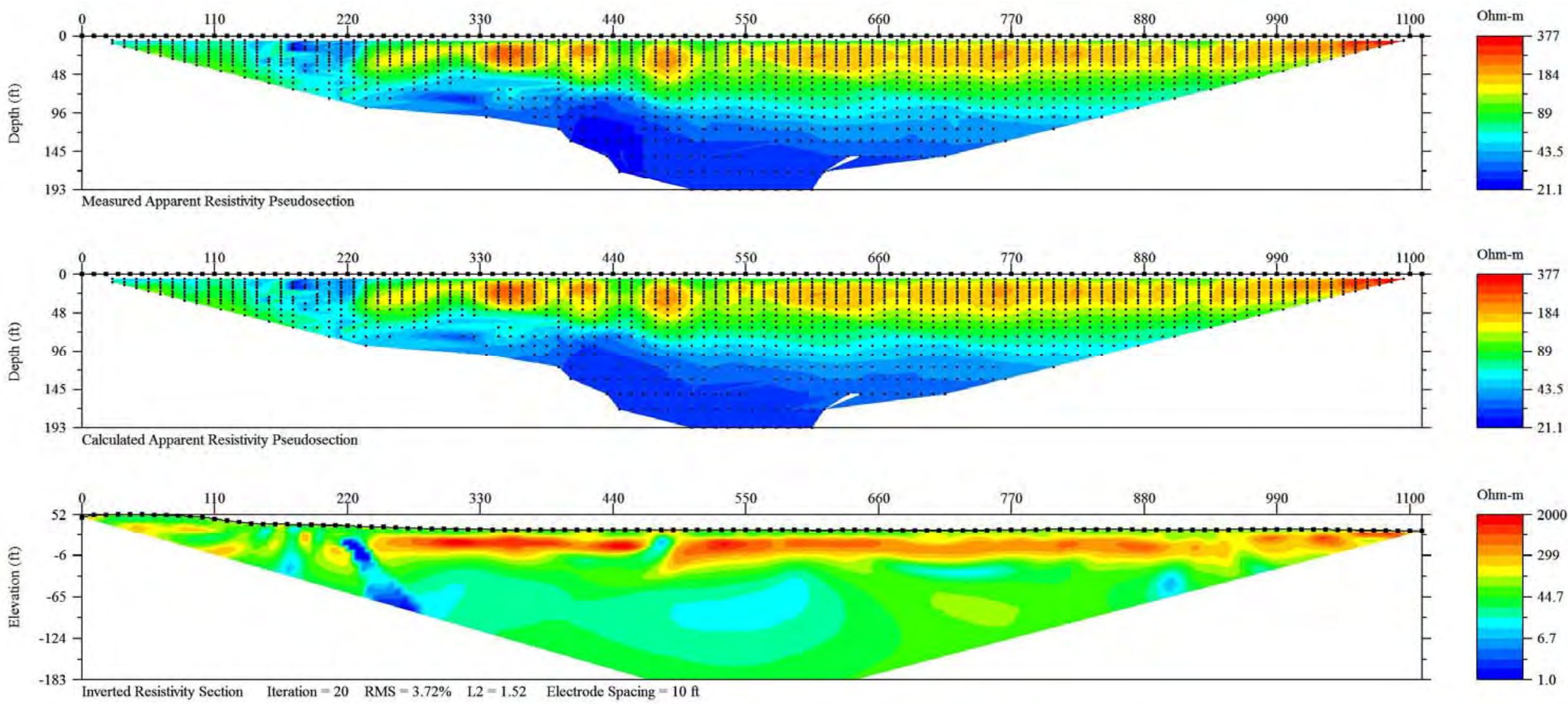

Figure 1-1. Direct-current resistivity line 201. 

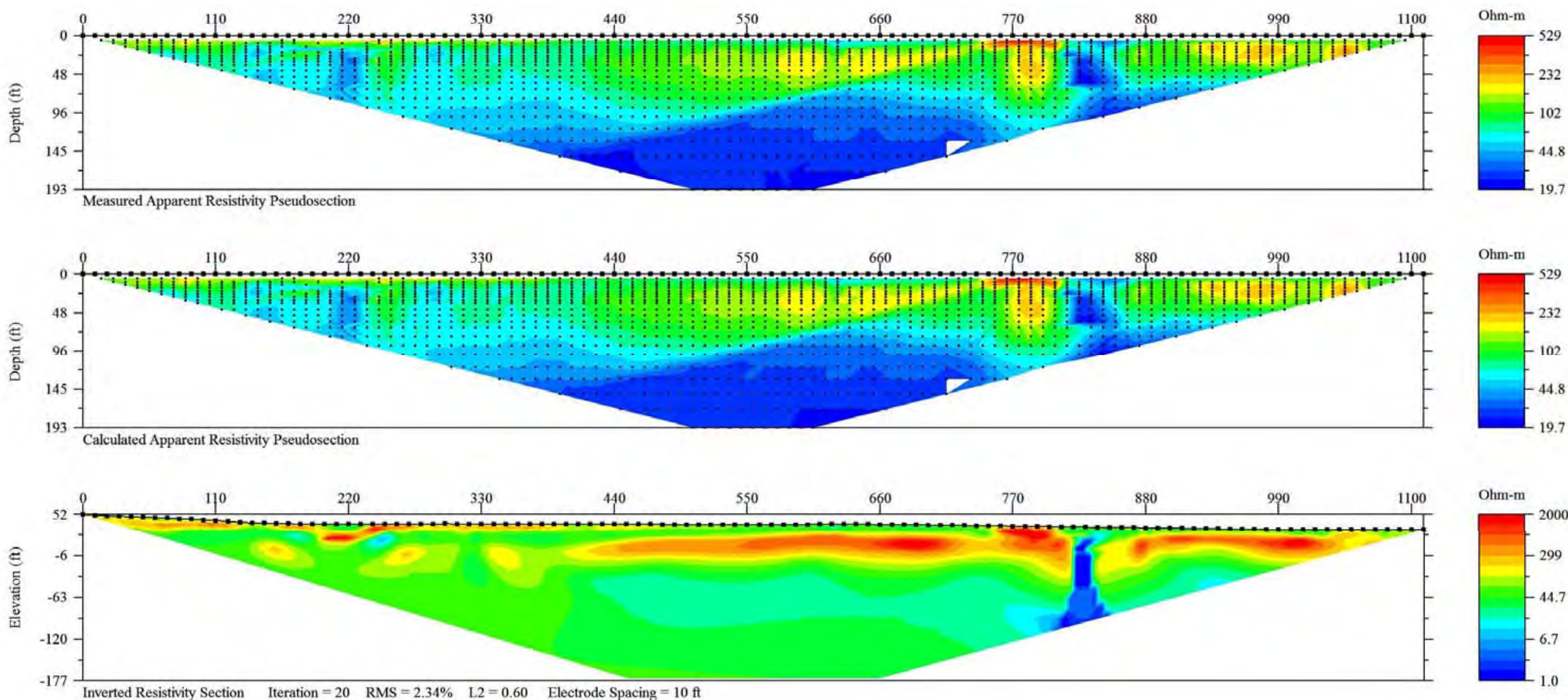

Figure 1-2. Direct-current resistivity line 202. 

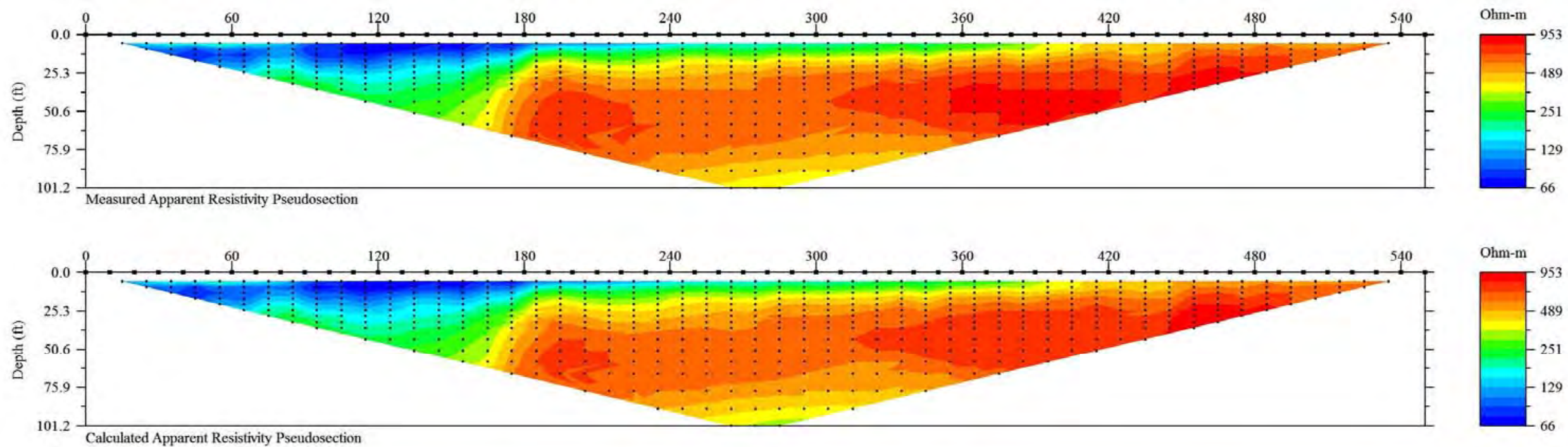

Ohm-m
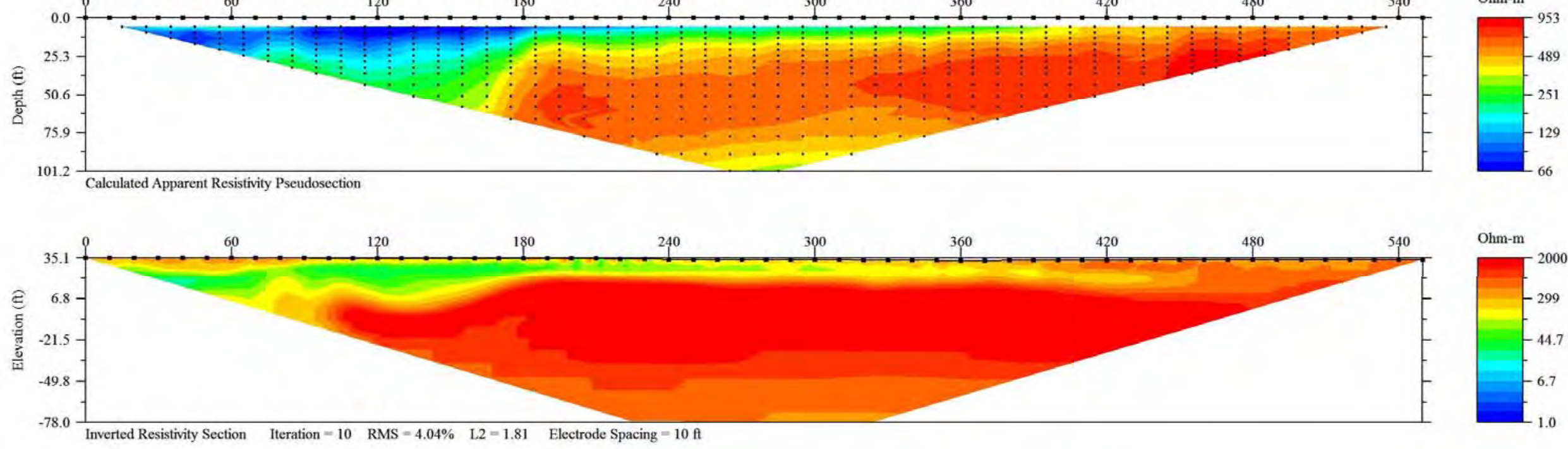

Figure 1-3. Direct-current resistivity line 203. 

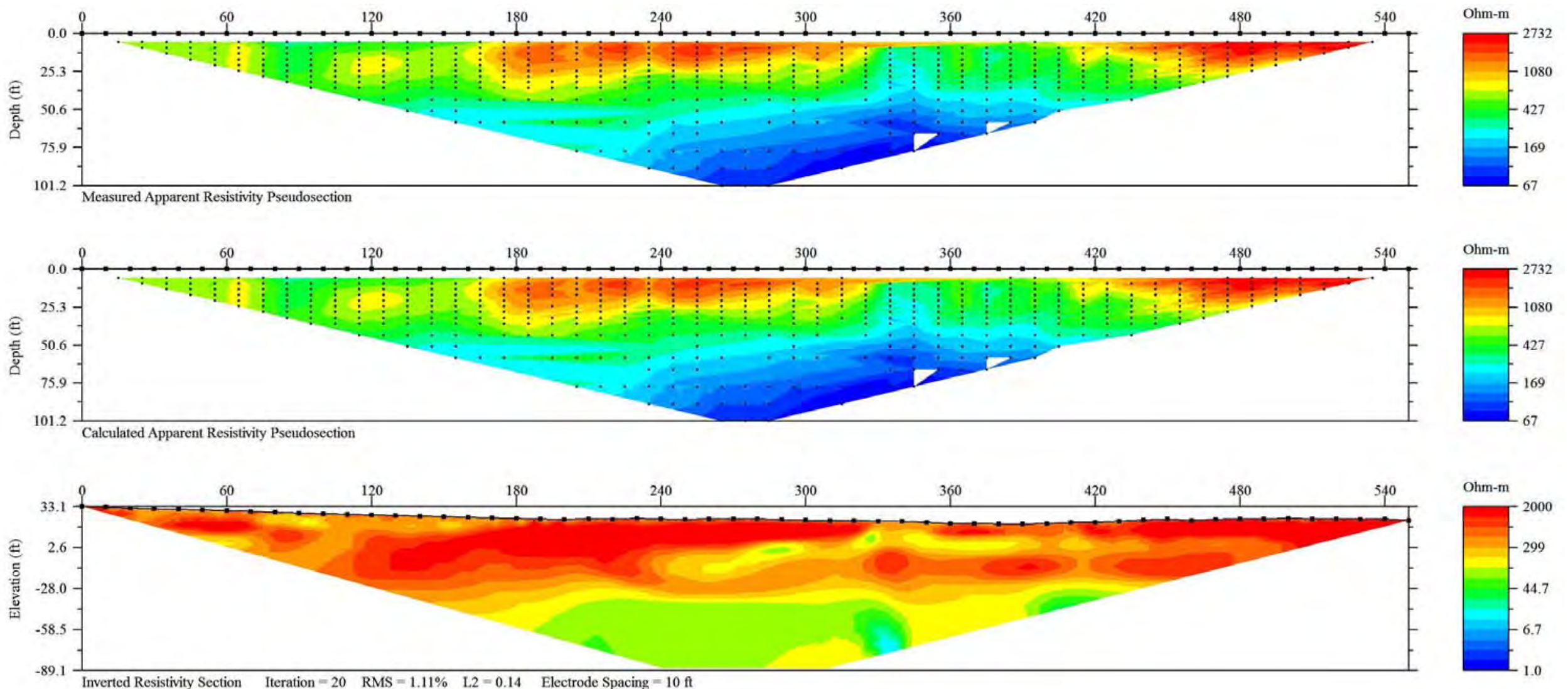

Figure 1-4. Direct-current resistivity line 204. 

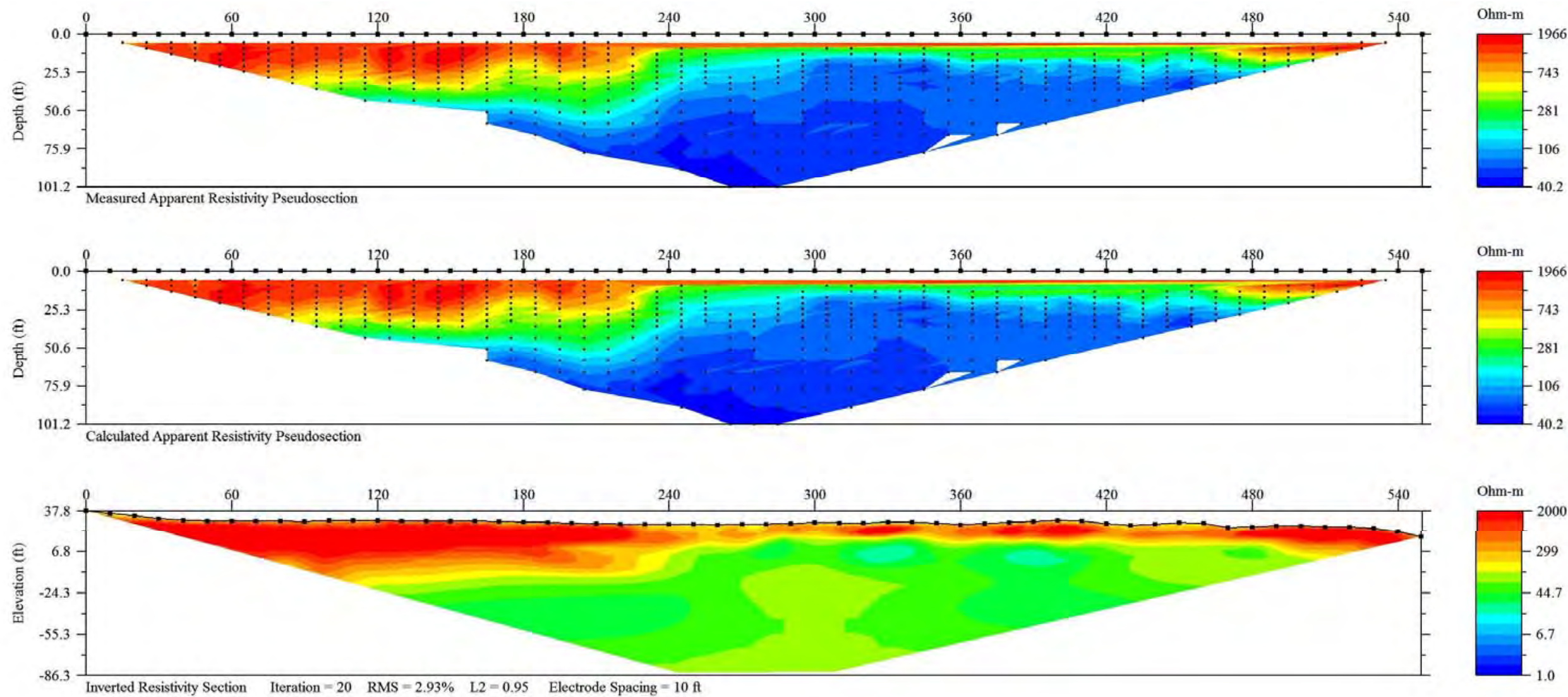

Figure 1-5. Direct-current resistivity line 205. 

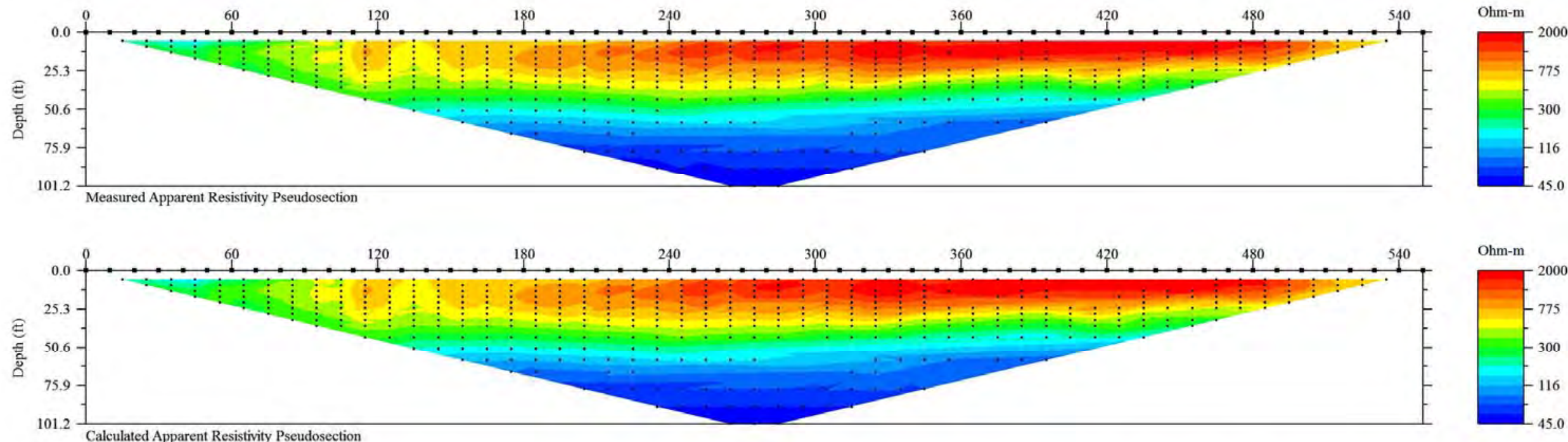

Ohm-m
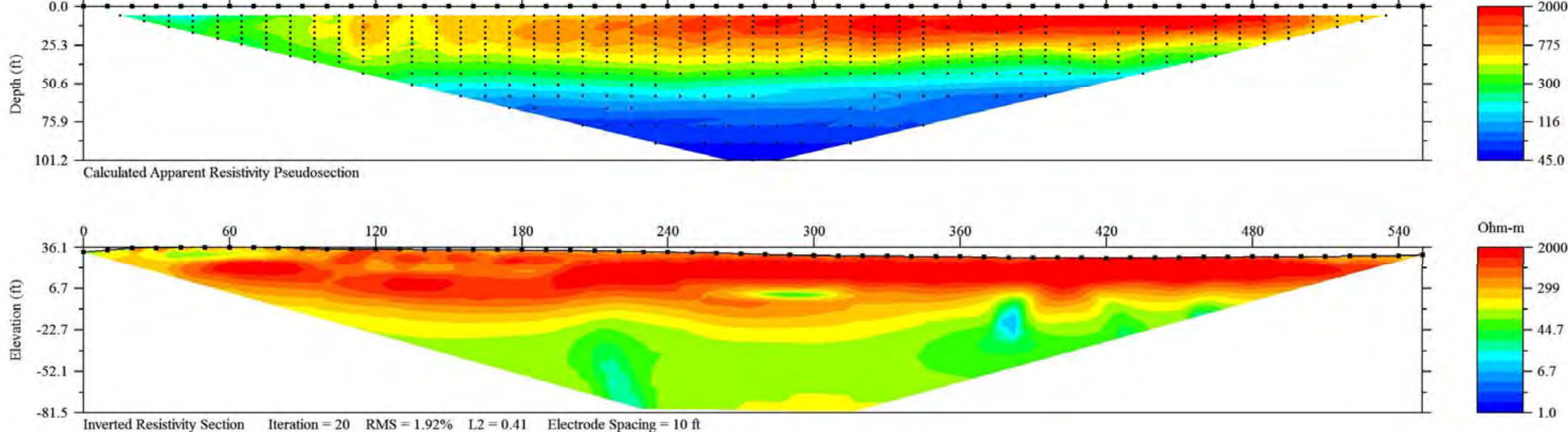

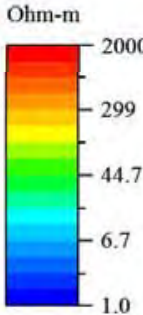

Figure 1-6. Direct-current resistivity line 206. 

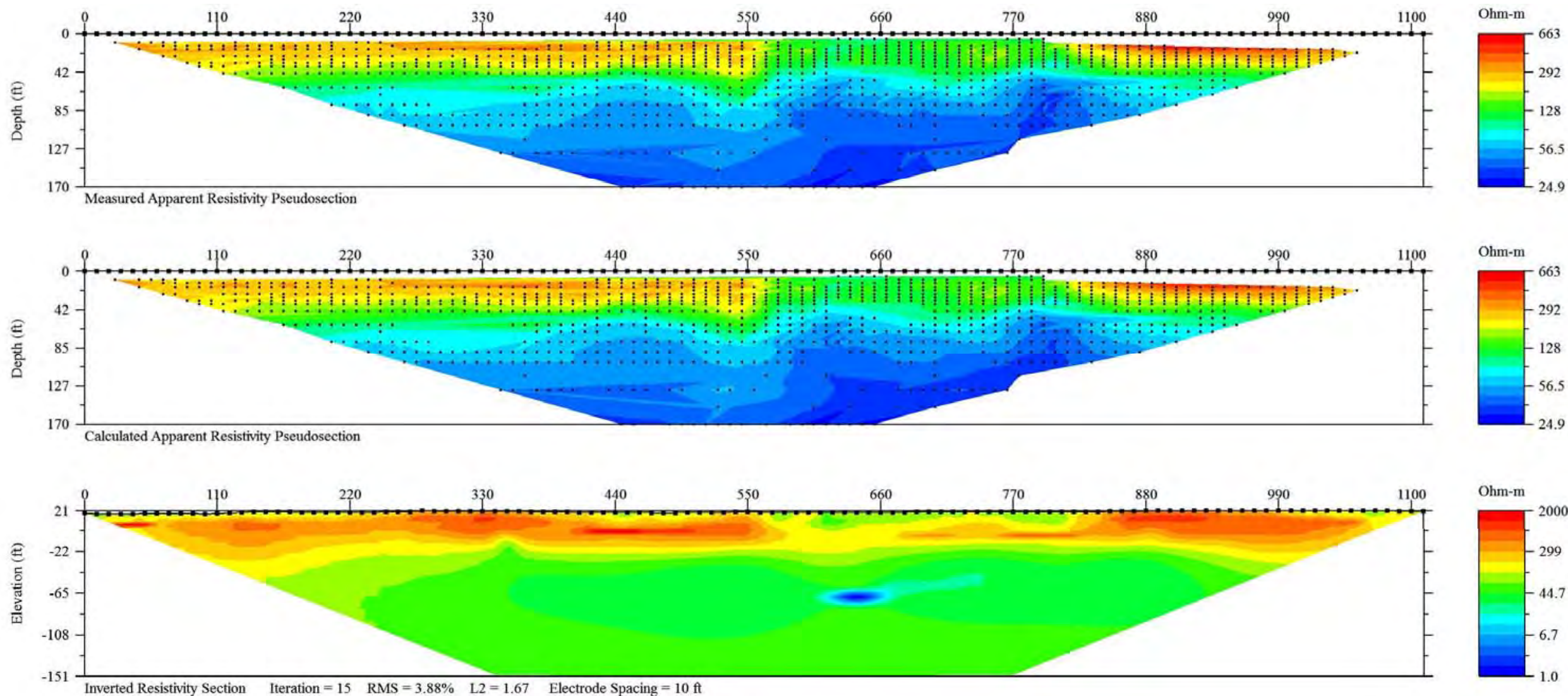

Figure 1-7. Direct-current resistivity line 207. 

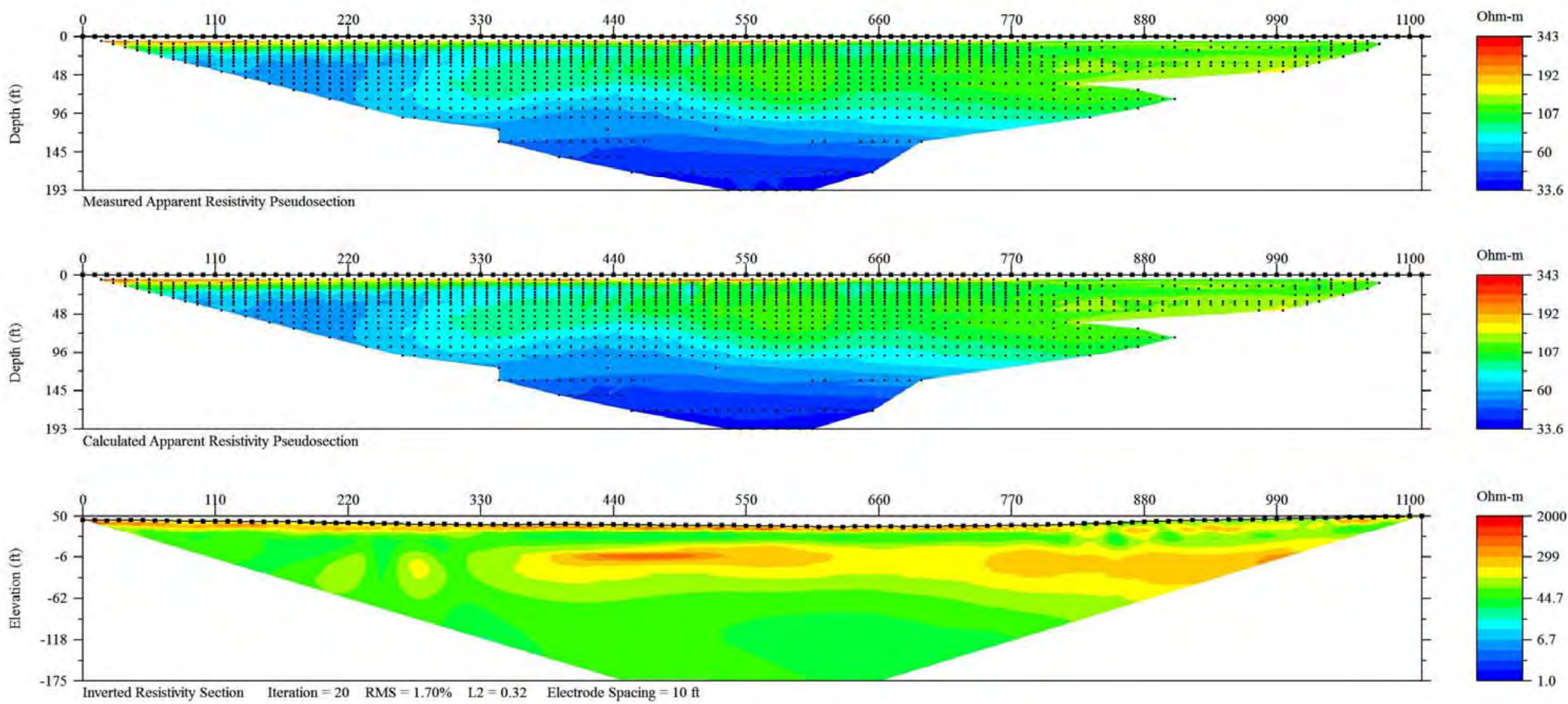

Figure 1-8. Direct-current resistivity line 208. 

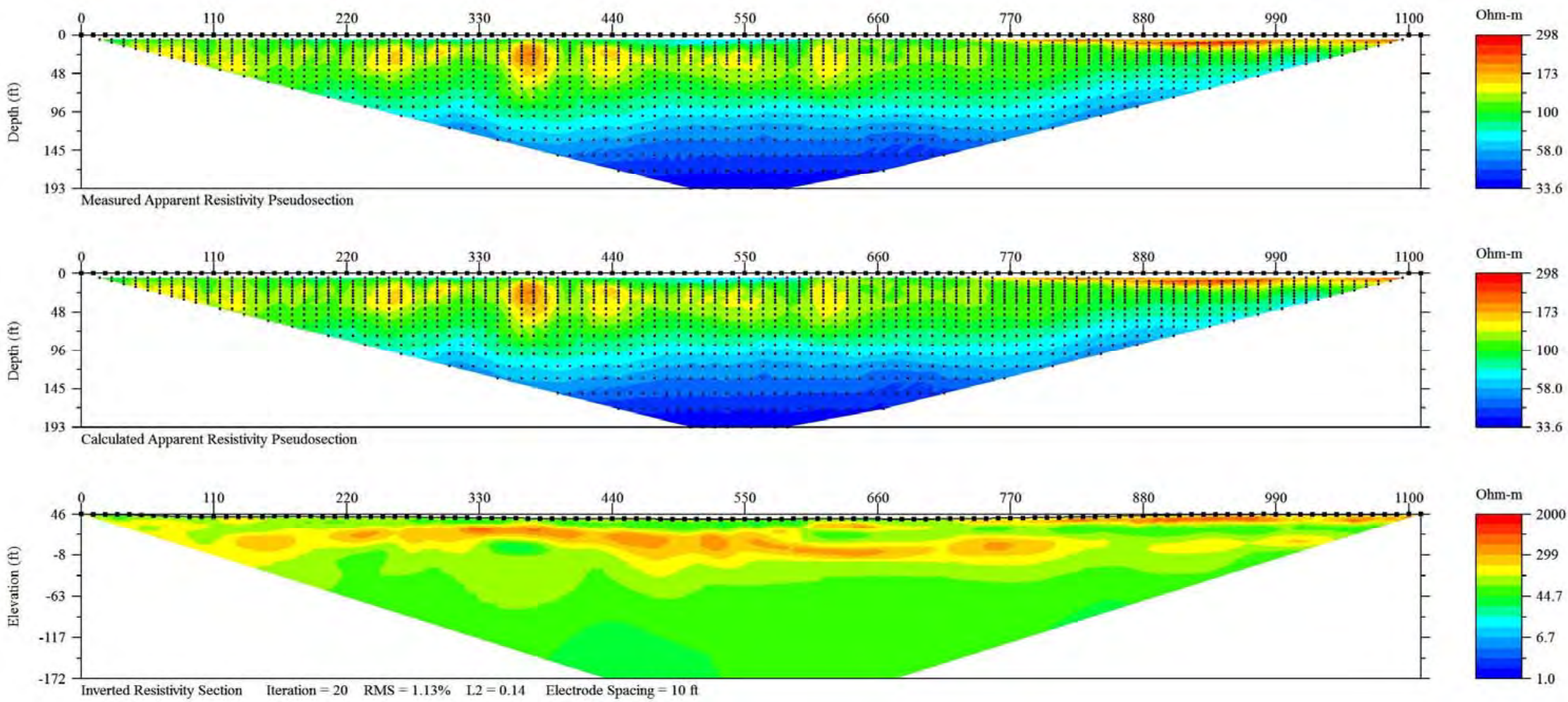

Figure 1-9. Direct-current resistivity line 209. 

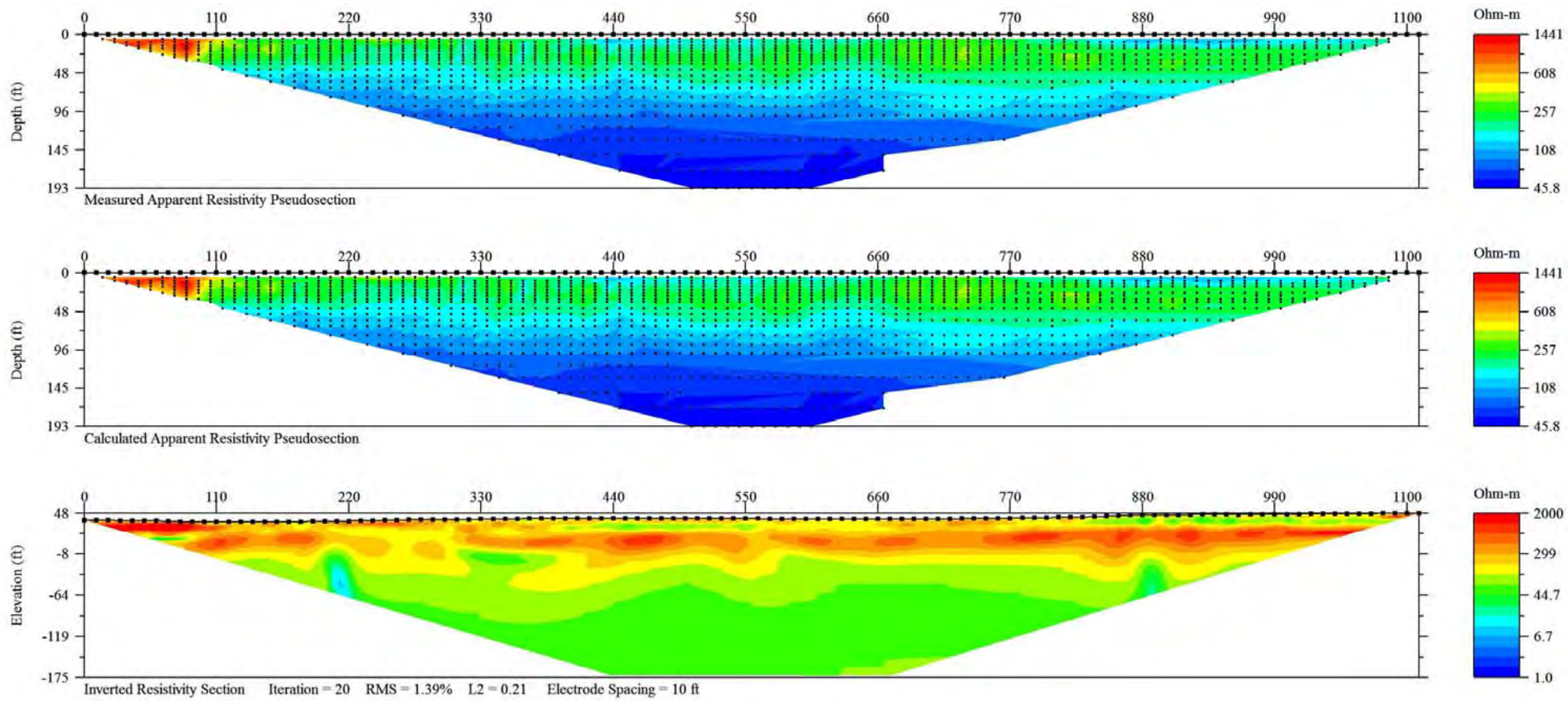

Figure 1-10. Direct-current resistivity line 210. 

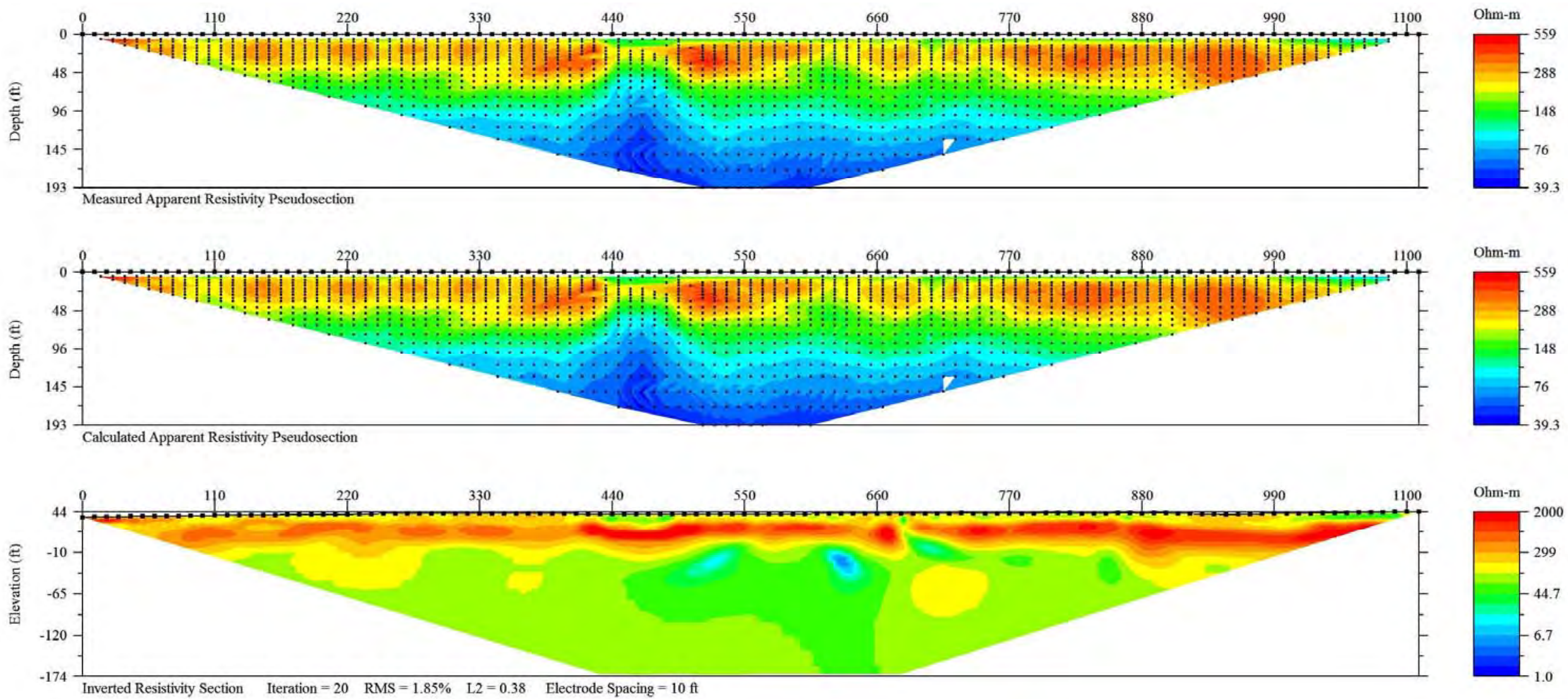

Figure 1-11. Direct-current resistivity line 211. 

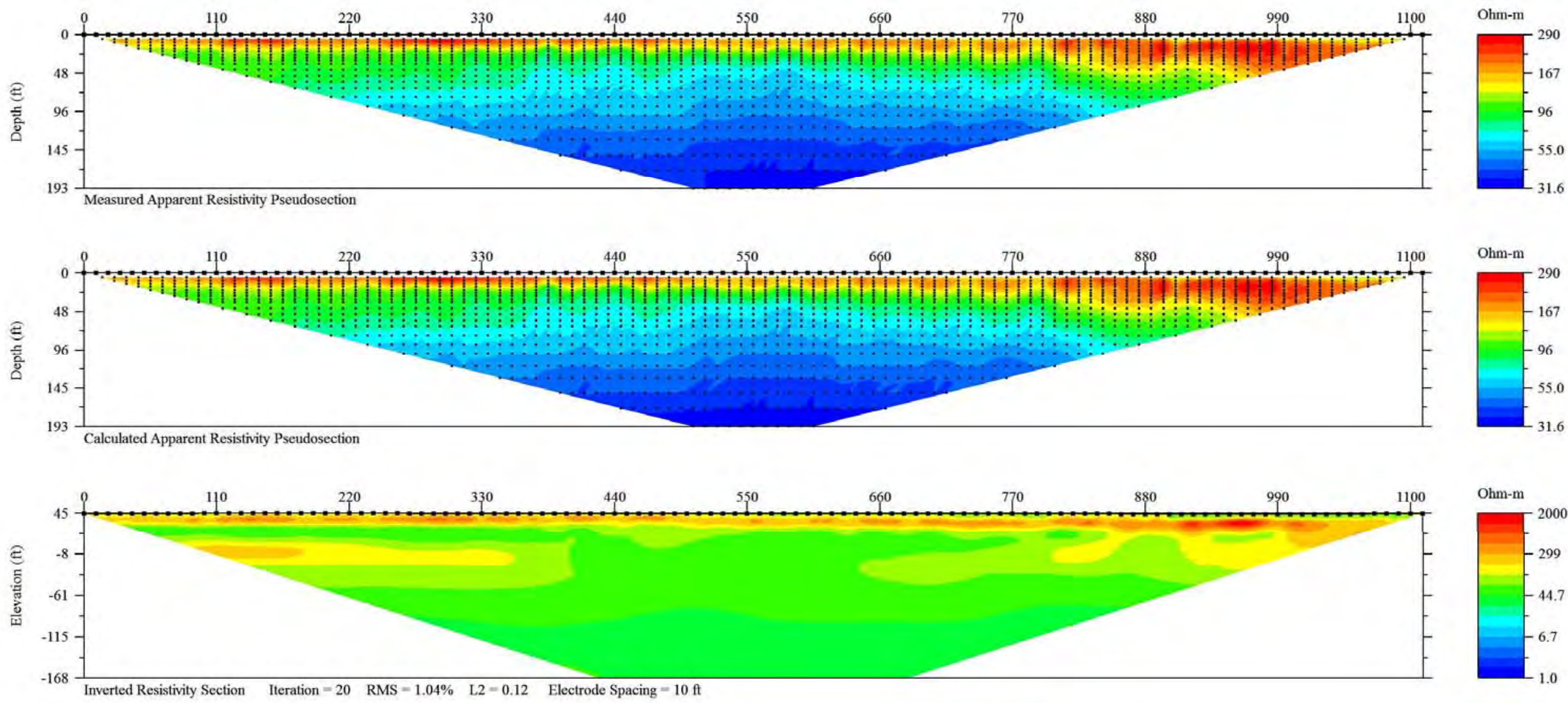

Figure 1-12. Direct-current resistivity line 212. 

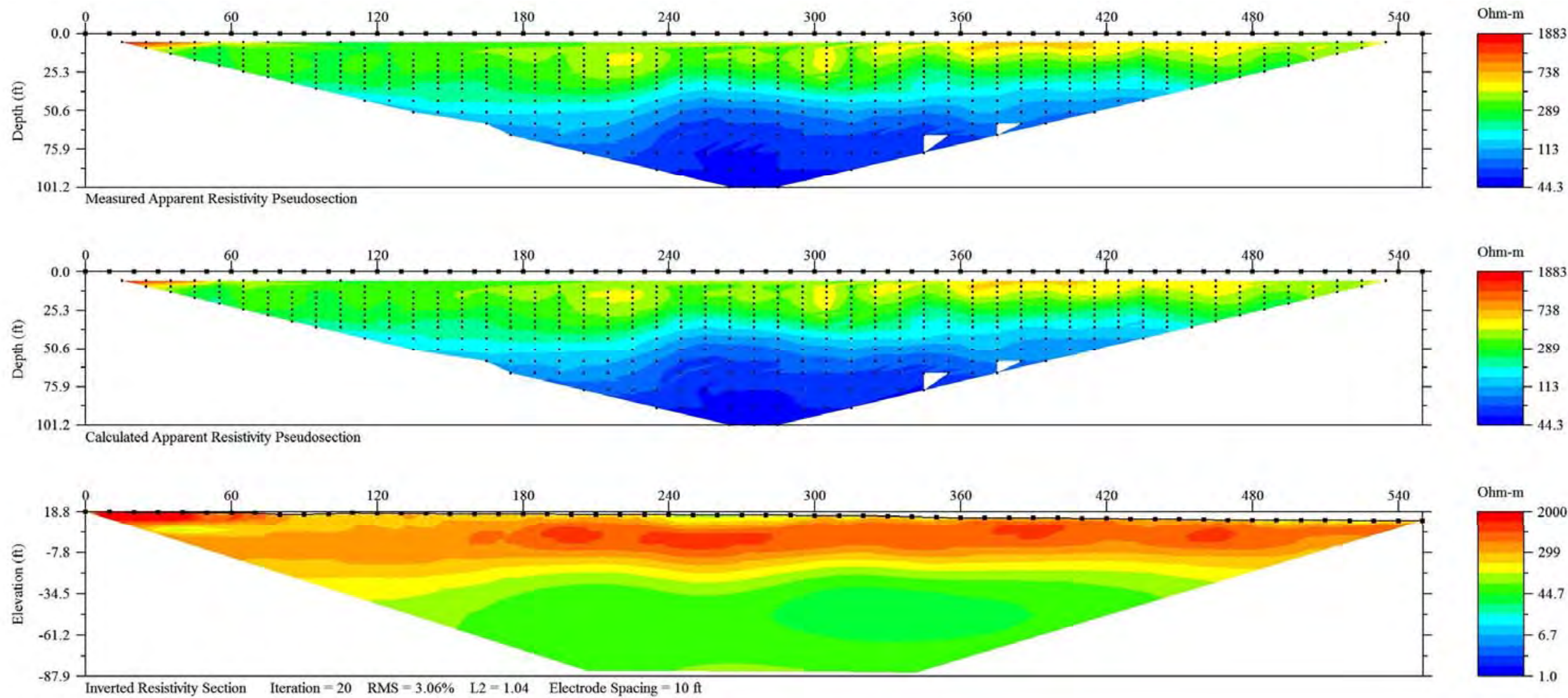

Figure 1-13. Direct-current resistivity line 213. 


\section{Appendix 2. Capacitively Coupled Resistivity Pseudosections}

Capacitively coupled resistivity measured data apparent resistivity pseudosection (top image), calculated forward model apparent resistivity pseudosection (middle image), and preliminary inverted resistivity section (bottom image) are presented for each line. For each figure, the vertical axis on the top two pseudosections is estimated depth, in feet, of the measured data points and on the inverted section is a more accurate NAVD88 elevation, in feet. The horizontal axis for all three images is the downline distance, in feet. The black dots on the top two pseudosections are individual data points, and gaps in the data coverage indicate areas where noisy data points were removed using the percentage data misfit threshold removal tool to improve the inverted model fit. All inverted sections are displayed with the same color scale: 1 to 2,000 ohm-m. 

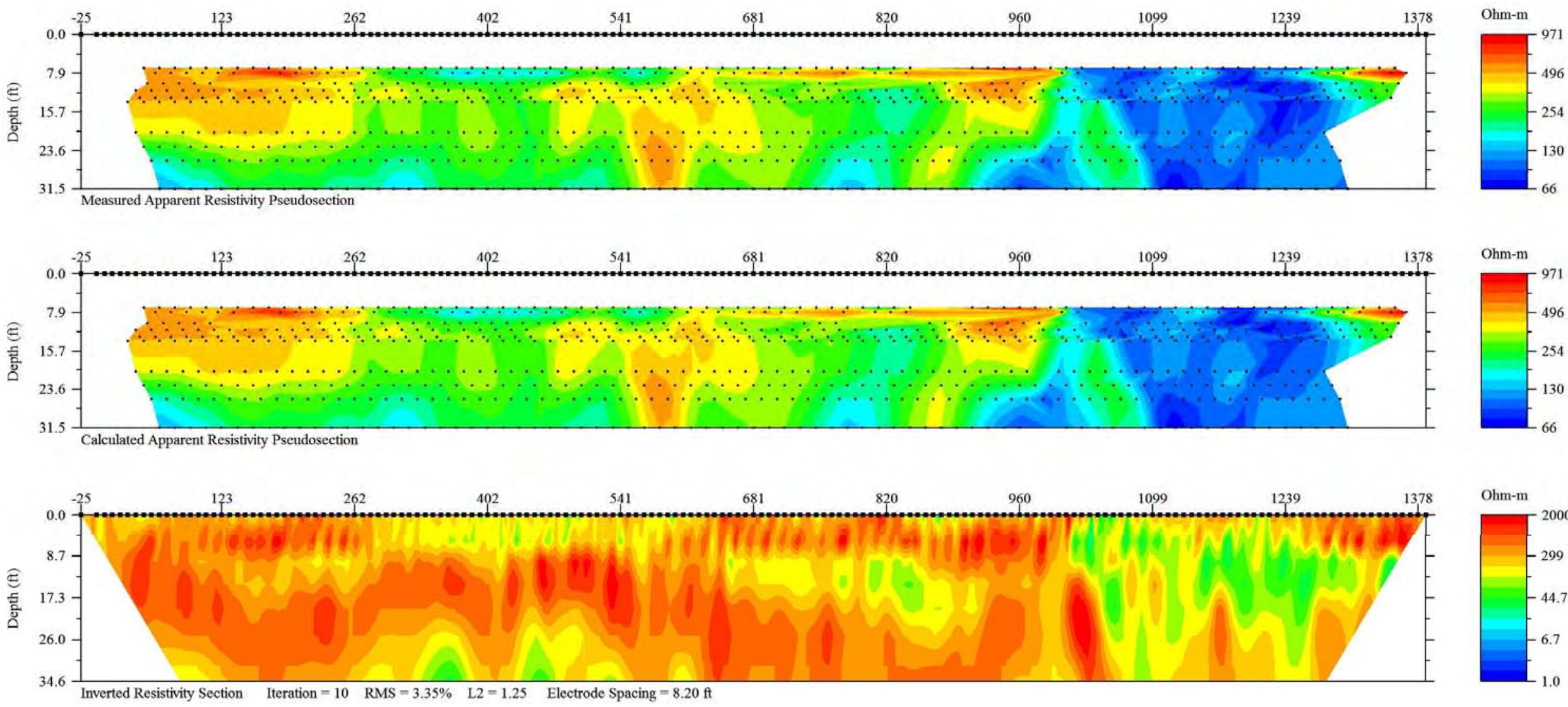

Figure 2-1. Capacitively coupled resistivity line 201. 

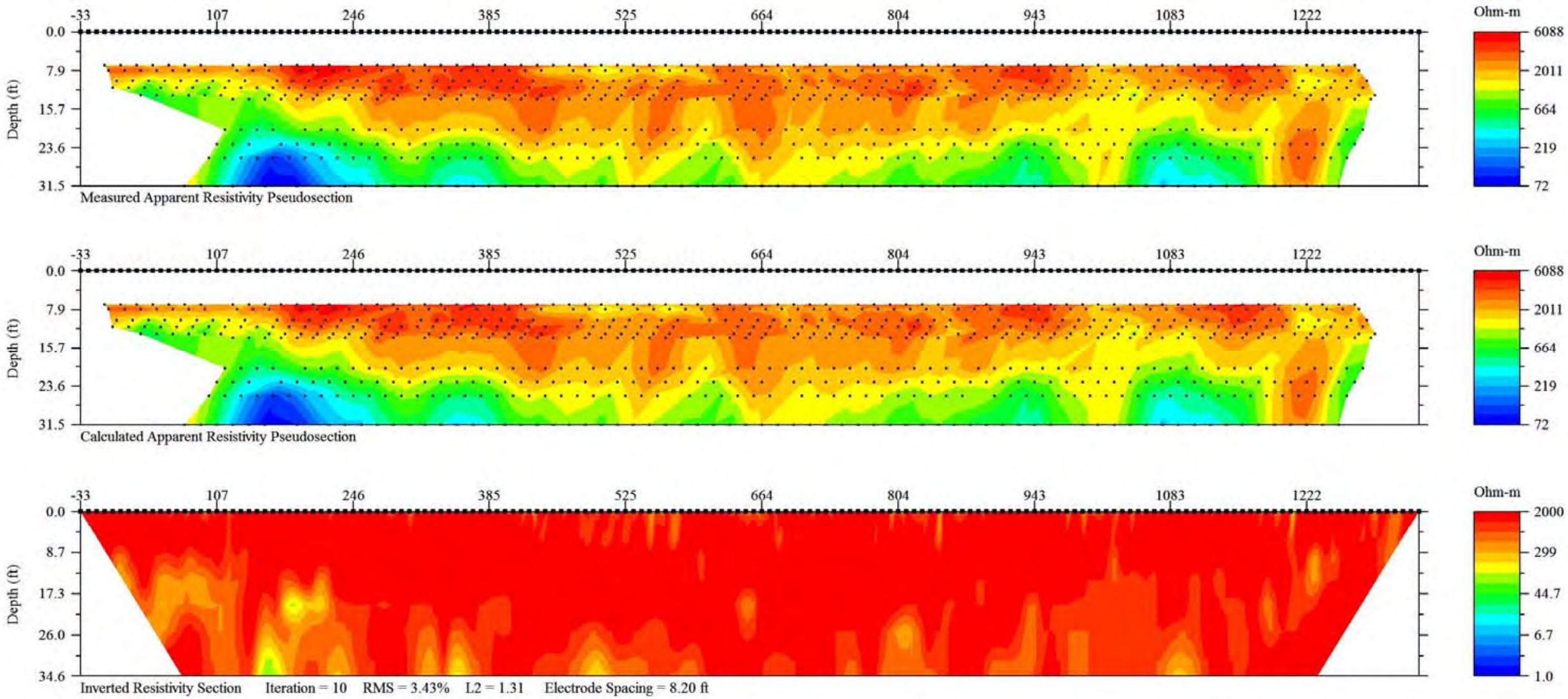

Figure 2-2. Capacitively coupled resistivity line 202. 

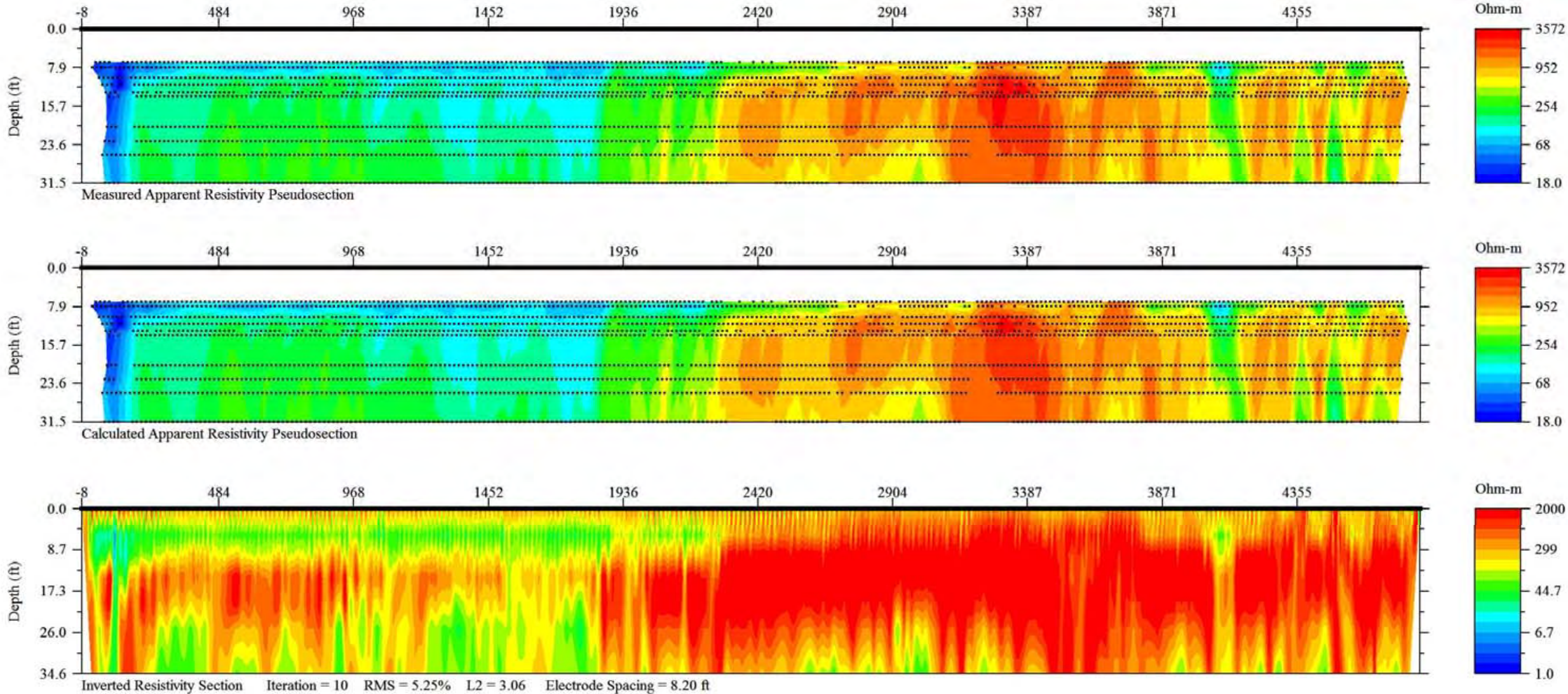

Figure 2-3. Capacitively coupled resistivity line 203. 

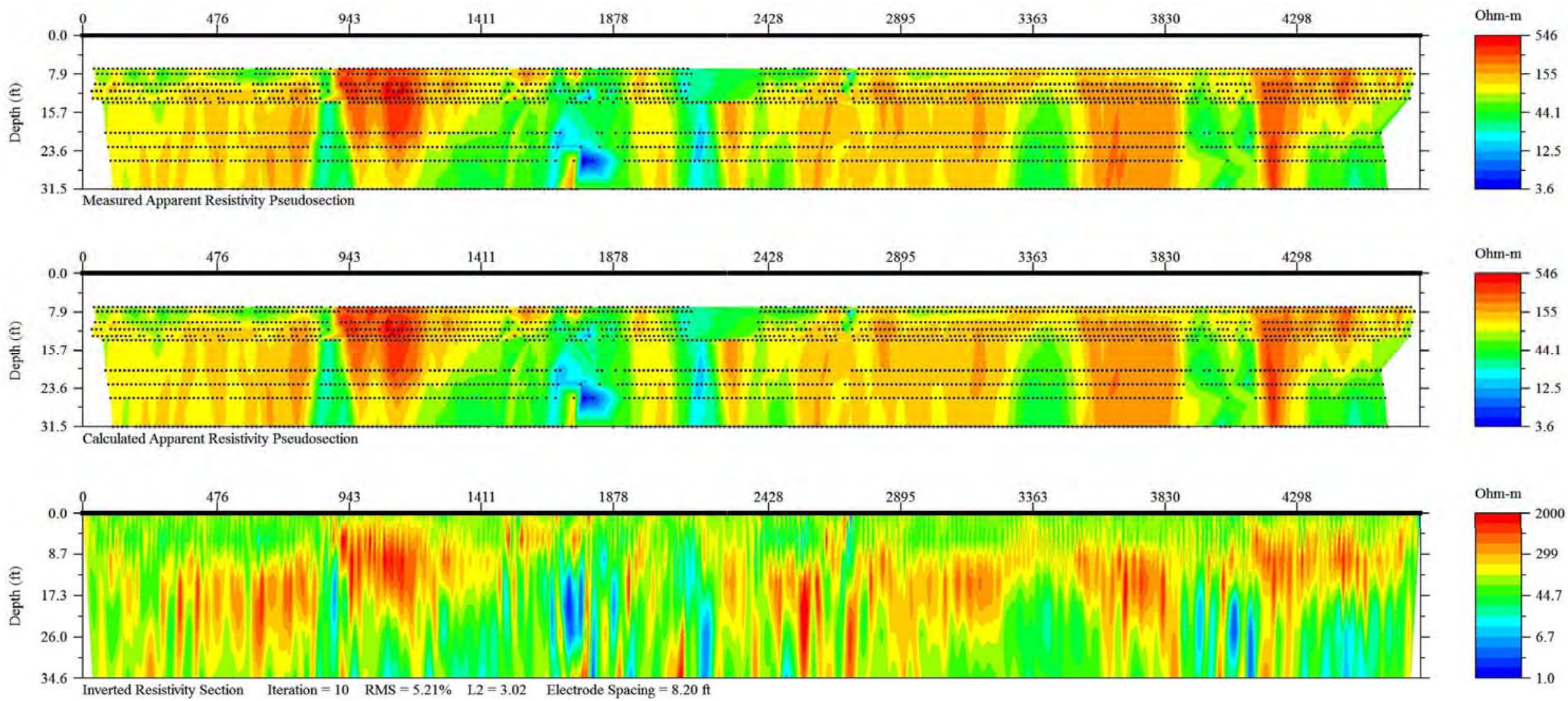

Figure 2-4. Capacitively coupled resistivity line 204. 

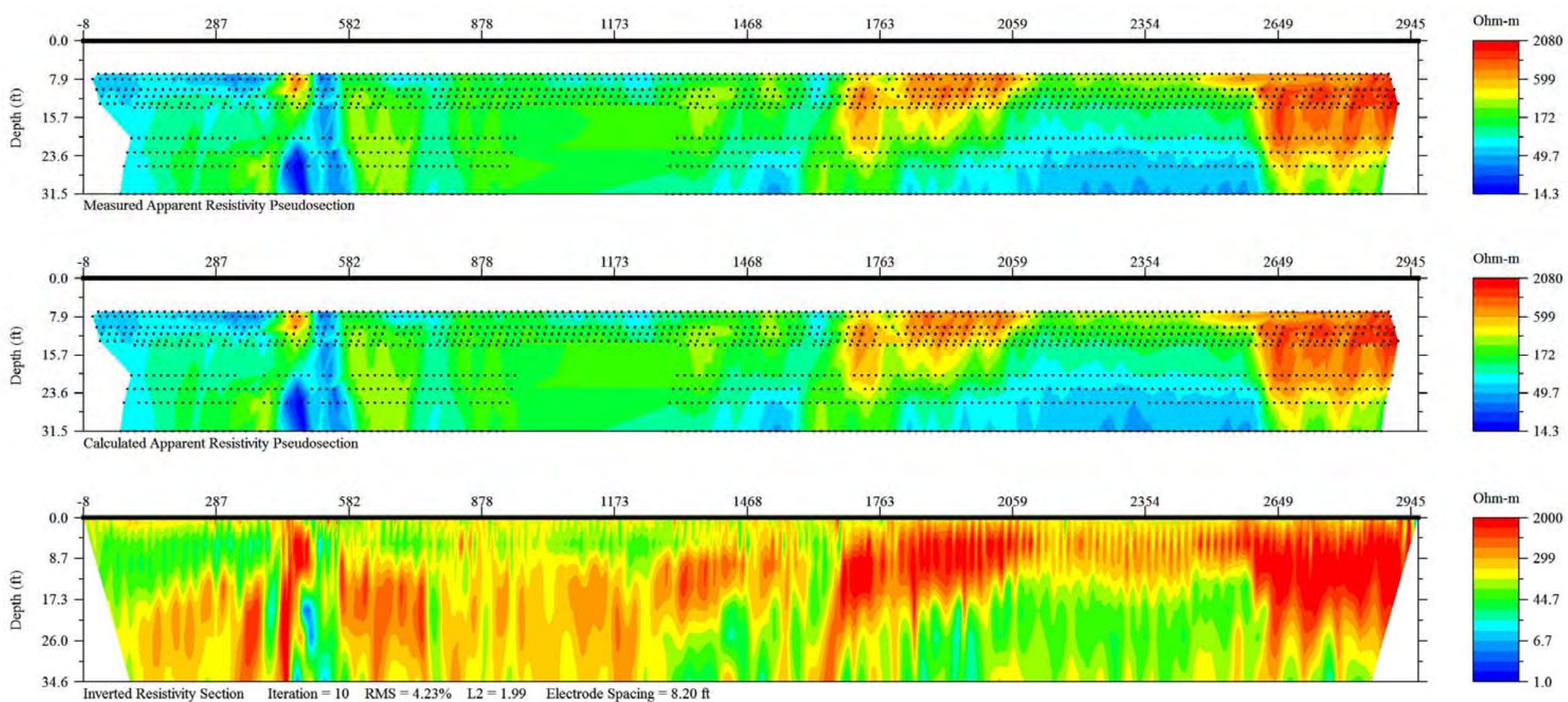

Figure 2-5. Capacitively coupled resistivity line 205. 

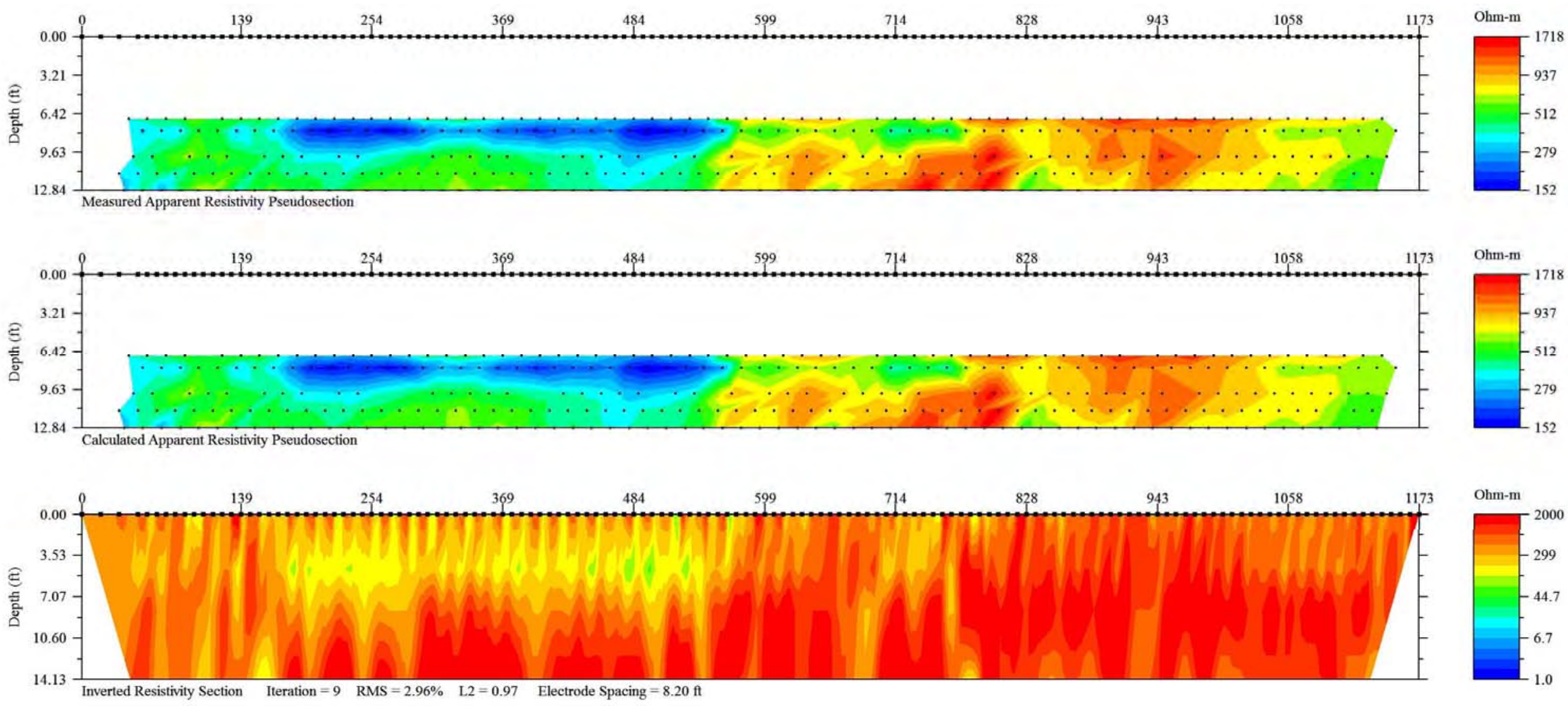

Figure 2-6. Capacitively coupled resistivity line 206. 

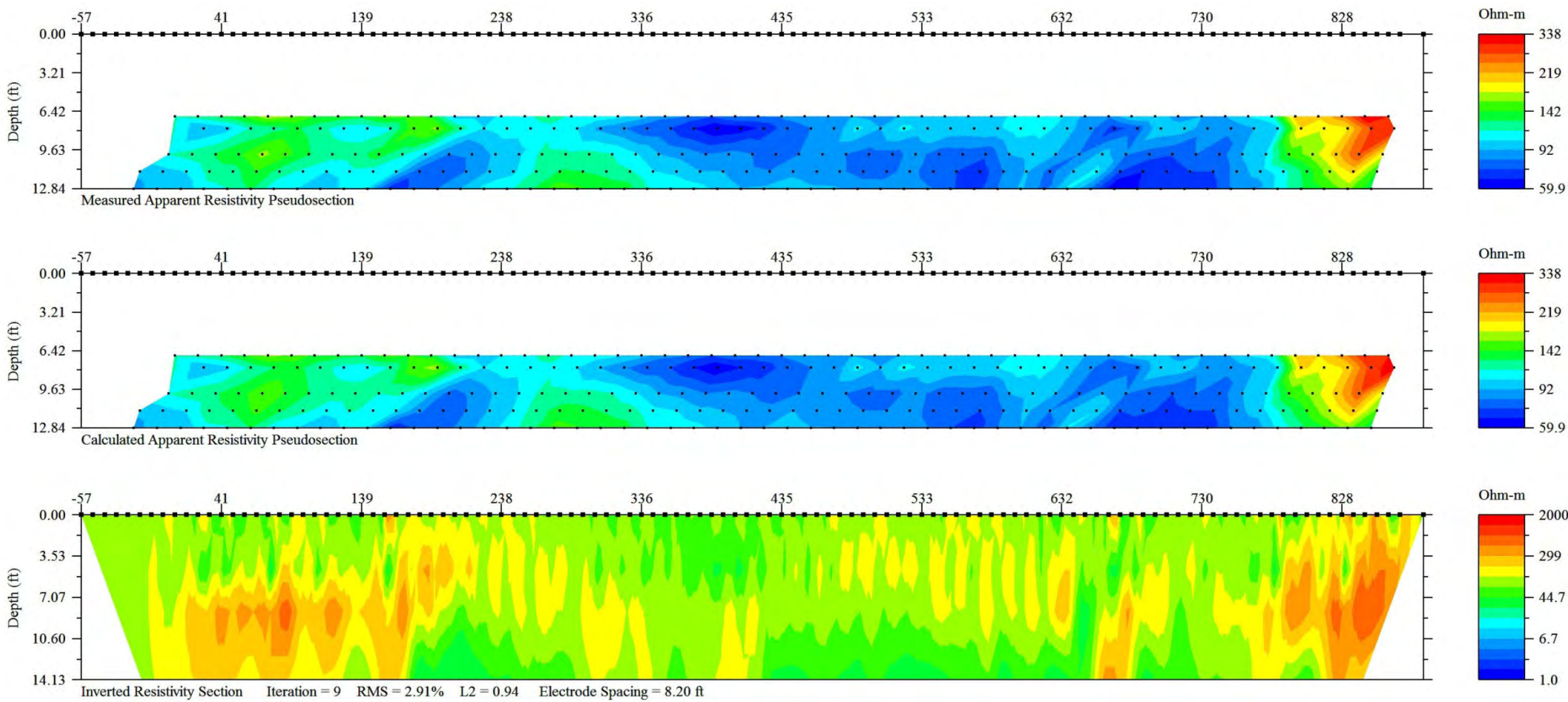

Figure 2-7. Capacitively coupled resistivity line 207. 

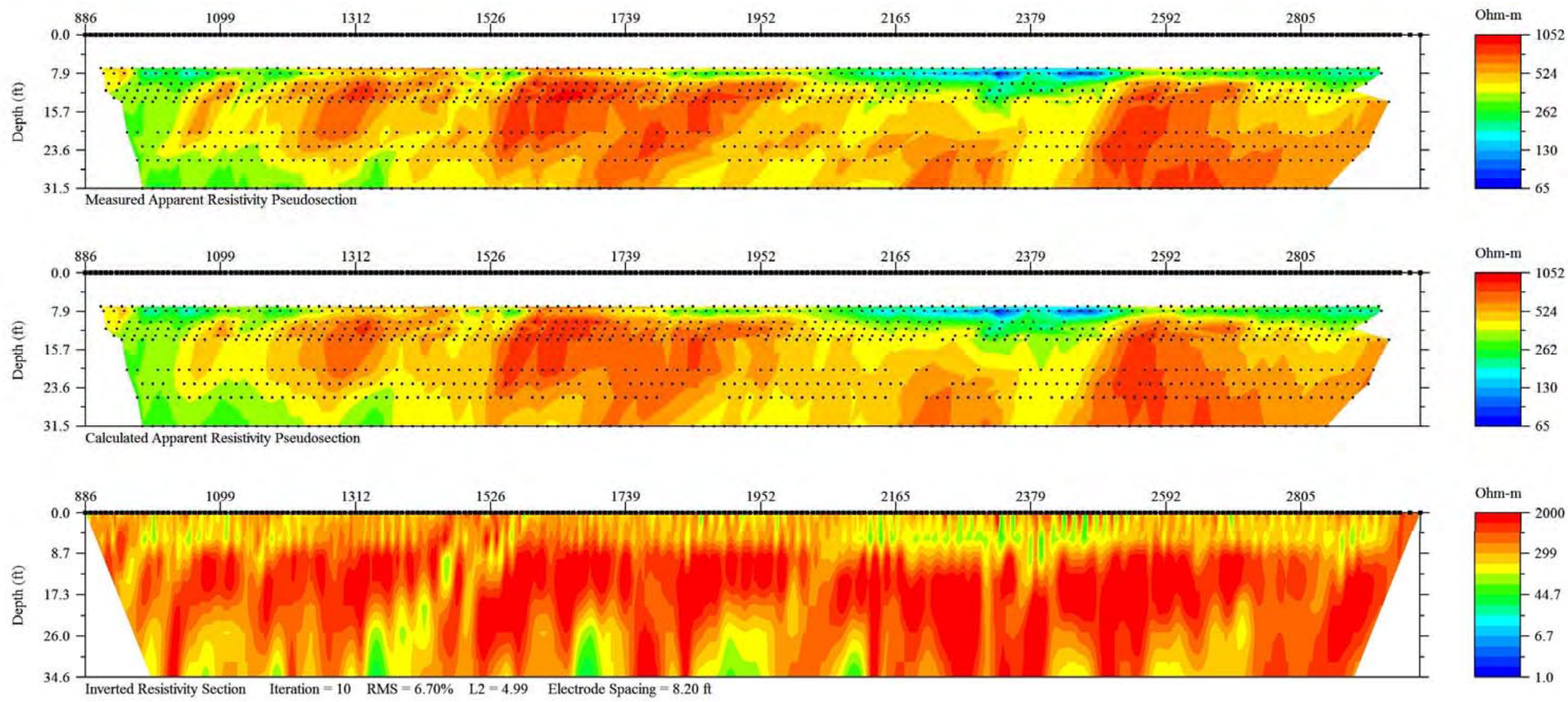

Figure 2-8. Capacitively coupled resistivity line 208. 


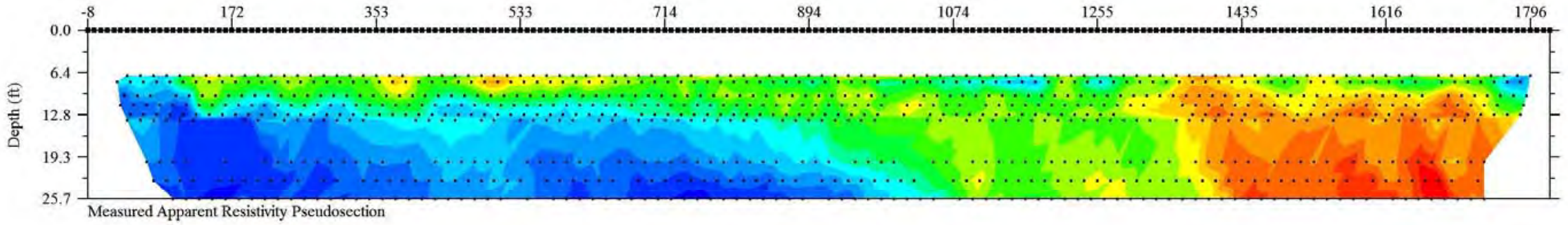

Measured Apparent Resistivity Pseudosection
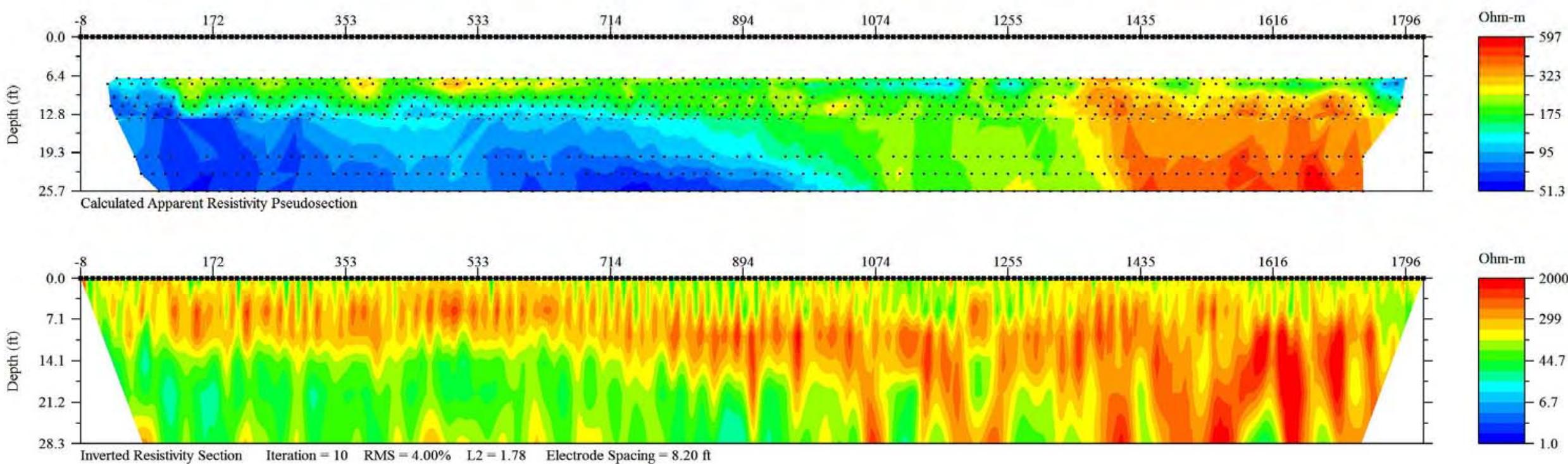

Figure 2-9. Capacitively coupled resistivity line 209. 

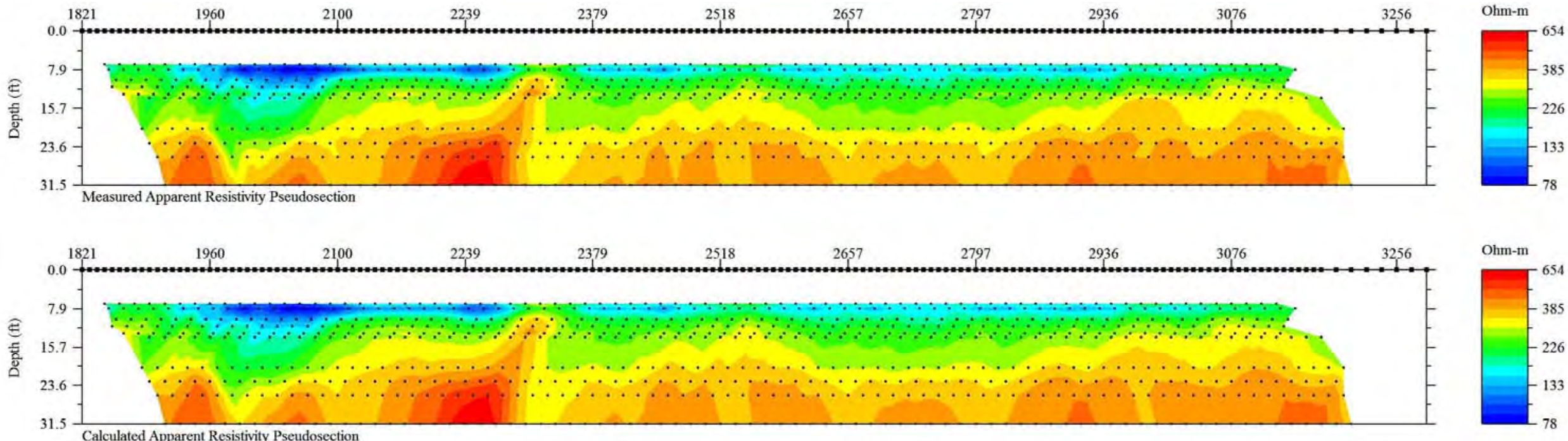

Ohm-m
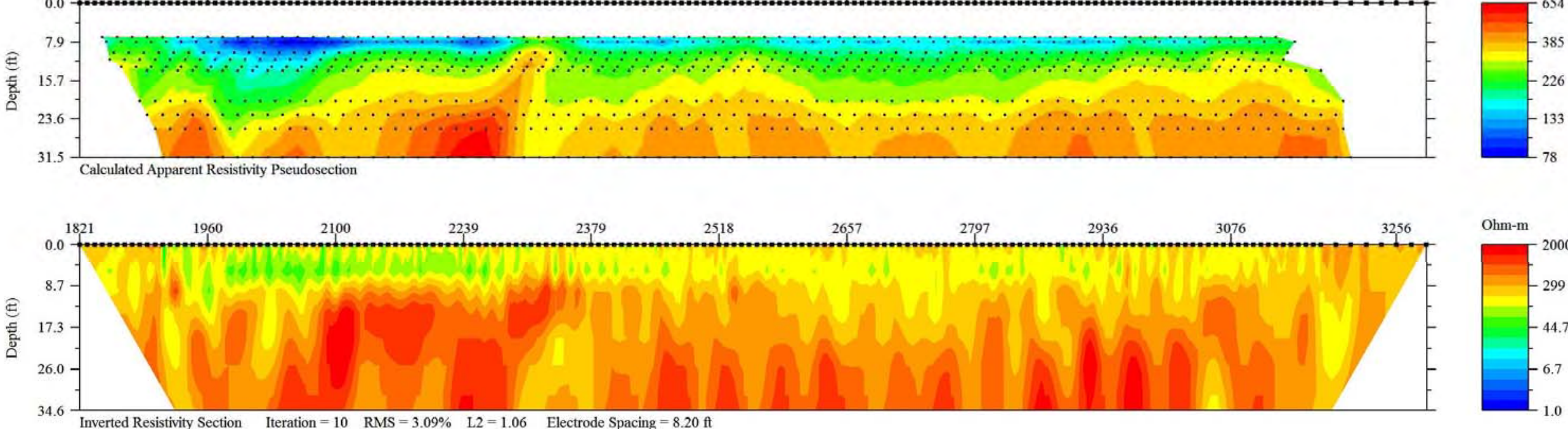

Ohm-m

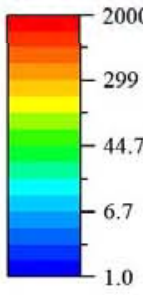

Figure 2-10. Capacitively coupled resistivity line 210 . 

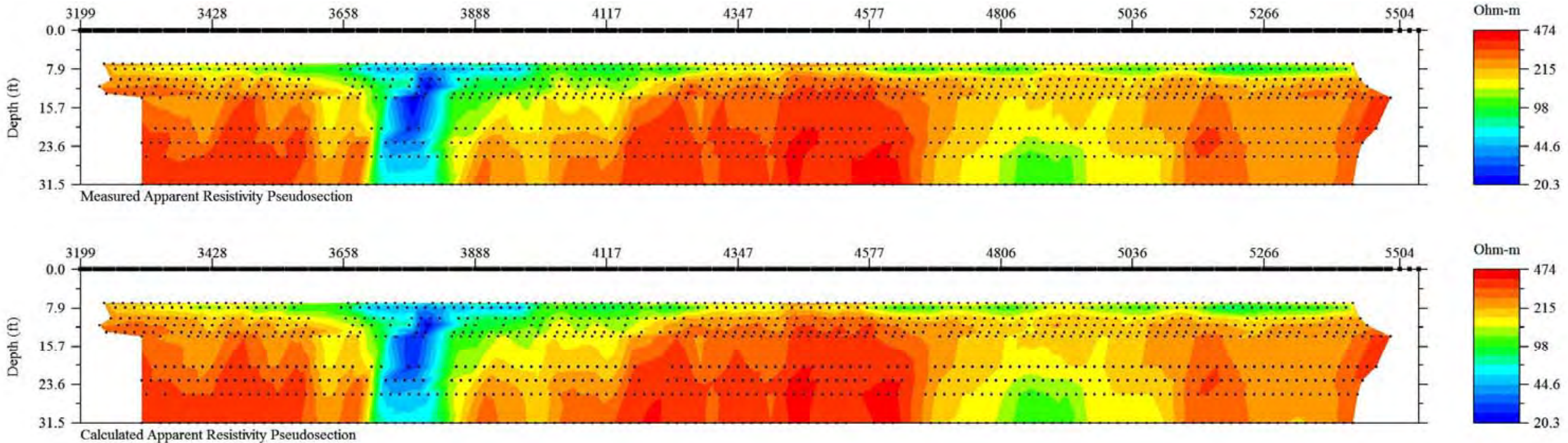

Ohm-m
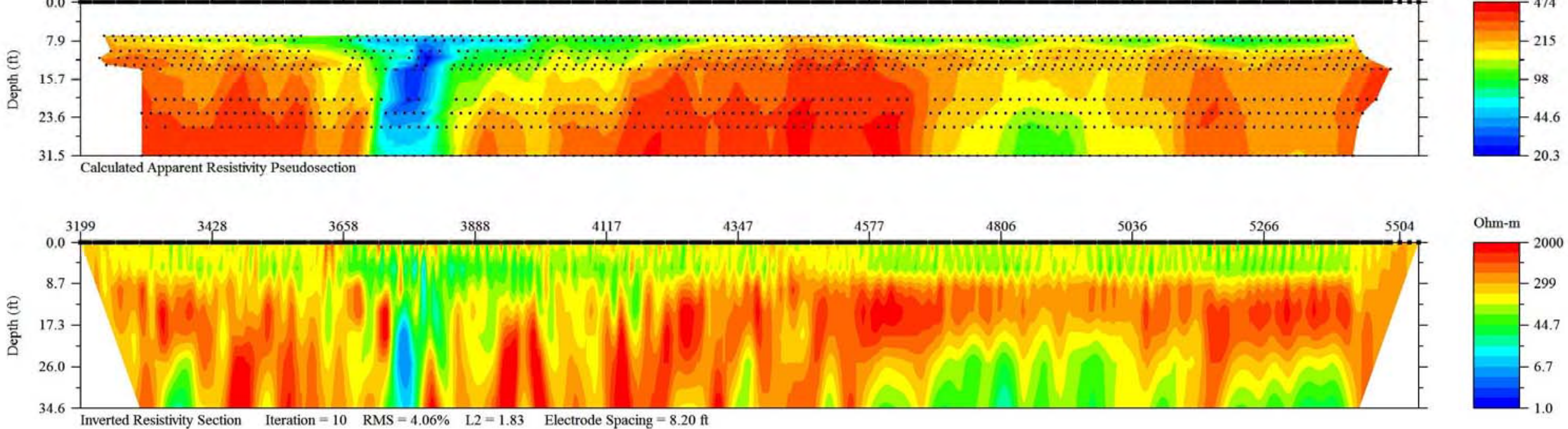

Ohm-m

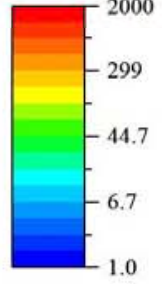

Figure 2-11. Capacitively coupled resistivity line 211. 

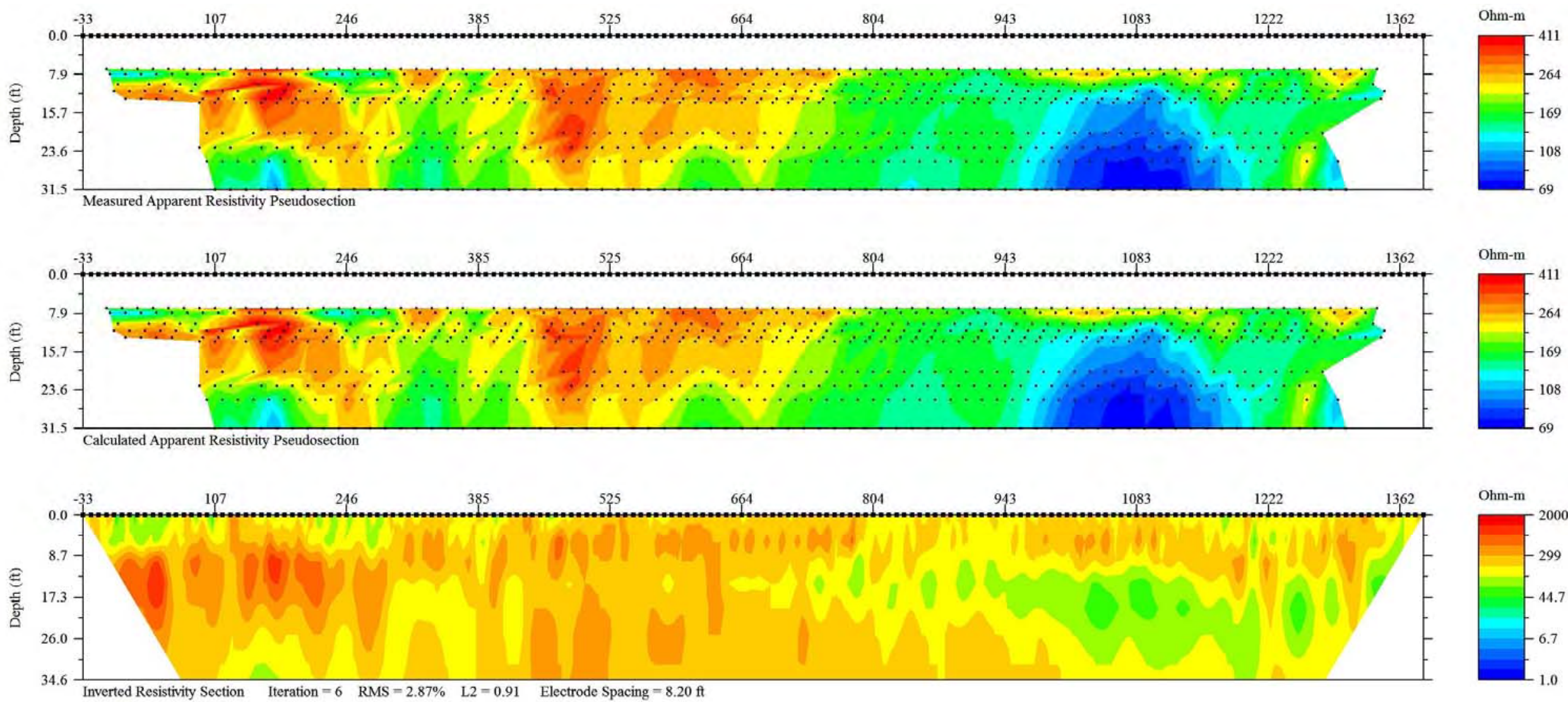

Figure 2-12. Capacitively coupled resistivity line 212 

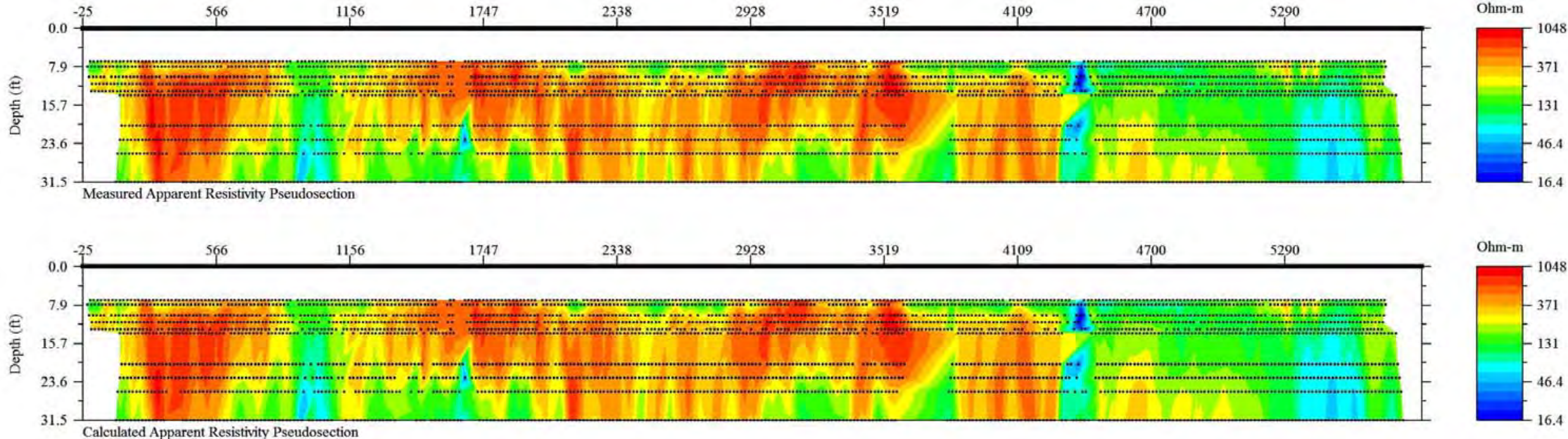

Ohm-m
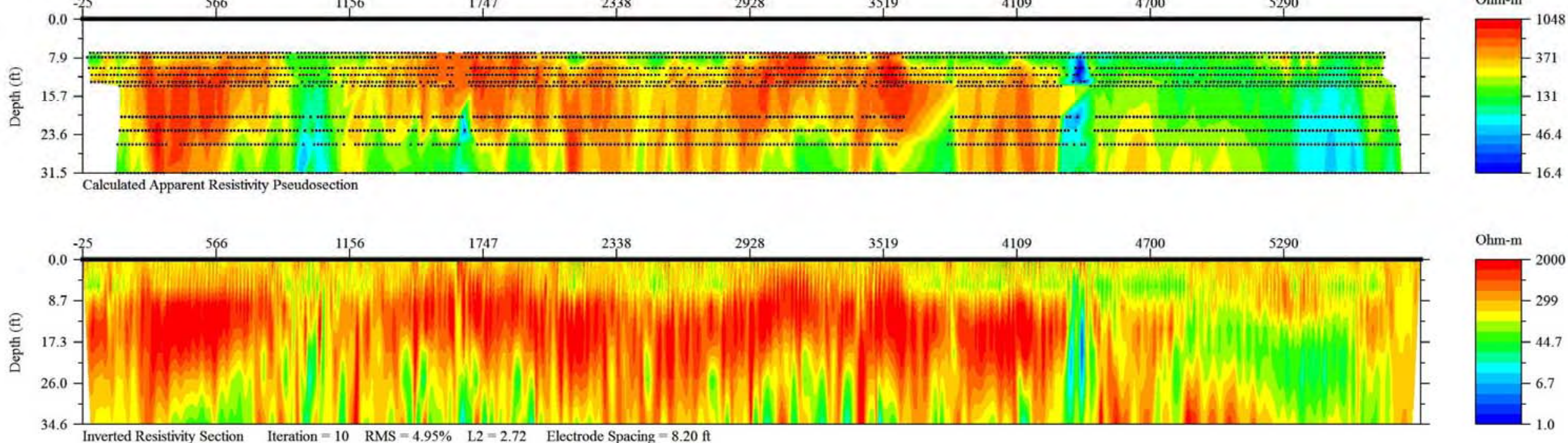

Ohm-m

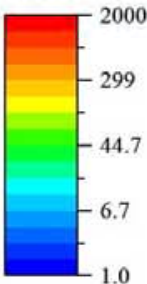

Figure 2-13. Capacitively coupled resistivity line 213. 

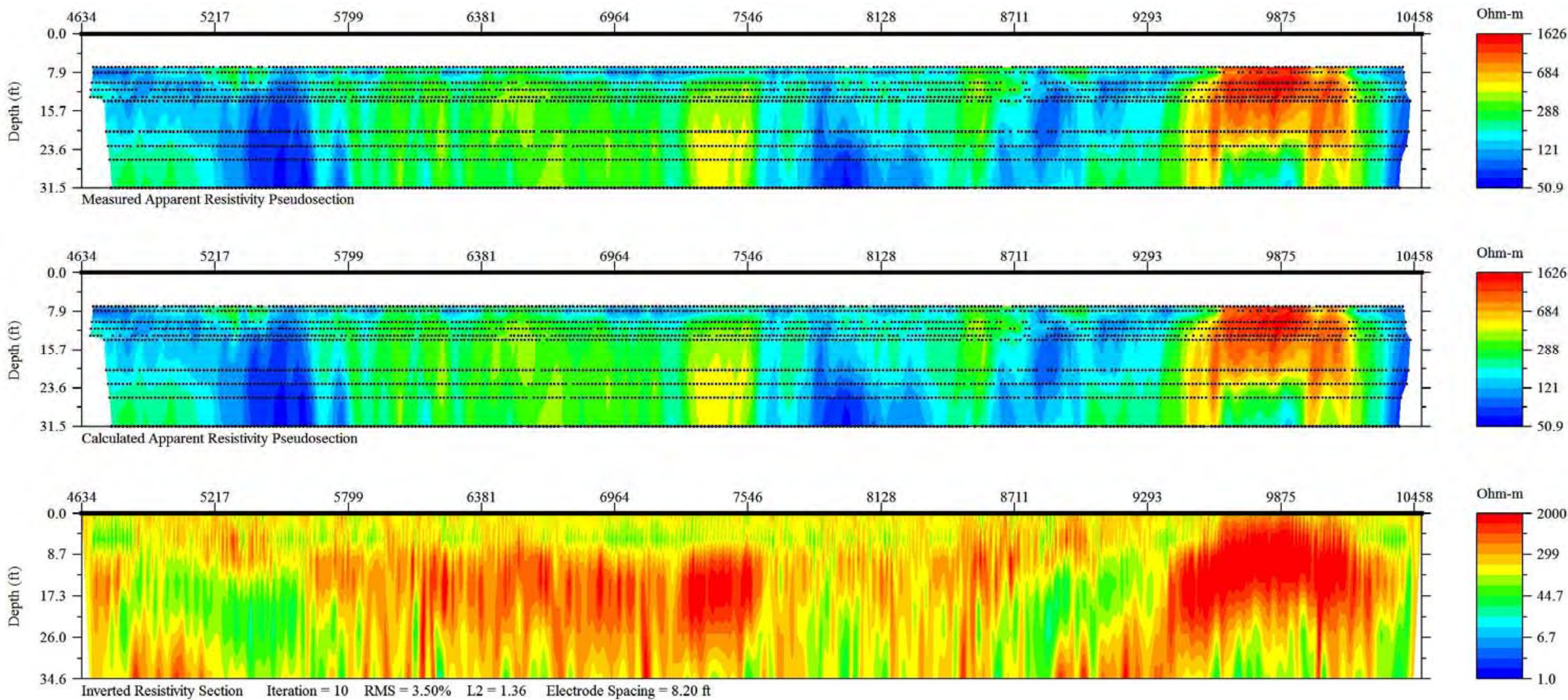

Figure 2-14. Capacitively coupled resistivity line 214. 


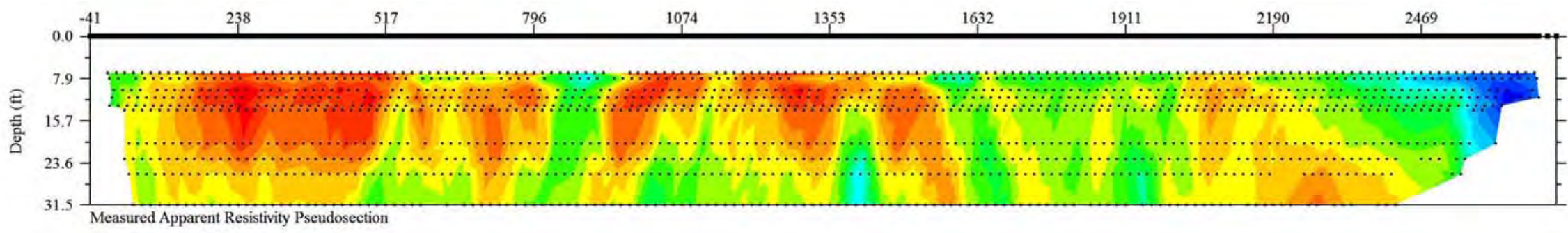

Ohm-m
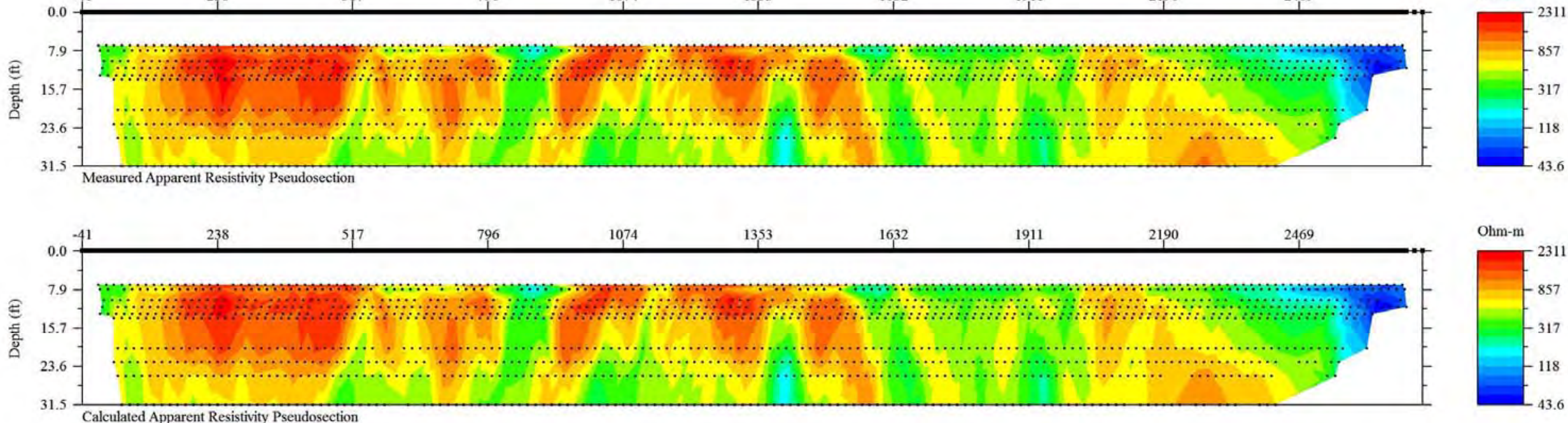

Ohm-m
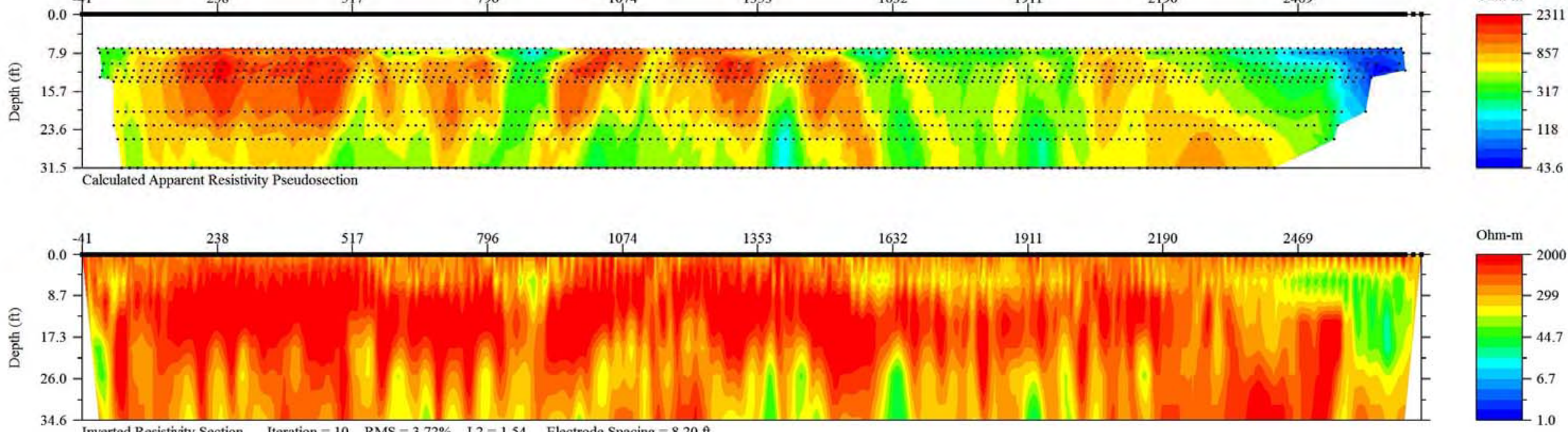

Ohm-m

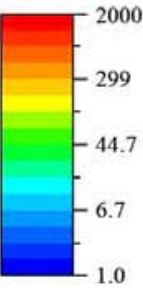

Figure 2-15. Capacitively coupled resistivity line 251. 

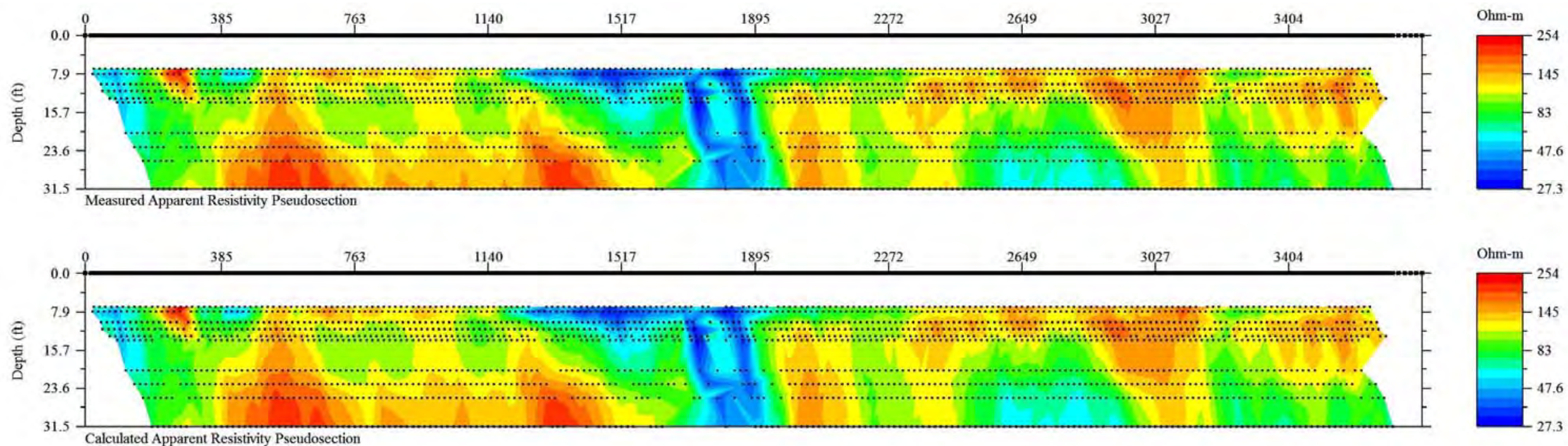

Ohm-m
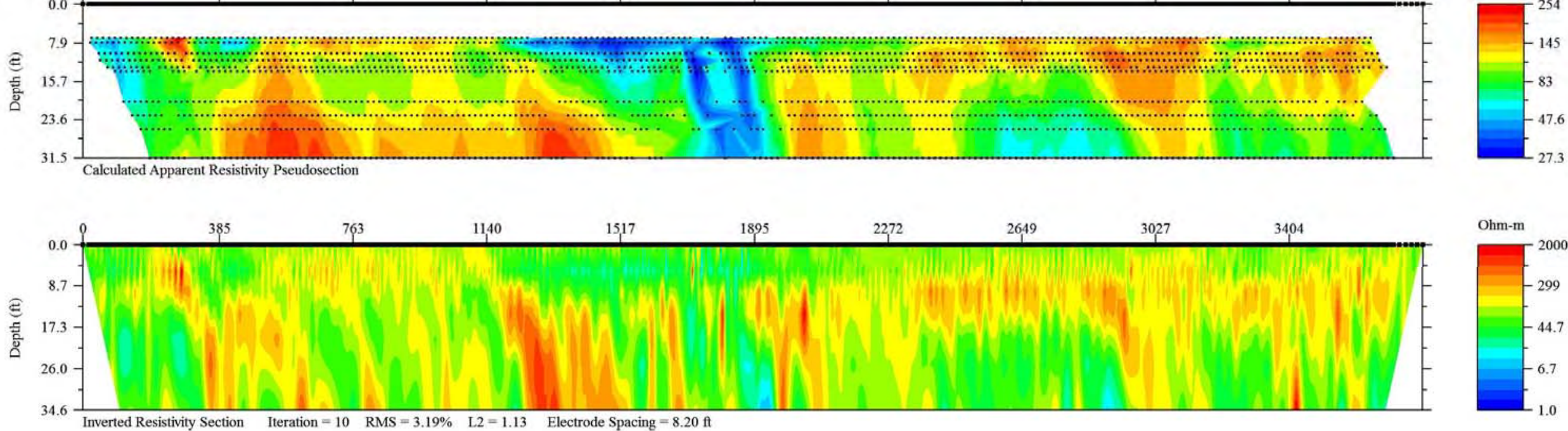

Figure 2-16. Capacitively coupled resistivity line 252. 


\section{Appendix 3. Digital Data}

\section{Direct-Current Resistivity Data}

Digital DC resistivity data are provided in a single compressed file.

AmRiv_DCres_stg.zip: raw .stg data files and associated .trn terrain files.

The raw DC resistivity data are provided in the Advanced Geosciences, Inc. 3D resistivity comma-delimited ASCII .stg file format.

Row 1-Information about instrument used

Row 2-Firmware version installed on instrument, survey period of the data in the file, and number of records in the file

Row 3-Units at time of download, feet or meter

Rows 4-End of file - one measurement per row with the following format:

- Consecutive data record number,

- USER,

- Date (YYYYMMDD),

- Time (hh:mm:ss),

- V/I (measured voltage/output current),

- Error, in tenths of percentage,

- Output current, in milliamps (mA),

- Apparent resistivity, in ohm-meters,

- Command file identifier,

- $\mathrm{X}$-, Y-, and Z-coordinate for the A-electrode,

- $\mathrm{X}$-, Y-, and Z-coordinate for the B-electrode,

- $\mathrm{X}$-, Y-, and Z-coordinate for the M-electrode,

- $\mathrm{X}-, \mathrm{Y}$-, and Z-coordinate for the N-electrode,

- Command number in command file,

- Instrument voltage, in volts (V),

- Number of measurement cycles per measurement,

- Measurement time, in seconds,

- Gain, and

- Channel used for measurement.

The elevation data for each profile is contained within a comma-delimited ASCII .trn file. Row 1 -Comment line with semicolon (;) at the beginning

Row 2-Unit of distance (unit=feet or unit=meters)

Row 3-1 = horizontal distance is given, 2 = tape measure is given

Rows 4-End of file-downline distance, in feet, and elevation (positive upward), in feet. 


\section{Capacitively Coupled Resistivity Data}

Digital CC resistivity data are provided in a single compressed file.

AmRiv_CCres_BIN.zip: processed, binned (5-m bin size) data.

All raw CC resistivity data are provided in an ASCII tab-delimited RES2DINV dat file format (Geotomo, 2014):

Row 1-Filename or comment

Row 2-Unit electrode spacing, in meters

Row 3-Array type (3 = dipole-dipole array)

Row 4-Number of data points

Row 5-Type of downline distance for data points $(1=$ midpoint $)$

Row 6-IP data flag $(0=$ no IP data $)$

Rows 7-End of file- One measurement per row with the following format:

- Downline distance, in meters

- 'a' electrode spacing (equivalent to dipole length), in meters

- Apparent resistivity value, in ohm-meters.

For each raw data file, there is a corresponding ASCII comma-delimited .xyz file that contains positional information. The data columns are as follows:

- Line-Line number,

- $\mathrm{X}$ and $\mathrm{Y}$-Easting and northing coordinates of acquired CC resistivity data in NAD83, California State Plane zone 2, in U.S. survey feet,

- Z-Elevation of acquired CC resistivity data in NAVD88, in feet,

- Dist_ft-Downline distance, in feet, and

- Dist_m-Downline distance, in meters.

Downline distances in the .xyz positional files are provided in units of both feet and meter, because the data were acquired in meters and converted to U.S. survey feet during post-processing. The raw .dat files provide downline distance in meters, which is the most useful method for georeferencing the raw data points. The elevation data have been sampled from a 9-ft resolution lidar-derived digital elevation model provided by the U. S. Army Corps of Engineers (Lew Hunter, USACE, written commun., 2012). 